\title{
CROSSCUTTING TECHNOLOGY DEVELOPMENT AT THE CENTER FOR ADVANCED SEPARATION TECHNOLOGIES
}

SEMI-ANNUAL TECHNICAL PROGRESS REPORT

Report Period

April 1, 2004 to September 30, 2004

Compiled by

Christopher E. Hull

Issued January 20, 2005

DOE Award Number:

DE-FC26-02NT41607

Center for Advanced Separation Technologies

Virginia Polytechnic Institute \& State University

Blacksburg, Virginia 24061-0258

National Research Center for Coal \& Energy

West Virginia University

Morgantown, WV 26506-6064

Dept. of Metallurgical Engineering

University of Utah

Salt Lake City, UT 84112-0114

NMBGR

New Mexico Inst. of Mining \& Technology

Socorro, NM 87801
Department of Mining Engineering University of Kentucky

Lexington, KY 40506-0107

School of Mines \& Engineering Montana Tech of The Univ. of Montana Butte, MT 59701

Metallurgical \& Materials Engineering University of Nevada, Reno Reno, NV 89557-0042 


\section{DISCLAIMER}

This report was prepared as an account of work sponsored by an agency of the United States Government. Neither the United States Government nor any agency thereof, nor any of their employees, makes any warranty, express or implied, or assumes any legal liability or responsibility for the accuracy, completeness, or usefulness of any information, apparatus, product, or process disclosed, or represents that its use would not infringe privately owned rights. Reference herein to any specific commercial product, process, or service by trade name, trademark, manufacture, or otherwise does not necessarily constitute or imply its endorsement, recommendation, or favoring by the United States Government or any agency thereof. The views and opinions of authors expressed herein do not necessarily state or reflect those of the United States Government or any agency thereof. 


\begin{abstract}
This Technical Progress Report describes progress made on the seventeen subprojects awarded in the first year of Cooperative Agreement DE-FC26-02NT41607: Crosscutting Technology Development at the Center for Advanced Separation Technologies. This work is summarized in the body of the main report: the individual sub-project Technical Progress Reports are attached as Appendices.
\end{abstract}

Note: SI is an abbreviation for "Le Systeme International d’Unites.” 


\section{TABLE OF CONTENTS}

DISCLAIMER

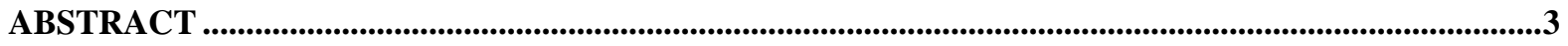

TABLE OF CONTENTS .....................................................................................................................................

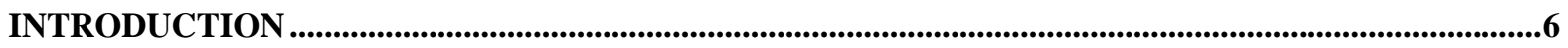

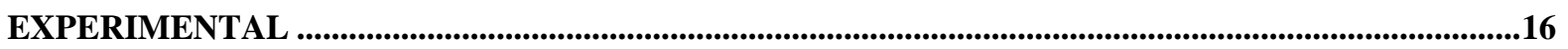

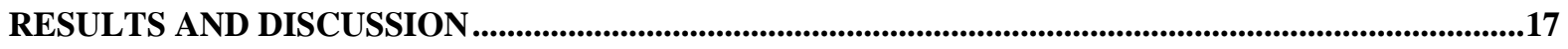

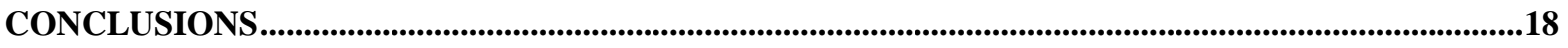

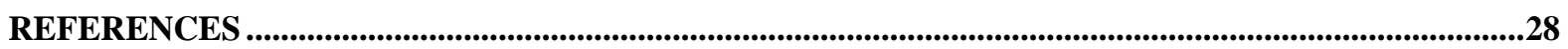

APPENDIX A: KY001 - DEVELOPMENT OF NOVEL ULTRAFINE SIZING METHODS.....................29

APPENDIX B: NMO01 - DISPERSION AND FLOTATION OF CLAYS FROM NEW MEXICO

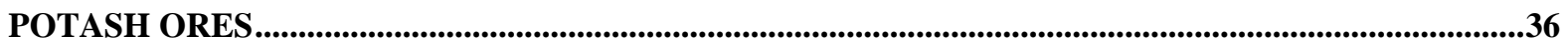

APPENDIX C: UT001 - FLOTATION TECHNOLOGY FOR THE TRONA INDUSTRY ..........................43

APPENDIX D: VA009 - FLOTATION PROCESSES/EXPERIMENTS AND ANALYSIS .........................54

APPENDIX E: WVO07 - COLUMN FLOTATION OF RELATIVE COARSE AND FINE

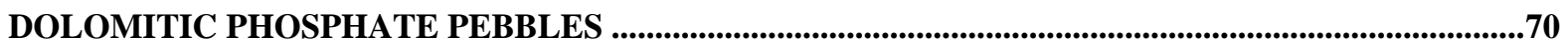

APPENDIX F: KYO02 - IMPROVING DENSIFICATION OF FINE COAL REFUSE SLURRIES

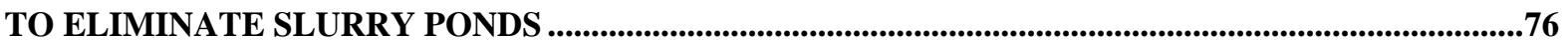

APPENDIX G: VA010 - DEVELOPMENT AND TESTING OF A HORIZONTAL PRESSURE

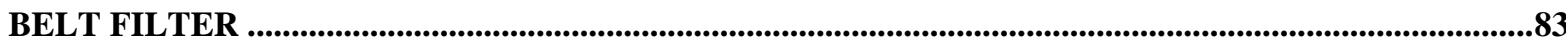

APPENDIX H: UT002 - BIO-ASSISTED HEAP LEACHING OF NICKEL LATERITES FOR THE

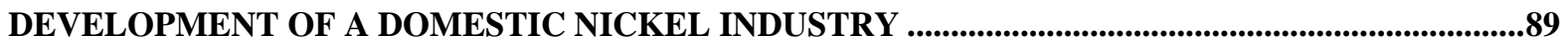

APPENDIX I: MT001 - THE DEVELOPMENT AND UTILIZATION OF ALKALINE SULFIDE

LEACHING AND RECOVERY OF GOLD ...................................................................................

APPENDIX J: NVO01 - HYDROMETALLURGICAL PROCESSING OF CHALCOPYRITE

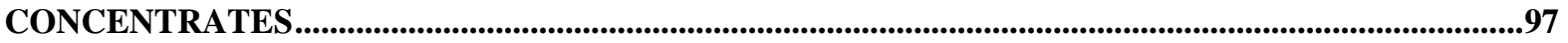

APPENDIX K: MT002 - SIMULTANEOUS ELECTROLYSIS OF COPPER AND FERROUS IONS TO PRODUCE COPPER CATHODE AND TO REGENERATE FERRIC SULFATE - THE LIXIVIANT TO DISSOLVE COPPER SULFIDE MINERALS. 
APPENDIX L: NMO02 - ION EXCHANGE RECOVERY OF COBALT FROM COPPER LEACH SOLUTIONS.

APPENDIX M: NM003 - THE EFFECT OF DIPHENYL OXIDE SURFACTANTS ON

NUCLEATION AND GROWTH OF POTASSIUM SULFATE CRYSTALS: DEVELOPMENT OF

ENHANCED SURFACTANTS FOR THE POTASH INDUSTRY

APPENDIX N: WV008 - ONLINE MONITORING AND DIAGNOSING OF COAL FINES

DURING SEPARATION PROCESS

APPENDIX O: KYOO3 - DEVELOPMENT OF A NOVEL OPTICAL RADIATION

DEPOLARIZATION TECHNIQUE FOR ON-LINE MEASUREMENTS OF PARTICLE AND

BUBBLE SIZES .130

APPENDIX P: UTO03 - ELECTROLYTIC SOLUTION PURIFICATION AND METAL

RECOVERY FROM METAL-BEARING TOXIC WASTE STREAMS .136

APPENDIX Q: MT003 - DETERMINING THE EFFECTIVENESS OF GOLD FILTERS FOR

REMOVING MERCURY FROM COAL FIRED POWER PLANTS 138 


\section{INTRODUCTION}

The U.S. is the largest producer of mining products in the world. In 2003, U.S. mining operations produced $\$ 57$ billion worth of raw materials that contributed a total of $\$ 564$ billion to the nation's wealth. Despite these contributions, the mining industry has not been well supported with research and development funds as compared to mining industries in other countries. To overcome this problem, the Center for Advanced Separation Technologies (CAST) was established to develop technologies that can be used by the U.S. mining industry to create new products, reduce production costs, and meet environmental regulations. Originally set up by Virginia Tech and West Virginia University, this endeavor has been expanded into a seven-university consortium - Virginia Tech, West Virginia University, University of Kentucky, University of Utah, Montana Tech, New Mexico Tech and University of Nevada, Reno - that is supported through U.S. DOE Cooperative Agreement No. DE-FC26-02NT41607: Crosscutting Technology Development at the Center for Advanced Separation Technologies.

Much of the research to be conducted with Cooperative Agreement funds will be longer-term, high-risk, basic research and will be carried out in five broad areas:

a) Solid-solid separation

b) Solid-liquid separation

c) Chemical/Biological Extraction

d) Modeling and Control, and

e) Environmental Control.

Distribution of funds is handled via competitive solicitation of research proposals through Site Coordinators at the seven member universities. The first of these solicitations, referred to as the CAST II-Round 1 RFP, was issued on October 28, 2002. Thirty-eight proposals were received by the December 10, 2002 deadline for this RFP - eleven (11) SolidSolid Separation, seven (7) Solid-Liquid Separation, ten (10) Chemical/Biological Extraction, six (6) Modeling \& Control and four (4) Environmental Control. These were first reviewed and ranked by a group of technical reviewers (selected primarily from industry). Based on these reviews, and an assessment of overall program requirements, the CAST Technical Committee made an initial selection/ranking of proposals and forwarded these to the DOE/NETL Project Officer for final review and approval. This process took some 7 months to complete but 17 projects (one joint) were in place at the constituent universities (three at Virginia Tech, two at West Virginia University, three at University of Kentucky, three at University of Utah, three at Montana Tech, three at New Mexico Tech, and one at the University of Nevada, Reno) by May 17, 2003. These projects are listed below by category, along with brief abstracts of their aims and objectives. 


\section{a) Solid-Solid Separation}

\section{Development of Novel Ultrafine Sizing Methods (Joint UK/VT Project)}

Principal Investigators: R.-H. Yoon and G.H. Luttrell, Virginia Tech

Principal Investigators: R.Q. Honaker and BK. Parekh, University of Kentucky

Period of Performance: May 1, 2003-May 31, 2005 (2-Year Project)

The conventional techniques employed for sizing ultrafine particles in the coal and mineral processing industries have inherent inefficiencies that negatively impact on separation performance and production costs. In light of this problem, a broad based R\&D program is proposed to investigate several innovative techniques for fine particle sizing. The processes to be evaluated will include a wide array of mechanical, hydraulic, and novel approaches for fine particle sizing. For each process, detailed tests programs will be conducted to optimize operating parameters so that maximum efficiency and capacity can be achieved while maintaining particle size cuts in the $25-50 \mu \mathrm{m}$ size range. The resultant test data will be used to mathematically simulate different circuit arrangements for the most promising technologies. A detailed economic study will be performed for those circuits that have the greatest potential for commercialization and industrial implementation. Due to the large scope of this project, the proposed work will be conducted as a joint effort between researchers at the University of Kentucky and Virginia Tech.

\section{Dispersion and Flotation of Clays from New Mexico Potash Ores}

Principal Investigators: I. Gundiler, S. Titkov, and M. Yekeler, New Mexico Tech Period of Performance: May 1, 2003-May 31, 2004 (1-Year Project)

New Mexico is the largest potash producer in the United States, supplying $70 \%$ of the domestic consumption of agricultural fertilizers. Potash mining began in the Carlsbad potash district in the early 1940s and while there are still vast reserves of potash minerals, producers are now dealing with low grade ores contaminated with clays and watersoluble magnesium minerals, which adversely affect the flotation of sylvite (KCl). Sylvite is floated from saturated brines with cationic collectors. The clays present in these brines absorb flotation reagents (thus increasing reagent costs), decrease recoveries of sylvite, contaminate the product and increase energy consumption for dewatering and drying. These clays are dispersed during grinding and/or attrition scrubbing and are then removed by hydrocyclones ahead of flotation. However, significant amounts of clay are carried over into flotation, where they are further dispersed by the mechanical action of impellers, thus hindering flotation. Furthermore, elevated brine temperatures during the summer affect collector adsorption on clays, depressing sylvite flotation. The presence of high concentrations of magnesium ions in the brine, which is peculiar to this district, also affects recoveries.

These technological problems must be solved for the state potash industry to remain viable and competitive. This study will investigate means of improving clay dispersion using organic and inorganic dispersants to increase the efficiency of slimes removal in existing facilities, and will study the effects of elevated magnesium ion concentrations 
and elevated temperatures on the flotation of sylvite. Clay flotation, which has been shown to be superior to hydroseparators for clay removal in foreign operations, will also be investigated.

\section{Flotation Technology for the Trona Industry}

Principal Investigator: Jan D. Miller, University of Utah

Period of Performance: May 1, 2003-May 31, 2005 (2-Year Project)

Soda ash $\left(\mathrm{Na}_{2} \mathrm{CO}_{3}\right)$ produced from the trona deposits of the Green River Basin in Wyoming by chemical treatment is valued at approximately $\$ 800$ million per annum. Existing process technologies for the production of soda ash from trona involve dissolution in hot brine, drying, sedimentation and filtration for the removal of impurities, and subsequent crystallization and calcination for the recovery of soda ash. In this regard, mining and operating costs, particularly energy costs, are higher than desired. A preferred processing strategy might be to remove gangue mineral contaminants from the plant feed prior to dissolution in hot brine. It is expected that in this way improved productivity can be achieved in addition to significant savings in energy. Such a preprocessing strategy at ambient temperature and pressure has been limited by the lack of satisfactory process technology. Now based on recent results from laboratory research at the University of Utah it seems that the run-of-mine trona ore can be treated at ambient temperature and pressure using a special flotation procedure to separate the gangue minerals and make a trona concentrate with a purity of almost 99\% trona at a recovery of more than $97 \%$. Development and utilization of this new technology will allow for energy conservation, improved resource utilization, increased productivity and the development of a new product for the marketplace. In this regard a two-year research program involving industrial participation is proposed to develop the technology and demonstrate its effectiveness at a plant site.

\section{Flotation Processes/Experiments and Analysis}

Principal Investigators: D. Telionis and P. Vlachos, Virginia Tech

Period of Performance: May 1, 2003-May 31, 2005 (2-Year Project)

Flotation processes involve complex, three-phase flow interactions between a liquid, air bubbles and solid particles. For decades, engineers and researchers based their calculations on algebraic formulas that model these interactions. These formulas were derived from simple models, experimental data and/or arbitrary assumptions. Considerable progress has been made but this approach is still far from providing a reliable tool for the design of flotation machines.

We will take a more rigorous approach to the analysis and modeling of the flotation process. The proposed effort will combine detailed theoretical analysis and modeling with state-of-the-art, global, multi-phase flow measurements to quantify the effects of the various hydrodynamic parameters on the flotation process. We will employ a Digital Particle Image Velocimeter (DPIV) that can record velocity vectors of all three phases. We will measure three-phase flow interactions of bubbles and model particles of different hydrophobicity with a turbulent flow field. We will deliver global, time-resolved velocity distributions and turbulence characteristics for each phase. Our modeling approach will 
incorporate all physical parameters that affect the collision efficiency of coal particles and flotation bubbles and the probabilities of attachment and detachment. An advanced model for predicting and quantifying the efficiency of the flotation process will be the final deliverable of this two-year effort. Such a tool will improve the design of flotation equipment and/or enhance the performance of existing systems.

\section{Column Flotation of Relative Coarse and Fine Dolomitic Phosphate Pebbles}

Principal Investigator: Felicia F. Peng, West Virginia University

Period of Performance: May 1, 2003-May 31, 2005 (2-Year Project)

Dolomite in phosphate flotation concentrates is troublesome for down-stream operations. High dolomite contents cause higher consumption of sulfuric acid, reduce filtration rates and lower $\mathrm{P}_{2} \mathrm{O}_{5}$ content in the fertilizer manufacturing process. However, the separation of dolomite particles from phosphate minerals is difficult because the dolomite is finely disseminated throughout the phosphatic pebbles and both are oxide type minerals with the same cationic component. Thus, they show similar electrokinetic, adsorptive and desorptive behavior in physical separation process such as flotation. Various flotation processes have been developed in the past four decades, but none is satisfactory due to high $\mathrm{MgO}$ content and/or low overall $\mathrm{P}_{2} \mathrm{O}_{5}$ recovery in the final phosphate concentrate. In this research project, dolomitic phosphate pebbles from Florida will be treated by column flotation. A liberation analysis of the dolomite-phosphate matrix will be conducted to determine optimum grinding conditions; new selective mixtures of fatty acid collectors and non-ionic surfactants will be evaluated on relatively coarse (minus 300 microns) and fine (minus 150 microns) dolomite particles; appropriate mixtures of phosphoric acid/sulfuric acid will be used to depress phosphate particles; and the effect of addition of non-ionic surfactants on the separation performance will be determined. The goal is to produce a phosphate concentrate containing $30 \% \mathrm{P}_{2} \mathrm{O}_{5}$ and less than $1.0 \% \mathrm{MgO}$ contents at high $\mathrm{P}_{2} \mathrm{O}_{5}$ recoveries from low grade phosphatic pebbles stockpiled at plant sites and from pebbles generated from mining lower grade reserves.

\section{b) Solid-Liquid Separation}

\section{Improving Densification of Fine Coal Refuse Slurries to Eliminate Slurry Ponds Principal Investigators: B.K. Parekh and R.Q. Honaker, University of Kentucky Period of Performance: May 1, 2003-May 31, 2005 (2-Year Project)}

Increased mechanization in underground coal mining has increased the volume of refuse generated by coal preparation plants. The fine refuse slurry, composed of coal and mineral matter, is usually disposed of in a holding pond (impoundment), but incidents of impoundment breakthrough have forced the industry to look for alternative methods for fine refuse storage in the future. The main objective of the proposed program is to evaluate a new technique known as "Paste Thickening Technology," which utilizes a DORR-OLIVER EIMCO DEEP CONE Thickener to discharge the waste slurry as a paste. The paste material should be stackable at low repose angles and would dry over a period of time, thus avoiding the storage of slurries in ponds. The proposed study will be conducted on coal waste slurries obtained from two different preparation plants. 
Laboratory studies will involve the characterization of the slurries, bench-scale flocculation studies and rheological analysis of the flocculated materials to identify yield stresses at various solid concentrations. This information will be used to establish optimum conditions for the production of a thickened paste product. A pilot-scale study will then be conducted at one of the coal preparation sites to obtain technical and economic data for a commercial installation and operation. It is anticipated that the outcome of the study will be an effective and economical process for the safe disposal of fine coal refuse.

\section{Development and Testing of a Horizontal Pressure Belt Filter}

Principal Investigators: R.-H. Yoon \& G.H. Luttrell, Virginia Tech

Period of Performance: May 1, 2003-May 31, 2005 (2-Year Project)

A variety of mechanical processes are available for dewatering fine particles in the coal and mineral processing industries. Unfortunately, many of these processes suffer from major shortcomings such as poor dewatering performance, low throughput capacity, and high capital and operating costs. This project seeks to overcome these problems by developing a new type of dewatering process that combines the operational flexibility of a continuous belt filter with the dewatering efficiency of a batch pressure filter. The proposed project involves the design, construction, testing, and evaluation of a prototype unit and pilot-scale test circuit having a production capacity of approximately $100 \mathrm{lb} / \mathrm{hr}$. Test data obtained from the project will be used to promote the engineering development of a full-scale commercial unit.

\section{c) Chemical/Biological Extraction}

\section{Bio-Assisted Heap Leaching of Nickel Laterites for the Development of a Domestic Nickel Industry}

Principal Investigator: S. Duyvesteyn, University of Utah

Period of Performance: May 1, 2003-May 31, 2005 (2-Year Project)

The U.S. currently imports all of its nickel, which is a strategic material used in stainless steels and other corrosion-resistant materials. Existing U.S. resources are worth around $\$ 10$ billion at current metal prices, but occur mostly in low-grade laterite deposits, for which conventional hydrometallurgical processes are not economically feasible production routes. These processes typically utilize mineral acids that cannot be recycled economically and can cause significant environmental problems. The solubilization of metal ions from ores by organic acids produced by microorganisms has been demonstrated to be a viable alternative for metal production with reduced environmental and remediation issues, as organic acids are readily biodegradable. The fact that many of these organic acids and other metabolites form strong chelating complexes with the base metal ions also results in a reduction in the acid requirements to achieve complete solubilization. 
This research proposal involves a biotechnological approach, called bio-assisted heap leaching (BAHL), for the production of nickel metal from low-grade ore synergistically with the co-production of citric acid. The BAHL process can be described as follows: laterite nickel ore is combined with an organic nutrient and put on heaps where fungi, such as Aspergillus niger, produce organic acids during their natural metabolic cycle. Recycle solution is sprayed over the heaps and its percolation through the heaps results in the dissolution of nickel. The resulting nickel-containing leach solution is collected and the nickel and citrate values are recovered.

\section{The Development and Utilization of Alkaline Sulfide Leaching and Recovery of Gold}

Principal Investigator: C. Anderson and L.G. Twidwell, Montana Tech Period of Performance: May 1, 2003-May 31, 2005 (2-Year Project)

Due to the increasing concerns over the emission of sulfur dioxide from roasting and smelting, there has been an increased interest in pressure oxidation as a means of treating gold bearing ores and concentrates. One of the problems with the partial oxidation of the sulfide host matrix to form elemental sulfur is that sulfur containing streams are difficult to treat using cyanidation. In the present study, the alkaline sulfide system will be studied as an alternative to cyanide for recovering gold from elemental sulfur. A complete thermodynamic model of the alkaline sulfide gold leaching system will be developed using Stab-Cal software and the leaching system and its kinetics will be optimized.

\section{Hydrometallurgical Processing of Chalcopyrite Concentrates}

Principal Investigator: M. Misra and M. Fuerstenau, University of Nevada, Reno Period of Performance: May 1, 2003-May 31, 2005 (2-Year Project)

Hydrometallurgical processing of chalcopyrite at moderate temperature and pressure has been a goal of the copper industry for decades. Research has shown that a protective sulfur layer forms on chalcopyrite when leached with ferric salts in acidic medium. This layer limits the transport of electrons from the mineral surface to the oxidant and precludes the use of this technology for chalcopyrite processing. Research at the University of Nevada, Reno has shown that the introduction of finely-divided silica improves the kinetics of leaching dramatically. Silica adsorbs on the surface of chalcopyrite, and since it is an n-type conductor, conduction of electrons from the mineral surface to the oxidant occurs by photocatalysis of the sulfur product layer. Dissolution amounts of as much as $80 \%$ have been achieved under the limited conditions examined, namely at atmospheric pressure and $50^{\circ} \mathrm{C}$.

\section{Simultaneous Electrolysis of Copper and Ferrous Ions to Produce Copper Cathode and to Regenerate Ferric Sulfate - The Lixiviant to Dissolve Copper Sulfide Minerals}

Principal Investigator: C. Young, H.-H. Huang and C. Fabian, Montana Tech Period of Performance: May 1, 2003-May 31, 2005 (2-Year Project) 
Copper leaching is primarily conducted on oxidized ore bodies at low $\mathrm{pH}$ by using sulfuric acid $\left(\mathrm{H}_{2} \mathrm{SO}_{4}\right)$. The sulfate acts as the lixivant to solubilize the copper as copper sulfate $\left(\mathrm{CuSO}_{4}\right)$. An oxidant is also needed to enhance reaction rates - typically this is dissolved oxygen $\left(\mathrm{O}_{2}\right)$ and/or ferric $\left(\mathrm{Fe}^{3+}\right)$ ion. The dissolved copper must then be extracted from the water to separate it from other dissolved constituents including iron. Traditional solvent extraction and electrowinning (SX/EW) procedures do this and ultimately yield quality copper cathode as product. After SX/EW, leach solution is recycled to the leaching process and replenished with oxidant as needed. For example, biological activity can regenerate ferric ions or mechanical agitation can produce dissolved oxygen (which in turn can regenerate ferric ions).

Ferric ions can also be regenerated electrolytically and simultaneously to copper cathode production. This is the basis of the proposed research. To accomplish this, a porous membrane will be used to keep the anode and cathode compartments separated and modern rotating cylinder electrodes will be used to stir solutions, obtain high current densities and ultimately produce superior grade copper cathode. Although it is possible to avoid the SX step, it will be used to produce two streams: raffinate, which will go to the anode compartment where ferric is regenerated, and pregnant or advance solution, which will be go to the cathode compartment where copper metal is produced. Various chemicals and additives may have to be added to control copper cathode formation and thereby avoid, for example, dendritic growth. Preliminary cost analyses show that copper can be produced for approximately $\$ 0.30 / \mathrm{lb}$ with this new, more energy efficient, technique.

\section{Ion Exchange Recovery of Cobalt from Copper Leach Solutions}

Principal Investigator: I. Gundiler and M. Hatch, New Mexico Tech

Period of Performance: May 1, 2003-May 31, 2005 (2-Year Project)

Cobalt is a strategic and critical metal which is used in production of super alloys for use in jet engine turbines, wear and corrosion resistant alloys, cutting tools, magnets and various other alloys and chemicals. It is not mined or refined in the United States; therefore, $80 \%$ of the cobalt consumed in the U.S. is imported. The remaining balance is met with recycled alloys and supplies from stockpiles. Although there is historical production and known reserves, these are not economical to exploit at the present. However, there is a readily available source of cobalt in the leach solutions generated in large copper mining operations in the Southwestern U.S. If only a fraction of this cobalt could be recovered, New Mexico and Eastern Arizona copper leach operations could potentially supply $20 \%$ of U.S. imports. Currently, the technology to recover the metal from these solutions economically is not available.

Ion exchange processes could recover this cobalt. However, commercially available resins are either too expensive, or do not function in acidic solutions. Absorption kinetics of these resins are also fairly slow. Three new resins will be synthesized at New Mexico Tech for copper and cobalt recovery from acidic solutions. The resins will be characterized and tested in the laboratory using pure chemicals, as well as process solutions to be obtained from the Phelps Dodge Mining Company, New Mexico 
operations. The performance of the synthesized resins will also be compared with that of commercially available resins.

\section{The Effect of Diphenyl Oxide Surfactants on Nucleation and Growth of Potassium Sulfate Crystals: Development of Enhanced Surfactants for the Potash Industry Principal Investigator: G. Bond and C. Hockensmith, New Mexico Tech Period of Performance: May 1, 2003-May 31, 2005 (2-Year Project)}

Surfactant-controlled crystallization leads to an increase in the efficiency of potassium sulfate production, particularly when alkyl diphenyl oxide-type (ADO) surfactants are employed in synthesis. Improved control of crystallization in both the initiation and termination phases can increase the ratio of granular particles to fines, decreasing costs associated with production and facilitating the utilization of lower-grade ores. Mother liquors in potash extraction contain high percentages of magnesium as well as other ions including chloride and impurities such as clay and silica. Potassium sulfate crystals will be produced in the presence of different ADO surfactants, and evaluated by SEM, TEM, XRD, FTIR and AFM. Crystallization processes, particularly those that affect crystal morphology, size, initiation and termination, will be studied in relation to the surfactant effect. This information will be used to improve control of potassium sulfate precipitation and develop the next generation of surfactants to facilitate extraction of granular potassium sulfate.

\section{d) Modeling and Control}

1. Online Monitoring and Diagnosing of Coal Fines During Separation Process Principal Investigator: B.S. Kang and E.K. Johnson, West Virginia University Period of Performance: May 1, 2003-May 31, 2005 (2-Year Project)

The goal of this research program is to develop an on-line, non-contact, elemental analysis of coal fines during solid-solid separation process through the use of LaserInduced Breakdown Spectroscopy (LIBS). Of particular interest is the detection and quantitative measurement of the amount of carbon, sulfur, mercury, and other trace elements in the separated coal fines. The proposed experimental technique will be applied to a circulating fluidized bed (CFB) riser system for determination of coal fines separation efficiency as well as optimization of the separation process variables using a fuzzy logic control approach.

\section{Development of a Novel Optical Radiation Depolarization Technique for On-Line Measurements of Particle and Bubble Sizes}

Principal Investigators: D. Tao, M.P. Menguc and C. Crofcheck, University of Kentucky Period of Performance: May 1, 2003-May 31, 2005 (2-Year Project)

Grinding and froth flotation are the two most important processes for mineral beneficiation. The importance of grinding is well reflected in the fact that approximately $80 \%$ of beneficiation costs are for grinding, mainly due to high energy consumption. To reduce 
energy consumed by grinding, fines should be removed quickly from the grinding circuit. This requires a reliable on-line particle size analysis technique. Similarly, froth flotation is the most widely used solid-solid separation process for coal and minerals beneficiation and about $90 \%$ of mineral concentrates are produced by froth flotation. Air bubble size distribution plays an important role in flotation separation performance but optimization of bubble size distributions will only be possible if bubble size can be monitored on-line.

The proposed project is aimed at developing an optical radiation depolarization technique for on-line size measurement of particle sizes in grinding and bubble sizes in flotation. The technique is based on the analysis of angular and radial profiles of reflection and transmittance of an object subjected to a collimated, polarized light beam. A hybrid Monte Carlo/Ray Tracing method will be used to simulate the depolarization of radiation by particles or air bubbles and size distributions will be determined by best fitting experimentally determined vertical and horizontal polarization components of the radial and angular profiles of reflection and transmission. The proposed technique should also be able to determine water film thicknesses and bubble separation distance distributions in foams.

\section{e) Environmental Control}

\section{Electrolytic Solution Purification and Metal Recovery from Metal-Bearing Toxic Waste Streams}

Principal Investigator: Michael L. Free, University of Utah

Period of Performance: May 1, 2003-May 31, 2004 (1-Year Project)

Industry creates numerous waste streams, many of which contain dissolved metal ions that must be removed to preserve the environment. Many of these waste streams can be created by natural processes that are accelerated by industry such as acid mine drainage, made as byproducts of chemical processing such as metal extraction, or as the result of manufacturing processes such as electronic component manufacturing. Often such wastes are complex and involve multiple metal ions. Regardless of the waste origin, toxic metal ions must be removed.

In the proposed project a novel method of removing multiple toxic metals from aqueous media by selective pulse-plating with high surface area electrodes will be evaluated and developed in a manner that will allow the metals to be recovered individually as purified metals in an environmentally sound way. The direct production of metal as a byproduct, rather than as a toxic waste, will contribute to better resource utilization as well as a reduction in toxic waste generation.

\section{Determining the Effectiveness of Gold Filters for Removing Mercury from Coal Fired Power Plants \\ Principal Investigator: K. Ganesan, Montana Tech \\ Period of Performance: May 1, 2003-May 31, 2004 (1-Year Project)}


Because the US EPA is planning to regulate mercury emissions from power plants, there is a clear need to develop devices that can cost effectively remove mercury from power plant flue gases. Most current research has focused on transferring mercury from the air stream to fly ash or converting elemental mercury to divalent mercury to absorb it in wet scrubbers. However, when low chlorine content coal is combusted most of the mercury in the flue gas exists as elemental mercury, which is very hard to remove. Thus, to comply with the potential $90 \%$ mercury reduction proposed by EPA, one must oxidize the elemental mercury to either mercuric chloride or oxide as a way to collect particulates. In either case, mercury is merely converted to a form that is also difficult and expensive to recover. Therefore, it appears that directly removing mercury from the flue gas will be the most cost effective and environmentally friendly approach. This proposal is focused on removing elemental mercury from flue gas using gold filters. The main objective of this research is to evaluate the effectiveness of gold wire mesh in removing mercury vapor from flue gas. A wire mesh made of thin $(<0.1 \mathrm{~mm}$ diameter) gold wires will be tested in the laboratory, initially with a synthetic gas stream containing mercury vapor in the range of $1-300 \mu \mathrm{g} / \mathrm{m}^{3}$. Similar tests will be conducted in combustion gases by burning six types of western and eastern coals. The study will be conducted for six concentration levels of mercury; 5, 10, 25, 50, 100 and $300 \mu \mathrm{g} / \mathrm{m}^{3}$. 


\section{EXPERIMENTAL}

The CAST initiative is comprised of a diverse group of subprojects, most of which are multistage, task-oriented developmental projects that cannot be conveniently categorized by the traditional reporting criteria required by the DOE Uniform Reporting Requirements. For example, several of the projects have required the construction of unique test equipment, others the generation of simulation models, etc., as preliminary tasks in the overall execution of the project. As such, they are more appropriately described and discussed as "Project Tasks” within the context of the individual Technical Progress Reports. These reports are attached to this document as Appendices and should be referred to for this information. 


\section{RESULTS AND DISCUSSION}

The CAST initiative is comprised of a diverse group of subprojects, most of which are multistage, task-oriented developmental projects that cannot be conveniently categorized by the traditional reporting criteria required by the DOE Uniform Reporting Requirements. For example, several of the projects have required the construction of unique test equipment, others the generation of simulation models, etc., as preliminary tasks in the overall execution of the project. As such, the presentation of results is more appropriately described and discussed within the context of the individual Technical Progress Reports. These reports are attached to this document as Appendices and should be referred to for this information. 


\section{CONCLUSIONS}

The initial RFP for this project resulted in seventeen (17) sub-projects being funded in early May, 2003. A six-month Progress Report (covering the period April 1, 2004September 31, 2004) was generated for each of these sub-projects and has been attached to this Document as an Appendix. A brief summary of progress during the second 6 months, along with plans for the future on each of the sub-projects is given below.

\section{a) Solid-Solid Separation}

\section{Development of Novel Ultrafine Sizing Methods (Joint UK/VT Project)}

Principal Investigators: R.-H. Yoon and G.H. Luttrell, Virginia Tech

Principal Investigators: R.Q. Honaker and BK. Parekh, University of Kentucky

Period of Performance: May 1, 2003-May 31, 2005 (2-Year Project)

Project work was initiated during the past reporting period to investigate a variety of new techniques for high efficiency sizing of ultrafine particles. Much of the work conducted to date focused on improving the performance of classifying cyclone circuits. This effort included (i) installation and testing of a two-stage classifying cyclone circuit at an industrial coal preparation plant and (ii) construction and initial testing of a closedloop test circuit for a new apex washing system. The test work conducted to date indicates that both of these technologies have the potential to substantially reduce amount of ultrafine solids that are bypassed to the coarse fraction in classifying cyclone circuits. Detailed test work will carried out during the next reporting period to fully evaluate these two technologies.

Investigations with several innovative processes for ultrafine sizing are expected to begin during the next reporting period. These processes will include (i) a continuous microsieve and (ii) free flow electrophoresis sizer. The microsieve uses hydrostatic pressure to force ultrafine solids through a fine mesh fabric wrapped around a horizontal rotating drum, while coarse solids trapped by the mesh are carried by the rotation to the top of the unit where they are discharged. To prevent blinding, the fine sieve is backwashed every cycle using high-pressure water sprays. The construction of a benchscale microsieve has been on hold to due a major breakdown of machine shop equipment and problems associated with the hiring of a skilled machinist/mechanic. These problems have now been corrected and work on this task has been restarted. While no additional experimental work has been undertaken during this reporting period using free flow electrophoresis (FFE), preliminary calculations conducted during the past quarter suggest that the FFE process has the potential to separate submicron particles from dilute feed slurries. The assembly of a laboratory-scale FFE test unit is expected to be completed during the first quarter of next year. Studies of the effects of surfactant addition on classification performance will also continue, as will experimental tests with a centrifugal elutriator (Knelson concentrator) to determine whether these technologies can improve classification efficiency. 


\section{Dispersion and Flotation of Clays from New Mexico Potash Ores}

Principal Investigators: I. Gundiler, S. Titkov, and M. Yekeler, New Mexico Tech Period of Performance: May 1, 2003-May 31, 2004 (1-Year Project)

During this phase of the study, flotation tests conducted with low and medium clay potash ores after 2-stage mechanical desliming, 1-stage mechanical desliming followed by flotation desliming. Although only slime flotation can be effective in removing clay-carbonate slimes ahead of potash flotation for ores with low I.R. content, mechanical desliming of the coarse ore followed by slime flotation yield the best results for medium clay ores.

This approach increases the potash recovery in the flotation concentrate, increases the potash flotation kinetics, hence, reduce flotation time, potash losses into slimes and I.R. impurities in the potash concentrates. Amine and guar binder consumptions are also reduced considerably. Application of slime flotation process at New Mexico processing plants could enable operators to be able to exploit high-clay ores, thus extending the ore reserves. This would also reduce mining costs by avoiding selective mining that is required to keep the I.R. content below certain limits $(<4.5 \%)$ for processing at the present plants. Further studies are currently underway for better assessment of processing conditions for high clay ores (7-9\% I.R.). These results will be reported in the final report.

\section{Flotation Technology for the Trona Industry}

Principal Investigator: Jan D. Miller, University of Utah

Period of Performance: May 1, 2003-May 31, 2005 (2-Year Project)

In the second research period the development of new flotation technology for the separation of gangue minerals and production of a trona concentrate of high purity continued using commercial amines. Results from initial pilot plant testing at the General Chemical plant are reported.

Laboratory flotation tests showed that insolubles in the feed were successively floated and a trona concentrate of $99 \%$ purity was obtained with a recovery of $90 \%$ at an amine dosage of $2.0 \mathrm{~kg} / \mathrm{t}$. The trona product meets the desired grade specifications for subsequent use. It has been determined that the insoluble content is one of the most important variables in amine flotation and successful flotation of insolubles is possible by proper control of the flotation conditions. The results show that if feed has a high insoluble content, a higher reagent dosage is required. Three different chain lengths of amine collectors were tested in laboratory flotation tests. As the chain length of the amine increases, the floatability of insolubles increases slightly. The $\mathrm{pH}$ of the amine solution is an important factor that influences floatability. As the $\mathrm{pH}$ of the amine solution increases, the floatability of insolubles increases. As might be expected, a good correlation was obtained between $\mathrm{pH}$ and the conductivity of the amine solution.

The parameters obtained from the bench scale experiments were applied in pilot scale flotation tests. Preparation for the evaluation of flotation parameters and optimum 
conditions for testing at the General Chemical plant site in the fall of 2004 was accomplished which include the transportation of necessary equipment from University of Utah and EIMCO, set-up, installation and finally the testing.

It is pretty much clear that this flotation chemistry system works very well for both small and large scale batch experiments but has not been successful for continuous pilot-plant tests. Detailed study is being continued at the University of Utah pilot plant due to weather conditions, feed availability and time considerations.

\section{Flotation Processes/Experiments and Analysis}

Principal Investigators: D. Telionis and P. Vlachos, Virginia Tech

Period of Performance: May 1, 2003-May 31, 2005 (2-Year Project)

In our previous report, we reported on measurements obtained in homogeneous isotropic turbulence. Our aim now is to simulate the anisotropy and nonhomogeneity found in a flotation cell. The turbulent dissipation rate was measured using a cross correlation based Particle Image Velocimeter. Particle Tracking Velocimetry will be used to determine the velocity fluctuations of the solid particles relative to the fluid phase. RMS velocities of the particles were calculated and compared to experimental and theoretical models that are based on the dissipation rate.

As described above, we have completed the design and made great progress on Task 1 , as described above. We have some preliminary data but we need to define a detailed set of experiments that will have to be conducted. These will require taking data along vertical planes that pass through the axis of the impeller. These will provide velocity components in the radial and axial direction and their fluctuations. We will then take data along planes normal to the impeller axis. These will provide components in the radial and circumferential direction.

The outside walls of the tank have an octagonal shape. This was chosen specifically to accommodate two cameras that will allow us to record three components of the velocity. It is not clear that we will be able to complete this phase of the work, which was not included in our original proposal.

Work on this effort will combine detailed theoretical analysis and modeling with state-of-the-art, global, multi-phase flow measurements to quantify the effects of the various hydrodynamic parameters on the flotation process. Our modeling approach will incorporate all physical parameters that affect the collision efficiency of coal particles and flotation bubbles and the probabilities of attachment and detachment. We will deliver global, time-resolved velocity distributions and turbulence characteristics for each phase. All the experimental results will be compared with their modeled counterparts.

\section{Column Flotation of Relative Coarse and Fine Dolomitic Phosphate Pebbles}

Principal Investigator: Felicia F. Peng, West Virginia University

Period of Performance: May 1, 2003-May 31, 2005 (2-Year Project) 
The dolomitic phosphate pebble sample were supplied by IMC Phosphates MP, Inc., Mulberry, FL. The study of size distribution and chemical analysis showed that the sample is a high $\mathrm{MgO}$ contant sample ranged from 1.22-4.5\% MgO for minus $0.25 \mathrm{~mm}$ (-60 mesh) size fraction. Four different fatty acid or soap types of dolomite collectors were evaluated at $\mathrm{pH} 5.1$ using the mixture of $1: 1$ phosphoric acid and sulfuric acid as $\mathrm{pH}$ modifier and depressant for size fraction of for $-0.25 m m+0.15 \mathrm{~mm}(-60+100$ mesh $)$ size fraction. The fatty acid collectors for dolomite are PA-31, USPA-31, S-500 and FAS40A supplied by IMC Phosphates. The tests results show that the increase in collector dosages can removal of $60-75 \% \mathrm{MgO}$ at $78 \%-90 \%$ P2O5 recovery, from the feed with average 2.9\% $\mathrm{MgO}$ and 24.2\% P2O5 dolomitic phosphate pebble samples.

The tests results show that the increased in collector dosages can removal of $60-75 \%$ of $\mathrm{MgO}$ in the float, at $80 \%-92 \%$ P2O5 recovery in the sink. However, the loss of P2O5 in the sink due to increase in dolomite collector dosages are also observed. In order to improve the removal of $\mathrm{MgO}$ and minimize the loss of P2O5 recovery, the selected depressants will be used for the evaluation. The feed for the flotation tests will also be increased to relatively coarser size range of $-0.43 \mathrm{~mm}+0.15 \mathrm{~mm}$. The delaying in the progress is due to take at least 2-4 weeks to receive the analysis results for the tested dolomite phosphate samples from the Analytical Lab of NRCCE. We can not make the determination of the flotation test conditions without the analysis results from the Lab. We have made the request to the Lab to place our sample analysis jobs at the top of their analysis priority list.

\section{b) Solid-Liquid Separation}

\section{Improving Densification of Fine Coal Refuse Slurries to Eliminate Slurry Ponds} Principal Investigators: B.K. Parekh and R.Q. Honaker, University of Kentucky Period of Performance: May 1, 2003-May 31, 2005 (2-Year Project)

The fine coal slurry from the Arch Coal Preparation Plant, WA was characterized for particle size distribution, percent solids, ash content and mineralogy. The combined addition of anionic flocculant followed by cationic flocculant was adopted for effective flocculation of the slurry. Preliminary tests conducted with the T-floc apparatus provided an underflow slurry concentration of $57 \%$.

Additional flocculation/settling tests to simulate Deep Cone thickener will be conducted using the T-Floc. A factorial design of experiments will be carried out to optimize settling parameters in the T-Floc apparatus. The underflow from the T-Floc apparatus will be characterized for yield stress and percent solids. Pilot-scale testing will be conducted at the Arch Coal of W.Va.

\section{Development and Testing of a Horizontal Pressure Belt Filter}

Principal Investigators: R.-H. Yoon \& G.H. Luttrell, Virginia Tech

Period of Performance: May 1, 2003-May 31, 2005 (2-Year Project) 
The basic design of a prototype horizontal belt pressure filter has been completed. The 2-inch wide by 6-ft long prototype has been designed to provide a throughput capacity of up to $100 \mathrm{lb} / \mathrm{hr}$ of dry solids. Unfortunately, problems associated with machine shop equipment and personnel caused a temporary delay in completing the construction of this prototype. These problems have now been resolved and work is now underway to procure the necessary construction materials and to complete the fabrication of the test unit.

Work during the next reporting period will focus primarily on the completion of construction activities. The machine work is expected to require approximately 3 months of dedicated shop time to complete. Shakedown tests will begin immediately after the construction work is finished. This work will be followed by a detailed test program and economic evaluation. The detailed test program will include a study of key operating variables including feed flow rate, feed solids content, feed size distribution, filter belt speed, filter cloth mesh size, and applied pressure.

\section{c) Chemical/Biological Extraction}

\section{Bio-Assisted Heap Leaching of Nickel Laterites for the Development of a Domestic Nickel Industry}

Principal Investigator: S. Duyvesteyn, University of Utah

Period of Performance: May 1, 2003-May 31, 2005 (2-Year Project)

This projected was terminated after 1 year and a final report is to be issued.

\section{The Development and Utilization of Alkaline Sulfide Leaching and Recovery of Gold \\ Principal Investigator: C. Anderson and L.G. Twidwell, Montana Tech \\ Period of Performance: May 1, 2003-May 31, 2005 (2-Year Project)}

During this reporting period, progress was made on both Task 2 (Phase I) and Task 3 (Phase I). Data that allowed optimization of alkaline sulfide leaching system chemistry and characterized the kinetics of the alkaline sulfide leaching system were collected with a quartz crystal microbalance. It was found that increasing either the sulfide or hydroxide concentration resulted in greater amounts of gold dissolution at lower potentials. Additionally, it was found that increasing the polysulfide ion concentration in the alkaline sulfide solution (by adding sulfur) resulted in faster leaching rates. The gold leaching rate was characterized at different temperatures. Increasing the temperature to $50^{\circ} \mathrm{C}$ resulted in a significant increase in the gold leaching rate. Thus, further leaching experiments at higher temperatures utilizing the quartz crystal microbalance are planned. 
Work will begin on Phase II tasks during the next reporting periods. Some initial work on these tasks was performed in the previous reporting periods. Based on the positive results obtained, more work will be completed. In particular, work focusing on recovering gold from an alkaline sulfide solution with a modified carbon adsorption process, ion exchange, electrowinning, and reduction of gold by the addition of a reducing agent to the solution will be pursued in the next reporting period as part of Task 1/Phase II. Additionally, Task 2 (Phase II) objectives will be completed by performing high temperature/pressure oxidation of the alkaline sulfide solution in an autoclave followed by treatment of the solution with lime. Optimum conditions are expected to produce a sodium sulfate and gypsum product. Finally, work will be performed on leaching refractory gold ores and concentrates Task 3 (Phase II). The general approach that will be taken to accomplish Task 3 (Phase II) will consist of applying the optimum leaching conditions developed as part of Task 1 and Task 2 (Phase I).

\section{Hydrometallurgical Processing of Chalcopyrite Concentrates}

Principal Investigator: M. Misra and M. Fuerstenau, University of Nevada, Reno Period of Performance: May 1, 2003-May 31, 2005 (2-Year Project)

When chalcopyrite is leached with oxidants in acidic medium, sulfur forms as an oxidation on the chalcopyrite surface which inhibits dissolution in a number of systems. The addition of nanosize silica, ethylene glycol and sodium nitrate apparently change the morphology of the sulfur, and dissolution is enhanced at moderate temperature and pressure. Important developments in this time period are the enhancement in dissolution of chalcopyrite that are obtained when ethylene glycol and sodium nitrate are added to these leaching systems.

Leaching experiments will be continued as a function of chalcopyrite particle size, temperature, oxidant concentration, silica concentration and degree of agitation to establish the reaction kinetics.

Electrochemical impedance spectroscopic measurements will be continued to establish impedance, conductivity and electrochemical parameters and compared with leaching data to determine the roles of silica, ethylene glycol and sodium nitrate leaching of chalcopyrite.

\section{Simultaneous Electrolysis of Copper and Ferrous Ions to Produce Copper Cathode and to Regenerate Ferric Sulfate - The Lixiviant to Dissolve Copper Sulfide Minerals}

Principal Investigator: C. Young, H.-H. Huang and C. Fabian, Montana Tech

Period of Performance: May 1, 2003-May 31, 2005 (2-Year Project)

A new, two-part membrane separated electrolytic cell was designed and constructed this reporting period. The new cell allowed rapid changing of the membrane and resulted in more efficient and reliable experimentation. Several different electrolytic 
cell parameters were varied including ferrous concentration, anode type, cathode type, and membrane type. The experimental results indicated that the anode type/surface area had a tremendous effect on the cathode current density and that the anodic reactions were the current limiting reactions when a catholyte solution containing typical industry amounts of copper were tested in the cell. The greatest cathode current densities obtained to date were produced when graphite anodes were used. Additionally, comparison of a commercially available anionic exchange membrane to a commercially available porous membrane showed greater current densities could be obtained with the anionic exchange membrane. However, the short life span of the anion exchange membrane in the highly acidic environment would preclude its use in an industrial environment. Preliminary copper concentrate leach tests showed an enhanced leaching rate due to the presence of ferric ions in the acidic sulfate leaching solution. Based on these positive results, further tests are planned with a goal of running a closed circuit leaching/membrane separated electrowinning process to recover copper from both copper sulfide concentrates and ores.

During the next reporting period further characterization studies will be completed. The experiments will continue to focus on optimizing the current density and current efficiency obtained from the cell. The effect of temperature, anode type, acid concentration, iron concentration, copper concentration, solution flow rate, and membrane life will also be characterized. Comprehensive ore and concentrate leaching studies, utilizing materials obtained from a local copper mine, will also commence to determine the optimum conditions for leaching the copper from sulfide minerals. Additionally, work on a rotating cylinder membrane separated electrolytic cell will also be completed during the next reporting period through collaborative effort with James Cook University in Australia

\section{Ion Exchange Recovery of Cobalt from Copper Leach Solutions}

Principal Investigator: I. Gundiler and M. Hatch, New Mexico Tech

Period of Performance: May 1, 2003-May 31, 2005 (2-Year Project)

In search for new resins to recover copper and cobalt from dilute H2S04 solutions, small quantities of two new chelating resins (1) a highly cross-linked, gel-type, and highly picolylated diethylene triamine resin (CHEL-38), and (2) a less picolylated diethylene triamine resins (CHEL-40) were synthesized and evaluated. Small-scale columns tests were made $\mathrm{pH} 1.7$ and $\mathrm{pH} 1.1$ solutions containing $\mathrm{Cu}$ (II), Co (II), and Fe (III) ions. Comparison tests were also made with comparable-sized commercially available, hydroxypropyl picolylamine resin (Dow XFS-43084), and bis-picolylated amine resin (Dow XFS-43578). The results indicate that both the highly picolylated diethylene triamine (CHEL-38) and less picolylated diethylene triamine resins were comparable to, or more effective, in absorbing $\mathrm{Cu} 2+$ from acidic solutions then the commercial resins. The CHEL-38 resin and the CHEL-40, on the other hand, had cobalt absorption capacities much better than those of the commercial resins. Ferric ion absorption on CHEL-38 and CHEL-40, moreover, were comparable to, or less then those of the commercial resins in the test made at $\mathrm{pH} 1.7$ solutions. 
In further laboratory development work we will try to improve the synthesis of the picolylated diethylenetriamine resins (small or intermediate lab-scale). Also we will make further column studies of loading capacity as a function of $\mathrm{pH}$ and of absorption and desorption kinetics, and selectivity for copper and cobalt in the presence of ferric ions. These studies will include mixtures that stimulate the leach solutions from copper mining operations, or with the actual mining liquors if available. If possible, these studies will be made on a larger laboratory scale.

\section{The Effect of Diphenyl Oxide Surfactants on Nucleation and Growth of Potassium Sulfate Crystals: Development of Enhanced Surfactants for the Potash Industry Principal Investigator: G. Bond and C. Hockensmith, New Mexico Tech Period of Performance: May 1, 2003-May 31, 2005 (2-Year Project)}

A modified MSMPR crystallizer is being used to grow potassium sulfate crystals. Crystal sizes, habits, phases, and growth rates are being evaluated by field-emission scanning electron microscopy, X-ray diffraction, and titration methods. Surfactants are being added with the goal of producing a modest inhibition of nucleation, and hence shifting the crystal size distribution, in order to increase the ratio of granular particles to fines, and thus decrease the costs associated with industrial production of potassium sulfate. Preliminary data obtained with concentrations of Calfax 16L-35 alkyl diphenyl oxide (ADO) surfactant at the critical micelle concentration (CMC) suggest that this ratio may indeed be increased for crystallization at $40^{\circ} \mathrm{C}$. Additional experiments are in progress to verify this result, to provide a better understanding of changes in crystal growth habit and growth rate as a function of surfactant concentration, and to investigate related surfactants.

Near-CMC concentrations of Calfax 16L-35 surfactant result in extensive crystallization, with crystals in a size range close to that for crystallization from the mother liquor. Initial data suggest that there may be fewer of the smaller crystals when precipitation occurs in the presence of the surfactant at $40^{\circ} \mathrm{C}$. Additional runs will be performed in order to verify this result. Changes in crystal growth habit and growth rate will be studied further, as a function of surfactant concentration. Analogous studies will also be conducted with related surfactants.

\section{d) Modeling and Control}

\section{Online Monitoring and Diagnosing of Coal Fines During Separation Process} Principal Investigator: B.S. Kang and E.K. Johnson, West Virginia University Period of Performance: May 1, 2003-May 31, 2005 (2-Year Project)

The findings from the preliminary experiments indicated that qualitative analysis of iron and coal sample using LIBS system can be accomplished. Iron was a good candidate to choose for qualitative analysis for two reasons 1.) Iron has many emission lines, which will make it easier to see qualitatively 2.) The MIT wavelength tables show 
that a few of the iron lines are very close to the mercury lines. If iron can be identified, mercury will be close to it in the spectrum.

A new WVU LIBS system is in the final stage of completion. The new LIBS system (Figures 1 and 2) will allow for time-delayed synchronization and temporal resolution measurement of selected target elements in coal samples such as iron, carbon, sulfur, and mercury.

The polygonal scanning mirror and the off-axis parabolic mirror are expected to arrive in late October 2004. Although, the data acquisition for the final laboratory phase was delayed due to technicalities in the procurement process and technical issues with the laser and the spectrometer, a new round of LIBS tests should begin in November 2004 using the new LIBS system. Qualitative analysis of sulfur, carbon, iron, and mercury are expected to be included in the initial LIBS testing.

\section{Development of a Novel Optical Radiation Depolarization Technique for On-Line Measurements of Particle and Bubble Sizes}

Principal Investigators: D. Tao, M.P. Menguc and C. Crofcheck, University of Kentucky Period of Performance: May 1, 2003-May 31, 2005 (2-Year Project)

An elliptically polarized light scattering (EPLS) approach was adapted for monitoring the column flotation parameters such as bubble size, average gas hold-up and coal size distribution. In order to monitor two phase flows (GL and SL), two different sensor locations were proposed.

The two-phase GL results show that the present EPLS concept is very promising for characterization of optically thin columns and has many advantages over imaging techniques when in-situ measurement of bubble size are necessary at high flow rates with high surfactant concentrations. For optically-denser bubble laden media, the reliability of this technique can be improved by incorporating multiple scattering algorithms in data reduction.

The two-phase SL experiments show the problem is more complex than GL phase measurements because of composite structure of the coal mixtures and wide range of size distribution. But it is still possible to sense the particle size distribution from the normalized scattering matrix elements.

Define parameter(s) based on scattering matrix elements at highly sensitive scattering angles to study the influence of various input parameters of the froth flotation column on light scattering within the two-phase mediums (GL \& SL).

Assemble two sensors for large size columns for online process monitoring.

\section{e) Environmental Control}

\section{Electrolytic Solution Purification and Metal Recovery from Metal-Bearing Toxic Waste Streams}


Principal Investigator: Michael L. Free, University of Utah

Period of Performance: May 1, 2003-May 31, 2004 (1-Year Project)

The project is completed and a final report is to be issued.

\section{Determining the Effectiveness of Gold Filters for Removing Mercury from Coal Fired Power Plants}

Principal Investigator: K. Ganesan, Montana Tech

Period of Performance: May 1, 2003-May 31, 2004 (1-Year Project)

In summary, in this progress reporting period three gold filters were tested with mercury containing gas stream at the Montana Tech of the University of Montana's laboratory. Since the filters show high mercury removal efficiency at the laboratory preliminary tests were conducted in a coal fired flue gas stack. The results indicate success in using the filter for mercury removal efficiency. However, the testing with stack gas needs further sample conditioning and long term testing to confirm the efficiency of the filter. Thus the preliminary tests results indicate that gold filters can remove mercury vapor over ninety percent from coal fired flue gas streams.

The performance test for gold will be continued for flue gas in a coal fired power plant. The filter efficiency and its removal capacity $(\mu \mathrm{g} / \mathrm{g})$, that is, the amount of mercury the filter can hold before its regeneration will be determined. The preliminary results also indicate that the spent filters may release mercury with minimum amount of heating. Similar tests are under way with silver filters also. The physico-chemical processes will be evaluated to better understand the amalgamation process. The literature review and analyzing the spent gold filters under SEM/EDX will give information to help understand the physico-chemical processes involved in amalgamation. The PI will write the final report at the end of the project. A project summary will be posted in the CAST web site as well as in Montana Tech's web site. 


\section{REFERENCES}

References utilized by the individual sub-projects are reported in the relevant Technical Progress Report in the attached Appendices. 
Appendix A: KY001/VA008 - Development of Novel Ultrafine Sizing Methods 


\section{TECHNICAL PROGRESS REPORT}

Contract Title and Number: Crosscutting Technology Development at the Center for Advanced Separation Technologies (DE-FC26-02NT41607)

Sub-Recipient Project Title:

Development Of Novel Ultrafine Sizing Methods

Principal Investigators:

Rick Q. Honaker and B.K. Parekh

Contact Address:

234-B Mining and Mineral Resources Building University of Kentucky, Lexington, KY 40506

Subcontractor Address:

No subcontracts issued.
Period of Performance:

Starting Date: 4/01/03

Ending Date: $\quad 5 / 30 / 05$
Report Information:

Type: Semi-Annual

Number: 3

Period: $\quad 4 / 1 / 04-10 / 30 / 04$

Date: $\quad 11 / 29 / 04$

Code: KY001

Contact Information:

Phone: (540) 231-4508

Fax: (540) 231-3948

E-Mail:_cast@vt.edu

Subcontractor Information:

Phone:

Fax:

E-Mail:

\section{ABSTRACT}

The objective of this project is to develop a broad base of new equipment and improved methods for fine particle sizing. The processes evaluated in this work include a wide variety of mechanical, hydraulic, and novel approaches. For each process, experimental test programs have been undertaken to optimize operating parameters so that maximum efficiency and throughput capacity can be achieved while maintaining particle size cuts in the 25-50 $\mu \mathrm{m}$ size range. The resultant test data has been used to mathematically simulate different circuit arrangements for the most promising technologies. Due to the large scope of this project, the proposed work has been carried out as a joint effort between researchers at the University of Kentucky and Virginia Tech. During this reporting period, much of the project work focused on the evaluation of techniques for improving the performance of classifying cyclone circuits. This effort included (i) installation and testing of a two-stage classifying cyclone circuit at an industrial coal preparation plant and (ii) construction and initial testing of a closed-loop test circuit for a new apex washing system. 


\section{INTRODUCTION}

\section{$\underline{\text { Background }}$}

Most mineral and coal processing plants are forced to size their particulate streams in order to maximize the efficiency of their unit operations. These sizing techniques commonly include various types of screens and classifiers. Screens exploit differences in the physical dimensions of particles by allowing fines to pass through a perforated plate or open mesh while coarser solids are retained. Unfortunately, screening systems are generally limited to particle size separations coarser than approximately $250 \mu \mathrm{m}$ due to limitations associated with capacity and blinding. Hydraulic classifiers are generally employed for finer size separations, including both static and centrifugal devices. Hydraulic classifiers exploit differences in the settling rates of particles and are influenced by factors such as particle shape and density as well as particle size. Classifiers are generally considered to be more practical than screens for fine sizing, but the separation efficiency decreases dramatically for particles smaller than approximately $150 \mu \mathrm{m}$ (Heiskanen, 1993). In addition, classifiers commonly suffer from bypass, which occurs when a portion of the ultrafine particles (slimes) are misplaced by hydraulic carryover into the oversize product. The unwanted misplacement can have a large adverse impact on downstream separation processes.

\section{$\underline{\text { Objective and Approach }}$}

The development of efficient techniques for fine particle sizing is widely considered to be a high research priority by both the mineral processing and coal preparation industries. In particular, the development of new screening and classification technologies, or improvements on existing technologies, is needed to overcome the current shortcoming of existing processes for fine particle sizing. Therefore, the primary objective of this project is to develop a broad base of new sizing equipment or techniques that can be used to efficiently size ultrafine particles. Processes to be evaluated in the proposed work will include a wide array of mechanical, hydraulic, and novel approaches for fine particle sizing. Because of the inherent difficulties and large scope of work associated with this problem, the research program is being carried out as a joint research program between researchers at Virginia Tech and the University of Kentucky. During this reporting period, much of the project work focused on the evaluation of techniques for improving the performance of classifying cyclone circuits. This effort included (i) installation and testing of a two-stage classifying cyclone circuit at an industrial coal preparation plant and (ii) construction and initial testing of a closed-loop test circuit for a new apex washing system.

\section{PROJECT TASKS}

\section{Task 1 - Development of Mechanical Sizing Methods}

No additional test work was conducted under this particular task during the past reporting period. 


\section{Task 2 - Development of Hydraulic Sizing Methods}

No additional test work was conducted under this particular task during the past reporting period.

\section{Task 3 - Development of Novel Sizing Methods}

No additional test work was conducted under this particular task during the past reporting period.

\section{Task 4 - Circuit Development and Evaluation}

\section{Evaluation of Two-Stage Cyclone Circuits}

The performance of classifying cyclones can also be substantially improved using circuit configurations specifically designed to minimize the bypass $(\phi)$ of ultrafine particles into the coarse underflow stream. Simulation data reported in a previous technical progress indicated that one very effective method for reducing bypass is to retreat the coarse underflow using a downstream bank of secondary cleaner cyclones. To this end, a two-stage classifying circuit was installed in an operating preparation plant located in eastern Kentucky. The particle size and quality distribution shown in Table 1 is typical of the minus 100 mesh material typically fed to the cyclone circuit. As shown, an efficient particle size separation at 400 mesh would allow about $22 \%$ of the solids now sent to the waste impoundment to be recovered at a very low ash content of 5.9\%.

The initial test performed at the plant site resulted in an ash reduction from $55.3 \%$ to $33.5 \%$ with a mass recovery to the secondary underflow stream of $32.7 \%$. The particle cut size $\left(d_{50}\right)$ for the overall circuit was about $39 \mu \mathrm{m}$ with a sharpness index $(\alpha)$ of $0.50(\alpha=0$ represents a perfect size separation). As shown in Table 1, the cut size of $39 \mu \mathrm{m}$ would have provided an excellent clean coal product. However, since $\alpha=0.50$ represents a relatively

Table 1. Particle size and quality distribution of the feed to the two-stage cyclone circuit.

\begin{tabular}{cccccc}
\hline \multirow{2}{*}{$\begin{array}{c}\text { Size } \\
(\mathrm{mesh})\end{array}$} & \multirow{2}{*}{$\begin{array}{c}\text { Size } \\
(\mu \mathrm{m})\end{array}$} & \multicolumn{2}{c}{ Individual } & \multicolumn{2}{c}{ Cumulative } \\
\cline { 3 - 6 } & +250 & 0.41 & 1.34 & 0.41 & 1.34 \\
+60 & $250 \times 150$ & 1.38 & 2.39 & 1.80 & 2.15 \\
$60 \times 100$ & $150 \times 75$ & 9.08 & 2.75 & 10.88 & 2.65 \\
$100 \times 200$ & $75 \times 44$ & 8.35 & 6.57 & 19.23 & 4.35 \\
$200 \times 325$ & 3.42 & 14.59 & 22.65 & 5.90 \\
$325 \times 400$ & $44 \times 37$ & 3.45 & Ash & Mass $\%)$ & Ash $(\%)$ \\
$400 \times 500$ & $37 \times 25$ & 4.41 & 27.58 & 27.06 & 9.43 \\
500 & -25 & 72.94 & 72.33 & 100.00 & 55.32 \\
\hline Totals & & 100.00 & 55.32 & --- & --- \\
\hline
\end{tabular}


inefficient separation, a significant amount of fine solids were misplaced to the underflow stream. Further analysis revealed that the main contributor to the misplacement was the secondary classifying cyclones which gave $\alpha=0.86$ and $\phi=0.50$, despite a very low $d_{50}$ of 13 $\mu \mathrm{m}$. The poor secondary cyclone performance has been attributed to the high feed solids concentration of around $17 \%$ by weight. As such, a second series of tests were conducted which involved dilution of the secondary cyclone feed and changing secondary underflow apex diameter. One test involved the removal of the secondary cyclone overflow stream from the primary cyclone feed and placing it in the circuit reject stream. Preliminary results obtained from the second round of tests are promising. The circuit reduced the ash content from $55.0 \%$ to around $23.3 \%$ as a result of diluting the secondary feed. The particle size distributions in each process stream and overall circuit efficiency for all tests are current being evaluated. The results will be presented and discussed in the next report.

\section{Evaluation of Apex Water Injection}

Another method of reducing bypass is through the application of a water injection apex. Unfortunately, existing water injection systems tend to substantially increase the particle cut size, which makes it unacceptable for ultrafine sizing applications. In addition, existing systems typically require large amounts of clarified injection water that may not be readily available in industrial plants. In light of these problems, technical personnel from Krebs Engineers have worked with the project team to develop a new type of water injected cyclone. The new system is specifically designed to overcome some of the inherent limitations associated with existing apex washing systems. To evaluate this new technology, a proprietary prototype was provided to the project team for initial testing. The experimental test program required the construction of a complete closed-loop test circuit (see Figure 1). The circuit, which is designed to be extremely flexible, incorporates a 6-inch diameter classifying cyclone with interchangeable components, an electronically controlled variable speed circulation pump, and an integrated linear-pass proportional sample cutter. The circuit if fully instrumented so that pressure and flow can be accurately monitored.

During this reporting period, several runs were conducted to evaluate the effects of vortex finder and apex geometries on pressure drop and volumetric flow rate. Experiments were carried out using water and minus 100 mesh coal slurry having a solids content of approximately $4.6 \%$ solids by weight. The pressure drop across a cyclone was measured by taking the difference between the feed pressure and the overflow pressure. Figure 2 shows that the size of the vortex finder and pressure drop are interdependent and the cyclone can handle more slurry at given pressure than water. A larger vortex finder results in a lower pressure drop for the same volume or a greater capacity for the same pressure drop. Conversely, a small diameter vortex finder will result in a larger pressure drop for the same volume. Particle size analyses are currently underway to determine the impacts of changes in these variables on the particle cut size. However, an increase in cyclone pressure drop usually leads to a higher volumetric throughput and a finer particle cut size (L. Svarovsky, 1984). Test data obtained with the new apex washing system is expected to be available during the next reporting period. 


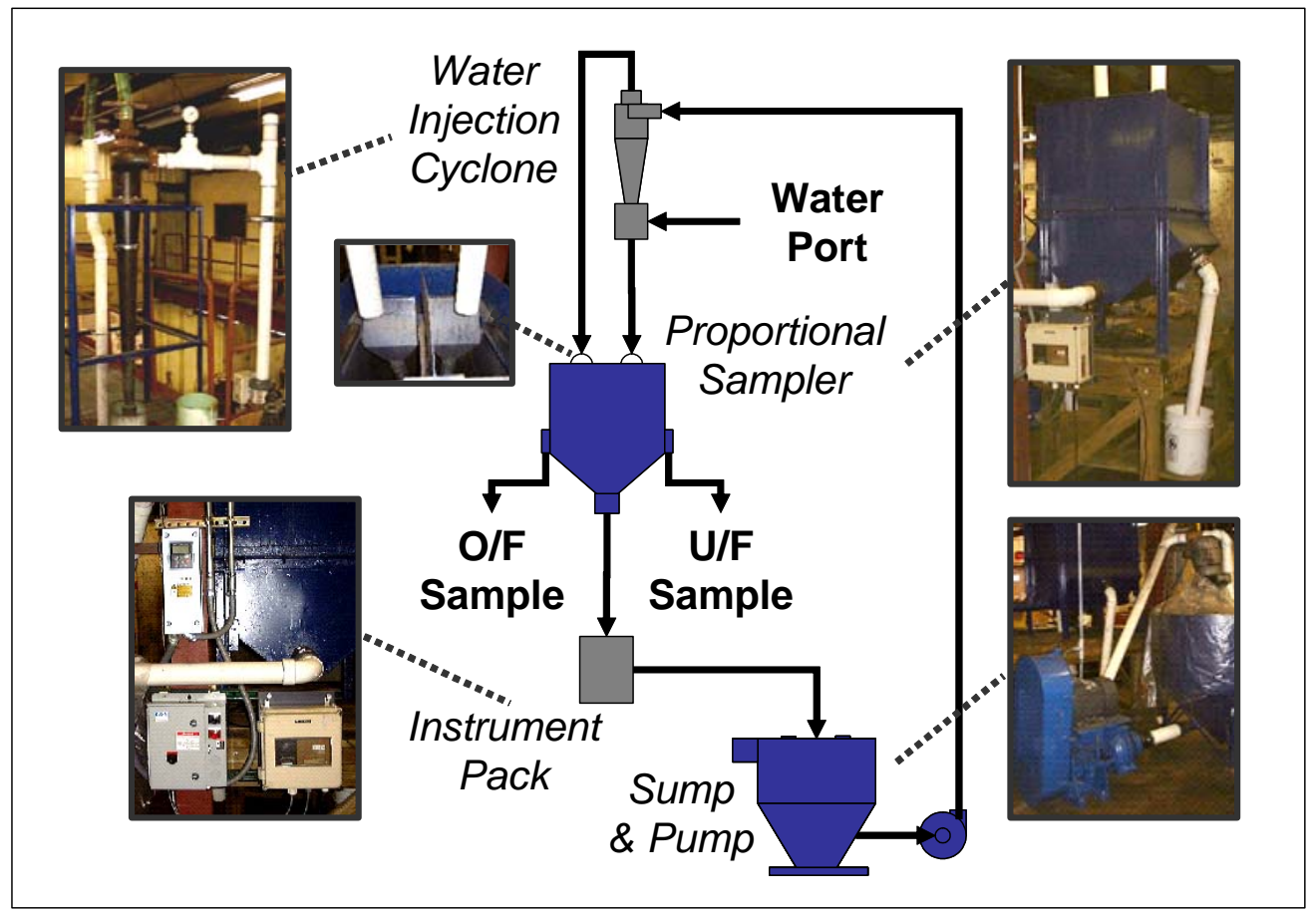

Figure 1. Test circuit used to evaluate the water injection apex technology.

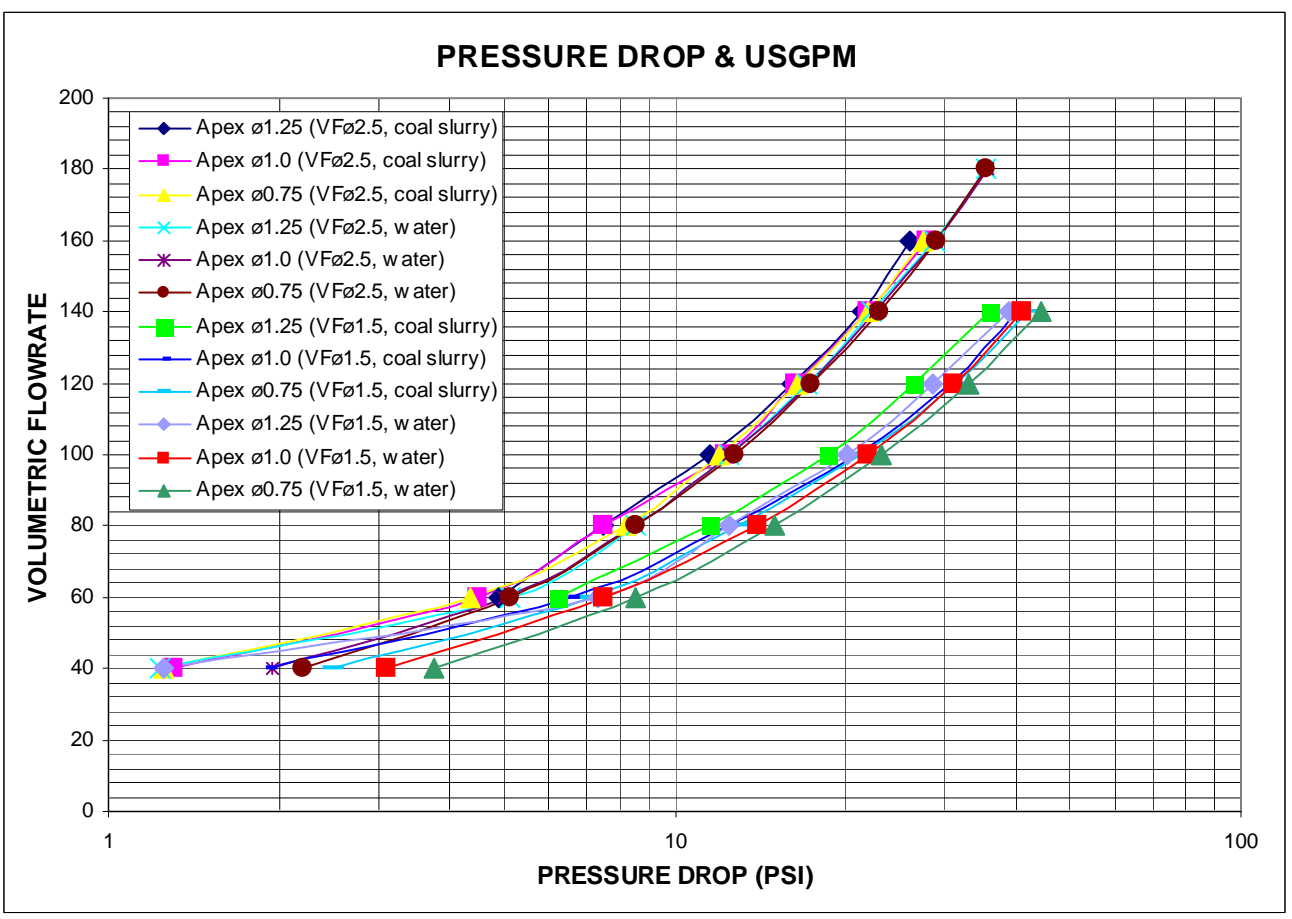

Figure 2. Effect of cyclone geometry on pressure drop and volumetric flowrate. 


\section{SUMMARY}

Project work was initiated during the past reporting period to investigate a variety of new techniques for high efficiency sizing of ultrafine particles. Much of the work conducted to date focused on improving the performance of classifying cyclone circuits. This effort included (i) installation and testing of a two-stage classifying cyclone circuit at an industrial coal preparation plant and (ii) construction and initial testing of a closed-loop test circuit for a new apex washing system. The test work conducted to date indicates that both of these technologies have the potential to substantially reduce amount of ultrafine solids that are bypassed to the coarse fraction in classifying cyclone circuits. Detailed test work will carried out during the next reporting period to fully evaluate these two technologies.

\section{FUTURE WORK}

Investigations with several innovative processes for ultrafine sizing are expected to begin during the next reporting period. These processes will include (i) a continuous microsieve and (ii) free flow electrophoresis sizer. The microsieve uses hydrostatic pressure to force ultrafine solids through a fine mesh fabric wrapped around a horizontal rotating drum, while coarse solids trapped by the mesh are carried by the rotation to the top of the unit where they are discharged. To prevent blinding, the fine sieve is backwashed every cycle using high-pressure water sprays. The construction of a bench-scale microsieve has been on hold to due a major breakdown of machine shop equipment and problems associated with the hiring of a skilled machinist/mechanic. These problems have now been corrected and work on this task has been restarted. While no additional experimental work has been undertaken during this reporting period using free flow electrophoresis (FFE), preliminary calculations conducted during the past quarter suggest that the FFE process has the potential to separate submicron particles from dilute feed slurries. The assembly of a laboratory-scale FFE test unit is expected to be completed during the first quarter of next year. Studies of the effects of surfactant addition on classification performance will also continue, as will experimental tests with a centrifugal elutriator (Knelson concentrator) to determine whether these technologies can improve classification efficiency.

\section{REFERENCES}

1. Heiskanen K, Particle Classification, Chapman \& Hall, 1993.

\section{PUBLICATIONS/PRESENTATIONS}

None for the current reporting period. 
Appendix B: NM001 - Dispersion and Flotation of Clays from New Mexico Potash Ores 


\section{TECHNICAL PROGRESS REPORT}

\begin{tabular}{|c|c|}
\hline Contract Title and Number: & Period of Performance: \\
\hline Crosscutting Technology Development at the Center for & 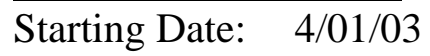 \\
\hline $\begin{array}{l}\text { Advanced Separation Technologies } \\
\text { (DE-FC26-02NT41607) }\end{array}$ & Ending Date: \\
\hline
\end{tabular}

Sub-Recipient Project Title:

Dispersion and Flotation of Clays

from New Mexico Potash Ores

Principal Investigators:

I. Gundiler, S. Titkov, M. Yekeler

Contact Address:

New Mexico Tech

Bureau of Geology \& Mineral Resources

801 Leroy Place

Socorro, NM 87801

Subcontractor Address:

"No subcontracts issued."
Report Information:

Type: Semi-Annual

Number: 003

Period: $\quad$ 03/30/04 - 09/30/04

Date: $\quad$ 10/26/04

Code: NM001-R03

Contact Information:

Phone: (505) 835-5730

Fax: (505) 835-6333

E-Mail: gundiler@gis.nmt.edu

\section{INTRODUCTION:}

Potassium is one of the three basic plant nutrients along with nitrogen and phosphorus. Potash is the common industrial term for potassium in various chemical combinations in water-soluble form. About $90 \%$ of potash produced worldwide is used as agricultural fertilizers. Other uses include glass manufacturing, soaps, plastics, chemicals and pharmaceuticals.

Flotation is the main treatment process of sylvinite $(\mathrm{KCl}-\mathrm{NaCl})$ ores for the recovery of sylvite $(\mathrm{KCl})$. The flotation process is carried out from saturated saline solutions (brines) with cationic collectors. Clay minerals present in the ore also absorb flotation reagents, thus increasing reagent costs, decrease recovery of sylvite, contaminate the product, and increase energy consumption for dewatering and drying. Therefore, clays are dispersed during grinding and in attrition scrubbers, and removed by mechanical desliming in hydrocyclones and hydroseparators ahead of sylvite flotation. Not all clays, however, are dispersed in the scrubbers. They are carried into the flotation cells and disperse in the cells due to the mechanical action of impellers, thus hindering flotation. Furthermore, elevated brine temperatures during the summer also affect collector adsorption on clays, depressing sylvite flotation.

New Mexico is the largest potash producer in the United States, supplying $70 \%$ of the domestic production. Potash mining began in the Carlsbad potash district in the early 1940s. Although, there are still vast reserves of potash minerals, clean, high-grade ores are virtually exhausted. Producers have to deal with low-grade ores contaminated with clays; water-soluble magnesium minerals and higher brine temperatures during the summer months also adversely affect the flotation of sylvite. 
Objectives and Approach:

This study was initiated to investigate possible means of improving sylvite recovery from Carlsbad potash ores by improving the mechanical desliming processes in the existing plants, and explore more efficient means of slime removal by flotation of slimes ahead of sylvite.

To achieve these objectives, 1) organic and inorganic clay dispersants in saturated saline brines were investigated to increase the efficiency of mechanical desliming by improving clay dispersion, and 2) flotation properties of oxyethylated surfactants (oxyethylated acids and amines) and cationic surfactants (etheramines) as collectors for flotation of clay-carbonate - sulfate slimes (insoluble admixture of potash ore - I.R.) in brines with high magnesium and sulfate ions content ( $\mathrm{Mg} \sim 2 \%$, sulfate $>5 \%$ ) were studied.

\section{PROJECT TASKS:}

Desliming and potash flotation tests:

A number of inorganic compounds, such as sodium silicate and poly-phosphates, have been utilized as dispersants for clay minerals in a number of flotation systems. However, in high ionic strength brines the surface charge on clay minerals is practically nil due to double layer compression. Studies at the Institute of Halurgy (Russia) showed that, inorganic clay dispersants added in the grinding circuit not only augment slime dispersion but also increase the selectivity of liberation of sylvite-halite mixed grains. Dispersant action of inorganic polyvalent salts, such as aluminum sulfate $\left(\mathrm{Al}_{2}\left(\mathrm{SO}_{4}\right)_{3}\right)$, have been postulated to be due to recharging of the clay particle surfaces in the presence of polyvalent ions.

In this study, aluminum sulfate and sodium lignin sulfonate have been used either individually or in combination in different proportions. Minus $9.5 \mathrm{~mm}$ (3/8”) ore samples were scrubbed with or without the addition of dispersant, deslimed, ground in the laboratory rod-mill to minus 20 mesh $(0.85 \mathrm{~mm})$ and again deslimed by siphon decantation. Slimes were filtered, dried, and analyzed for I.R. and $\mathrm{K}_{2} \mathrm{O}$ content, sands were placed in a flotation cell, conditioned with flotation reagents and potash was floated. Concentrates and tailings were also filtered, dried, and analyzed for I.R. and $\mathrm{K}_{2} \mathrm{O}$ content.

Two different ore samples with I.R. content approximately $2.5 \%$ and $3.5 \%$ were collected from IMC Carlsbad Potash operations. Rantec KP-4000 guar gum (60 g / tonne ore) is used as slimes depressant, Witco Arosurf MG 140 tallow amine (30 g / tonne ore) as potash flotation collector, Philflo Flotation oil (13 g / tonne of ore) as extender, and Phillips Orfom F2 Frother (30 g / tonne ore).

Results of these tests showed that in the presence dispersants, especially organic and inorganic dispersants combined,

- $\mathrm{K}_{2} \mathrm{O}$ recovery in potash concentrate increase $5-7 \%$; $\mathrm{K}_{2} \mathrm{O}$ losses to slimes decrease

- Quality of the concentrate increase, i.e., higher grade and lower I.R. content

- I.R. recovery in potash concentrate decreases.

Slime Flotation and Potash flotation tests:

Flotation of clays has been established to be superior to mechanical desliming with hydroseparators for clay removal in foreign operations during the last two decades. However, this method has never been applied in the Carlsbad potash district. Desliming by flotation method allows the recovery of not only fine slime particles but also the most flotation active slimes from the potash flotation feed. Therefore, it allows processing of high I.R. content ores (6-8\% in Canada and 8-12 \% in Russia), whereas 
mechanical desliming is effective up to $4.5 \%$ I.R. content. Oxyethylated fatty amines and fatty acids, as well as ether amines were obtained from various sources and tested in this study (Table 1).

Table 1. List of slime collectors tested in this study

\begin{tabular}{|c|c|c|}
\hline Type & Trade mark & Company \\
\hline \multirow[t]{3}{*}{ Oxyethylated Fatty Acid (OEFAc) } & Genogen & Clarian, Germany \\
\hline & MD 20261 & Akzo Nobel Surface Chemistry, Sweden \\
\hline & Aerosurf 8-190 & $\begin{array}{l}\text { Degussa, Goldschmidt Chemical } \\
\text { Corporation, USA }\end{array}$ \\
\hline \multirow[t]{5}{*}{ Oxyethylated Fatty Amines (OEFAm) } & ETHOMEEN 18/25 & \multirow[t]{4}{*}{ Akzo Nobel, USA } \\
\hline & ETHOMEEN C25A & \\
\hline & ETHOMEEN C15 & \\
\hline & ETHODUMEEN T14 & \\
\hline & Varonic T-205 & $\begin{array}{l}\text { Degussa, Goldschmidt Chemical } \\
\text { Corporation, USA }\end{array}$ \\
\hline \multirow[t]{3}{*}{ Ethermonoamine } & Lilaflot $810 \mathrm{M}$ & \multirow{4}{*}{$\begin{array}{l}\text { Akzo Nobel Surface Chemistry, } \\
\text { Sweden }\end{array}$} \\
\hline & Lilaflot 810 & \\
\hline & Lilaflot 811 & \\
\hline Etherdiamine & Lilaflot D 817 & \\
\hline
\end{tabular}

Preliminary treatment of flotation feed by flocculants is required for slime flotation.

Water solution of two flocculants mixture in equal proportions was used, namely:

- Low anionic flocculant - Hyperfloc AF 304 (molecular weight 15 millions, anionic degree $15-20 \%)$,

- Non-anionic flocculant - Hyperfloc NF 301 (molecular weight near 15 millions);

Flotation Desliming tests were conducted with minus 20 mesh $(0.85 \mathrm{~mm})$ dry-ground ore samples. After 15 minutes scrubbing at $1100 \mathrm{rpm}$, the pulp was then conditioned with flocculant followed by slime collector. Slimes were floated; froth product and tailings were filtered, dried and analyzed for I.R. and $\mathrm{K}_{2} \mathrm{O}$ content. For increased reproducibility of test results, a "blank" test was conducted, mixing brine with flotation reagents in the flotation cell before every flotation test.

Three types of potash ores used in this phase of the investigation containing different quantities of I.R., namely: Present IMC Carlsbad Ore or Mississippi Potash Co Ore (2-25\% I.R.), Medium Clay IMC Carlsbad Ore and High Clay Mississippi Potash Co Ore (3.5 - 4.5 \% I.R.), and High Clay IMC Carlsbad Ore ( $7 \%)$.

Initial investigations carried out on Present IMC Carlsbad Ore showed that;

- Slime flotation results show very high dependence on flocculant consumptions; slimes recovery reaches a maxima and then decreases with increasing flocculant concentrations. Optimal flocculant consumption depends on the free slime content in the flotation feed.

- Oxyethylated collectors are more efficient for slime flotation in brines with higher content of magnesium and sulfate ions. Best slime recoveries were obtained using OEFAm whereas OEFAc concentrations were three times as much for comparable recoveries for medium clay ores.

- Etheramines, which are used for slime flotation in sylvite brines (KCL-NaCL- $\left.\mathrm{H}_{2} \mathrm{O}\right)$ at Canadian potash plants, are not effective as slime collector in comparison with oxyethylated surfactants for New Mexico ores. 
Slime flotation tests with IMC Medium Clay Ore (3.5\% I.R.) are presented in Figure 1. These results show that:

- Oxyethylated amines are more efficient slime collectors than oxyethylated fatty acids at lower concentrations than the oxyethylated fatty acids. Slimes flotation efficiency, however, is highly dependent on the collector concentrations, reaching a maximum and decreasing precipitously at higher concentrations.

- Oxyethylated amine efficiency increase with increasing degree of oxyethylation and the length of the hydrocarbon chain.

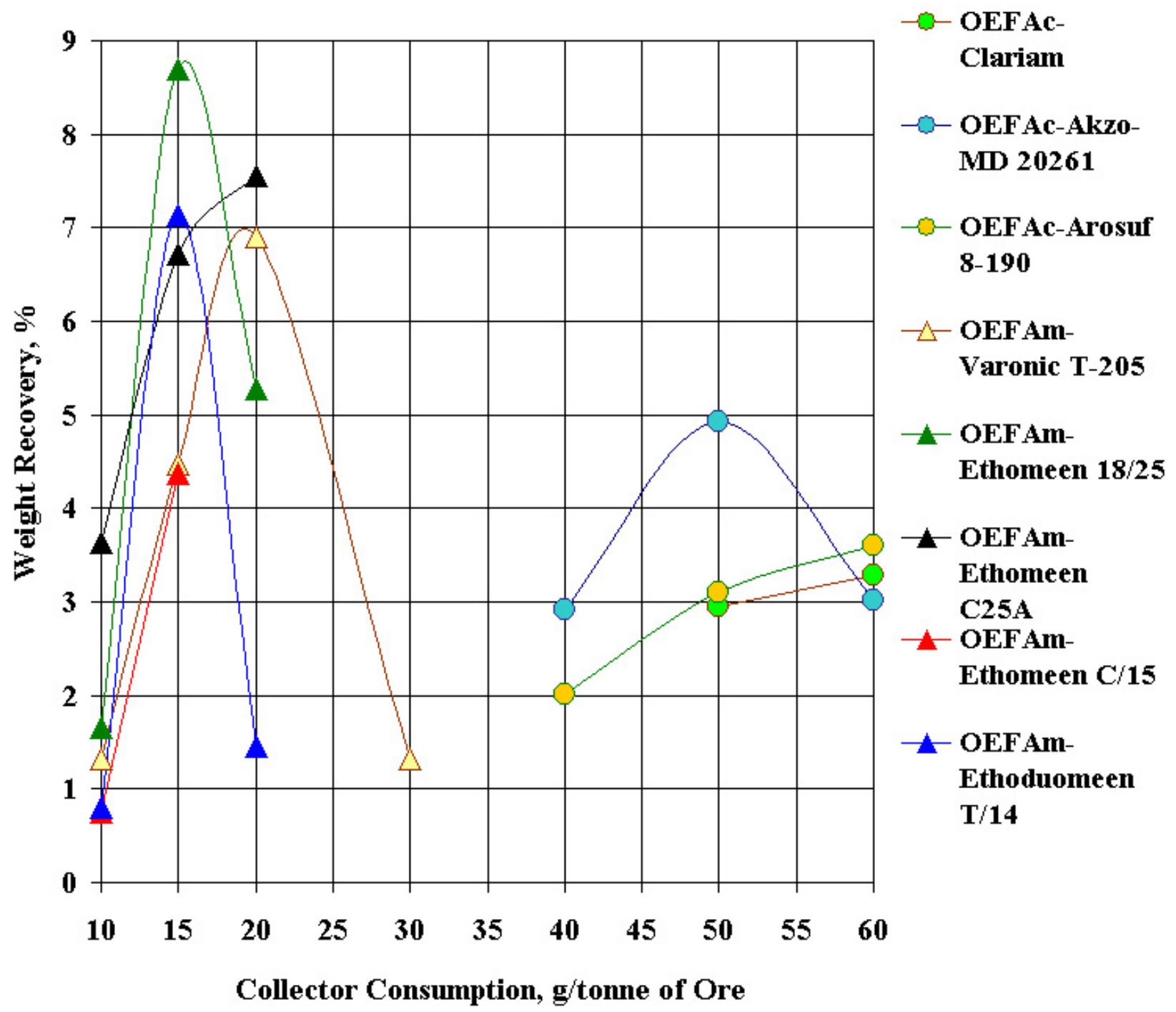

Figure 1. Weight Recovery of Slime Product using different oxyethylated Collectors.

Flocculant Consumption - 55 g/tonne of IMC Medium Clay Ore (I.R. Content - 3.5\%)

Further tests were carried out to compare the efficiency of potash flotation after 2-stage desliming Medium Clay Ore with different desliming methods: 2-stage Mechanical Desliming, and Mechanical Desliming at the $1^{\text {st }}$ stage followed by Flotation Desliming at $2^{\text {nd }}$ stage. These results, tabulated in 
Table 2, show that application of combined organic and inorganic dispersant in mechanical desliming stage followed by slime flotation at the $2^{\text {nd }}$ stage of desliming process yield the highest weight potash concentrate recovery and at the lowest levels of binder and amine consumptions (Table 2).

Table 2. Comparison Results of Desliming IMC Medium Clay Ore using Mechanical and Mechanical Flotation Desliming Methods

\begin{tabular}{|c|c|c|c|c|c|c|}
\hline \multirow[t]{3}{*}{ Desliming Mode } & \multirow[t]{3}{*}{$\begin{array}{c}\text { Dispersant } \\
\text { Consumption }\end{array}$} & \multirow{2}{*}{\multicolumn{5}{|c|}{$\begin{array}{c}\text { Weight Recovery Potash Concentrate, \% (based on } \\
\text { Potash Flotation Feed) } \\
\text { Reagents Consumption, g/t of ore }\end{array}$}} \\
\hline & & & & & & \\
\hline & & \begin{tabular}{|c|} 
Guar - 60 \\
Amine - 30
\end{tabular} & $\begin{array}{c}\text { Guar - 60 } \\
\text { Amine - } 20\end{array}$ & \begin{tabular}{|c|} 
Guar - 50 \\
Amine - 20
\end{tabular} & $\begin{array}{c}\text { Guar }-40 \\
\text { Amine - } 20\end{array}$ & \begin{tabular}{|c|} 
Guar - 30 \\
Amine - 20
\end{tabular} \\
\hline $\begin{array}{l}2 \text { stage Desliming } \\
\text { Mechanical Desliming }\end{array}$ & \multirow[t]{3}{*}{0} & 27.61 & 24.73 & & 5.04 & \\
\hline $\begin{array}{l}\text { 2 stage Desliming } \\
\text { 1.stage - Mechanical Desliming } \\
\text { 2.stage - Flotation Desliming } \\
\text { Collector : } \mathrm{M} 2026140 \mathrm{~g} / \mathrm{t} \text { of ore } \\
\text { Flocculant: } 0 \mathrm{~g} / \mathrm{t} \text { of ore }\end{array}$ & & & 27.56 & & & \\
\hline \begin{tabular}{l}
\multicolumn{1}{c}{2 stage Desliming } \\
1. stage -Mechanical Desliming \\
2. stage - Flotation Desliming \\
Collector: Varonic T-208 $15 \mathrm{~g} / \mathrm{t}$ of ore \\
Flocculant: $20 \mathrm{~g} / \mathrm{t}$ of ore
\end{tabular} & & & 25.64 & 28.24 & & \\
\hline $\begin{array}{l}\text { 2 stage Desliming } \\
\text { Mechanical Desliming }\end{array}$ & \multirow{3}{*}{$\begin{array}{c}\mathrm{Al}_{2}\left(\mathrm{SO}_{4}\right)_{3}- \\
100 \mathrm{~g} / \mathrm{t} \\
\mathrm{LS}-40 \mathrm{~g} / \mathrm{t}\end{array}$} & & 27.00 & & & \\
\hline \begin{tabular}{l}
\multicolumn{1}{c}{2 stage Desliming } \\
1.stage - Mechanical Desliming \\
2.stage - Flotation Desliming \\
Collector : MD $2026140 \mathrm{~g} / \mathrm{t}$ of ore \\
Flocculant: $0 \mathrm{~g} / \mathrm{t}$ of ore
\end{tabular} & & & & & 29.56 & 29.98 \\
\hline \begin{tabular}{l}
\multicolumn{1}{c}{2 stage Desliming } \\
1. stage -Mechanical Desliming \\
2. stage - Flotation Desliming \\
Collector: Varonic T-208 $15 \mathrm{~g} / \mathrm{t}$ of ore \\
Flocculant: $20 \mathrm{~g} / \mathrm{t}$ of ore
\end{tabular} & & & & & 28.52 & 28.36 \\
\hline
\end{tabular}

\section{SUMMARY:}

During this phase of the study, flotation tests conducted with low and medium clay potash ores after 2stage mechanical desliming, 1-stage mechanical desliming followed by flotation desliming. Although only slime flotation can be effective in removing clay-carbonate slimes ahead of potash flotation for ores with low I.R. content, mechanical desliming of the coarse ore followed by slime flotation yield the best results for medium clay ores.

This approach increases the potash recovery in the flotation concentrate, increases the potash flotation kinetics, hence, reduce flotation time, potash losses into slimes and I.R. impurities in the potash concentrates. Amine and guar binder consumptions are also reduced considerably. Application of slime flotation process at New Mexico processing plants could enable operators to be able to exploit highclay ores, thus extending the ore reserves. This would also reduce mining costs by avoiding selective mining that is required to keep the I.R. content below certain limits $(<4.5 \%)$ for processing at the 
present plants. Further studies are currently underway for better assessment of processing conditions for high clay ores (7-9\% I.R.). These results will be reported in the final report. 
Appendix C: UT001 - Flotation Technology for the Trona Industry 


\title{
TECHNICAL PROGRESS REPORT
}

Contract Title and Number:

Crosscutting Technology Development at the Center for

Advanced Separation Technologies

(DE-FC26-02NT41607)

$\underline{\text { Sub-Recipient Project Title: }}$

Flotation Technology for the Trona Industry

Principal Investigators:

J.D. Miller

Contact Address:

Department: Metallurgical Engineering

University of Utah

Salt Lake City

Utah 84112

Subcontractor Address:

No subcontracts issued.
Period of Performance:

Starting Date: 10/1/2002

Ending Date: 5/30/05
Report Information:

Type: Semi-Annual

Number: 3

Period: $\quad$ 4/1/04 - 9/30/04

Date: 1/13/05

Code:

Contact Information:

Phone: $\quad$ 801-581-6386

Fax: $\quad$ 801-581-4937

E-Mail: jdmiller@mines.utah.edu

Subcontractor Information:

Phone:

Fax:

E-Mail:

\begin{abstract}
In the second research period the development of new flotation technology for the separation of gangue minerals and production of a trona concentrate of high purity continued using commercial amines. Results from initial pilot plant testing at the General Chemical plant are reported.

Laboratory flotation tests showed that insolubles in the feed were successively floated and a trona concentrate of $99 \%$ purity was obtained with a recovery of $90 \%$ at an amine dosage of $2.0 \mathrm{~kg} / \mathrm{t}$. The trona product meets the desired grade specifications for subsequent use. It has been determined that the insoluble content is one of the most important variables in amine flotation and successful flotation of insolubles is possible by proper control of the flotation conditions. The results show that if feed has a high insoluble content, a higher reagent dosage is required. Three different chain lengths of amine collectors were tested in laboratory flotation tests. As the chain length of the amine increases, the floatability of insolubles increases slightly. The $\mathrm{pH}$ of the amine solution is an important factor that influences floatability. As the $\mathrm{pH}$ of the amine solution increases, the floatability of
\end{abstract}


insolubles increases. As might be expected, a good correlation was obtained between $\mathrm{pH}$ and the conductivity of the amine solution.

The parameters obtained from the bench scale experiments were applied in pilot scale flotation tests. Preparation for the evaluation of flotation parameters and optimum conditions for testing at the General Chemical plant site in the fall of 2004 was accomplished which include the transportation of necessary equipment from University of Utah and EIMCO, setup, installation and finally the testing. The system flowsheet is shown in Figure 8 (see APPENDICES) being attached with this report.

\section{INTRODUCTION}

\section{$\underline{\text { Background }}$}

Almost all (90\%) of the soda ash $\left(\mathrm{Na}_{2} \mathrm{CO}_{3}\right)$ production in the U.S. comes from the trona deposits of the Green River Basin in Wyoming. This U.S. trona production of 17.1 million tons per annum is shared by 4 companies

- FMC Corporation

- General Chemical

- OCI

- Solvay

Soda ash is used in the production of glass, chemicals, soap and detergents, flue gas desulfurization, pulp and paper, and in water treatment. The total value of soda ash sold by the U.S. industry amounts to about 800 million dollars per annum. Production of soda ash from trona has been limited to some extent by the existing process technology, which involves dissolution of the ore in boiling brine, sedimentation, and filtration for the removal of impurities, crystallization, and subsequent calcination for the recovery of soda ash. A preferred processing strategy would be to remove gangue mineral contaminants from the plant feed prior to dissolution in hot brine. Such preprocessing at ambient temperature and pressure would:

1. Reduce costs substantially by allowing for the use of less selective high capacity mining techniques such as long wall mining,

2. Offer the possibility of obtaining a new product (trona concentrate),

3. Make available additional trona resources which currently are of marginal value, and

4. Result in improved operation of the chemical plant by providing high quality feed to more readily achieve refined product specifications.

This preprocessing strategy has not been realized because of lack of satisfactory process technology. For example, it has been well known that processing by flotation could not achieve the desired separation. Now, based on our recent results from laboratory research, it seems that the run-of-mine trona ore can be treated at ambient temperature and pressure using a special flotation procedure to separate the gangue minerals and make a trona concentrate (Wang et al., 2002). Preliminary estimates indicate that more than $97 \%$ of the 
trona can be recovered in the trona concentrate and that this product will have a purity of almost 99\% trona.

\section{$\underline{\text { Objective and Approach }}$}

The objective of our two-year research program is the development of a flotation procedure for the preprocessing of trona ore to remove insoluble mineral contaminants prior to chemical treatment and production of soda ash.

The scope of the work includes:

- Collector chemistry study including surface chemistry, collector composition/stability and characterization.

- Bench scale flotation experiments to provide the preferred conditions and operating variables for plant-site testing.

- Plant-site testing.

- Economic Analysis

\section{PROJECT TASKS}

\section{Surface Chemistry Aspects in the Flotation of Gangue Minerals}

Fundamental studies continued with samples of selected gangue minerals, floor shale and roof shale, which were obtained from the General Chemical Plant. Previous studies showed that both shales are composed of mostly quartz, calcite, shortite, dolomite and feldspar as determined by X-ray diffraction (XRD) powder pattern analysis.

Electrokinetic properties of the samples such as zeta potential provide important information for flotation separation processes. In this regard, zeta potential measurements of shale suspensions were completed. Zeta potential measurements for both shales were performed in water with the ZetaPALS instrument utilizing phase analysis light scattering to determine the electrophoretic mobility of the charged suspensions. The PALS technique measures the zeta potential of the suspended particles. The pzc values (point of zero charge) of both shales were found to be between $\mathrm{pH} 2$ and 3. Furthermore, the surface charge of these shales is negative and their negative character arises from the relative abundance of $\mathrm{Al}$, Ca and $\mathrm{Mg}$ species and their preferential dissolution from shale as well as dissociation of surface acid groups. As expected, the absolute value of electrophoretic mobility for both shale samples was found to decrease with increasing concentration of dissolved trona.

The contact angle is often used as a measure of the extent of hydrophobicity of solid surfaces. In this regard, the sessile drop technique for contact angle measurements of roof shale was carried out using an NRL goniometer. The equilibrium contact angle values were determined as a function of amine concentration (see APPENDICES).

2. Flotation Experiments to Determine Appropriate Flotation Conditions and Operating Variables for Pilot Testing at the Plant Site 


\subsection{Evaluation of Collector Dosage}

A series of standard laboratory flotation experiments was carried out with three different samples as a function of amine dosage. With these experiments the aim was to establish appropriate flotation conditions and operating variables for plant-site testing. Consequently commercial amines were used for the flotation tests. The effect of amine dosage on insoluble content and recovery was determined. The results are presented in Figure 1 (see APPENDICES). Amine dosages were varied from $2 \mathrm{~kg} / \mathrm{t}$ to $5 \mathrm{~kg} / \mathrm{t}$. The flotation results for different amine dosages show that as the insoluble content of the feed increases, the amount of amine needed to achieve a specified grade increases. However, there is not a big difference in recovery.

\subsection{Effect of Amine Solution $\mathrm{pH}$}

The $\mathrm{pH}$ of the amine solution is an important factor that influences floatability. Several experiments were done to investigate the effect of $\mathrm{pH}$ of the amine solution on the insoluble content of the concentrate. The $\mathrm{pH}$ was varied from $\mathrm{pH} 4$ to $\mathrm{pH} 10$ and the optimum floatability of insoluble was achieved between $\mathrm{pH} 8.5$ and $\mathrm{pH} 10$. The results, shown in Figure 2 (see APPENDICES), indicate that as the $\mathrm{pH}$ of the amine solution increases, the floatability of insoluble also increases and therefore the $\mathrm{pH}$ of the amine solution must be greater than 8.5 to realize a high purity concentrate.

In addition to these experiments, microscopic analyses have been carried out on the trona product. These analyses have shown that the insoluble material consists mostly of quartz. The particle microscopic analysis also shows that the amount of quartz decreases as the $\mathrm{pH}$ of the amine solution increases. Thus the amine solution which is prepared at high $\mathrm{pH}$ values plays a significant role, especially on the floatability of quartz. These results are very important to explain the flotation chemistry of gangue minerals from trona ore and the interaction between collector and gangue minerals.

Conductivity measurements were also carried out to investigate the relation between the $\mathrm{pH}$ and the conductivity of the amine solution. The conductivity data is presented in Figure 2 (see APPENDICES) and support the above finding. It was found that when the $\mathrm{pH}$ increases, the floatability of insoluble also increases and these conditions correspond to a low value of conductivity. The experimental results reveal that there is a direct correlation between $\mathrm{pH}$ and conductivity of the amine solution.

\subsection{Effect of Amine Chain-Length on Flotation}

Amine solutions with three different carbon chain lengths (12C, 16C \& 18C) were prepared for the bench scale flotation experiments in our laboratory. In these experiments, the amine dosage was $2 \mathrm{~kg} / \mathrm{t}$. Flotation results indicate that the $18 \mathrm{C}$ gives the best result. It was determined that as the chain length of the amine increases, the floatability of insolubles also increases slightly. However, 12C was used in further tests because of its high selectivity and improved froth stability. 


\section{Pilot Plant Testing at General Chemical and Experimental Results}

\subsection{Experimental Procedure}

For the pilot-plant setup, the flowsheet and equipment list were prepared with the assistance of Roberts \& Schaefer during summer semester. The Trona flotation system includes two high solids (> 70\% by weight) reagent conditioning tanks with an impeller for stirring, dilution tank with a mixer, vibratory feeder with belt conveyor to transfer feed material to the conditioning tank, pulp circulation pipe, Galigher pump to pump 15\% solids into flotation cells and a $10 \mathrm{ft}^{2}$ belt filter. In addition, the system included amine preparation tank, reagent preparation tank, mine water/trona saturation tank, impellers for amine, reagent tanks and reagent pump and concentrate recirculation pump.

Based on previous bench scale flotation results, an appropriate reagent schedule was prepared and an exploratory series of tests were carried out to evaluate the effectiveness of this trona flotation system as a function of operating variables such as percent solids, reagent dosages, reagent ratio and flow rates. The pilot plant test series was conducted in order to establish preferred conditions for trona flotation and to determine the influence of operating variables on the separation efficiency.

\subsection{First Pilot Plant Results}

Initially, the flotation machine shown in Figure 3 (see APPENDICES) was used for the first pilot plant tests and several flotation tests were performed with this unit. But experimental observations showed that this flotation unit was not convenient for our study. The equipment was too large and hard to handle since its capacity is about 66 gal consuming a huge amount of feed material. Therefore, another pilot plant was designed after taking the above issues into account. A 2-cell flotation machine shown in Figure 5 (see APPENDICES) was taken from the University of Utah to the General Chemical plant. The total flotation volume of this second pilot plant system is about 18.6 gal.

\subsection{Large Scale Batch Flotation}

Since some problems occurred during previous continuous pilot scale flotation experiments, several batch flotation experiments were performed in one of the large cells (9.3 gallons) to find the optimum conditions in the second pilot plant system. Tests were first performed with mine water which was obtained from the plant. As seen from the results in Table 2 (see APPENDICES), a trona concentrate of $97.43 \%$ purity was obtained with a recovery of $60.79 \%$. Removing the fine particles from the system increased the recovery, but only slightly reduced the insoluble content of the product.

As the insoluble content of the trona concentrates are high (2.57\% and $2.3 \%)$; it was decided to use trona brine instead of mine water for flotation tests to see the effect of brine composition on pilot scale flotation tests. The results are shown in Table 3 (see

APPENDICES). As can be seen, the brine also has a significant effect on flotation. By using trona brine, it is possible to reduce the insoluble content of the feed to less than $1 \%$. In 
addition, the removal of fines from the system not only increased the recovery but also reduced the insoluble content of the product. Hence a trona concentrate of $99.57 \%$ purity was obtained with a recovery of $87.27 \%$ using commercial amine with pilot scale flotation equipment. However, this situation requires the use of incredibly more trona for preparation of brine. The effect of brine on flotation experiments is shown in Figure 7 (see APPENDICES). As mentioned previously the presence of fines significantly affects the recovery of trona.

Further results showed that a trona saturated solution is most effective for the trona flotation process and a trona concentrate of $99.5 \%$ purity can be obtained with a recovery of around $90 \%$. Under these conditions, trona product meets concentrate grade specifications for use in glass industry and for other purposes.

\subsection{Second Pilot Plant Results}

The results obtained from these large scale batch experiments were applied in continuous pilot scale flotation tests. Instead of two conditioning tanks, one tank was used to avoid the long conditioning time. In addition, the dilution tank and Galigher pump were removed from the system and conditioned slurry was discharged into a plastic container (as a dilution tank) which was connected to the flotation cell. The brine was also added in this container for dilution. Meanwhile trona brine was used instead of mine water. A couple of continuous tests were carried out with this new system but the campaign had to be terminated because of weather conditions and time constraints.

\section{FUTURE WORK}

It is pretty much clear that this flotation chemistry system works very well for both small and large scale batch experiments but has not been successful for continuous pilotplant tests. Detailed study is being continued at the University of Utah pilot plant due to weather conditions, feed availability and time considerations.

\section{REFERENCES}

Wang, X., Li, M. and Miller, J. D., Flotation as a process alternative for the treatment of trona resources. Paper presented at the SME Annual Meeting, Phoenix, Arizona, February, 2002. Preprint No. 02-157 


\section{APPENDICES}

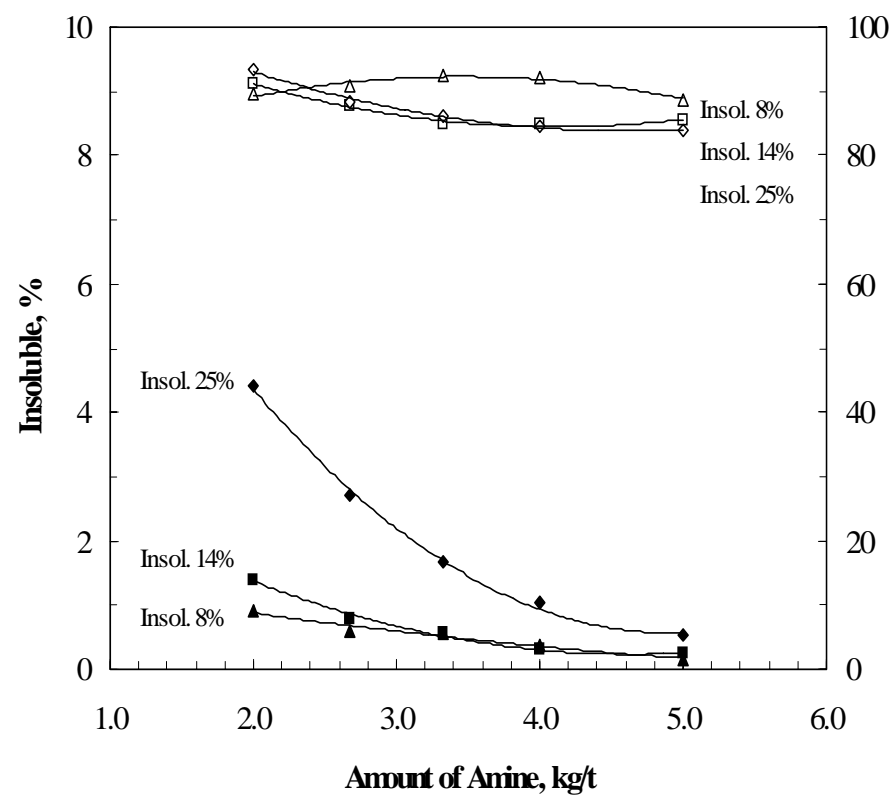

Figure 1. Flotation Recovery as a function of Collector Dosage for Feed Material Containing Different Amount of Insolubles

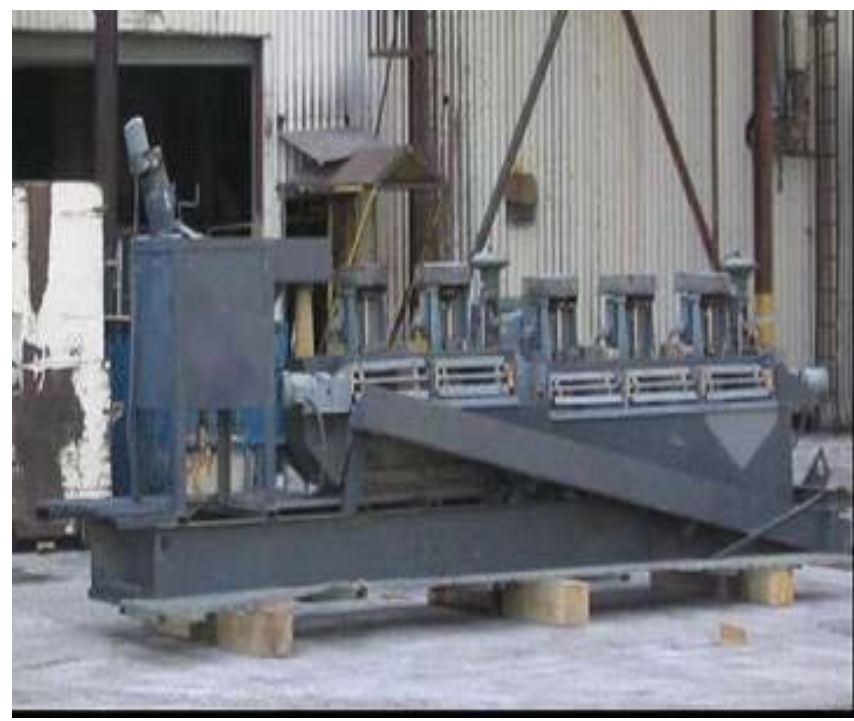

Figure 3. The Flotation Equipment Used for First Pilot Scale Tests

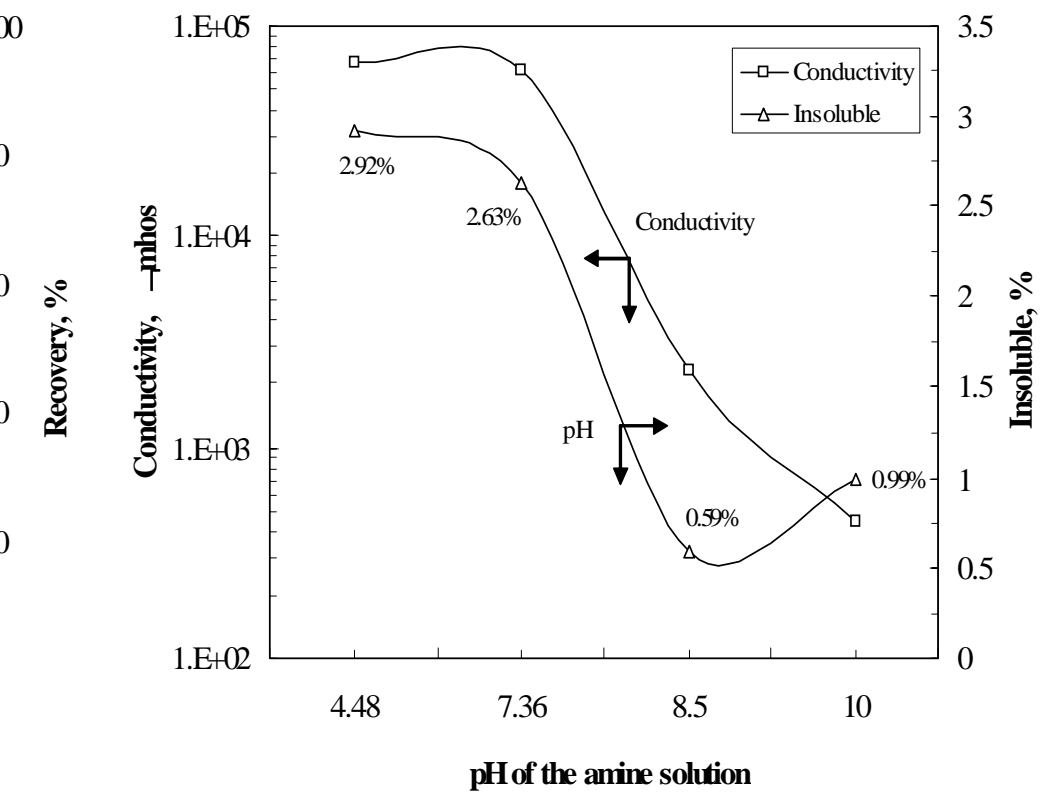

Figure 2. Effect of $\mathrm{pH}$ of the Amine Solution on the Grade of the Trona Product and Correlation with Solution Conductivity

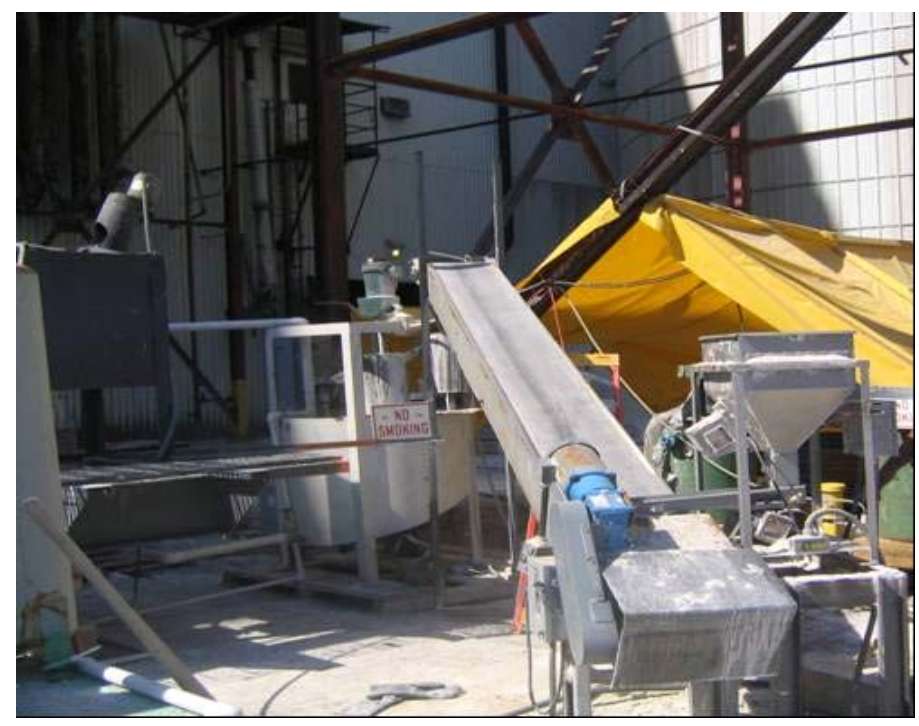

Figure 4. Facilities for the Pilot Scale Flotation Test Campaign at the General Chemical 


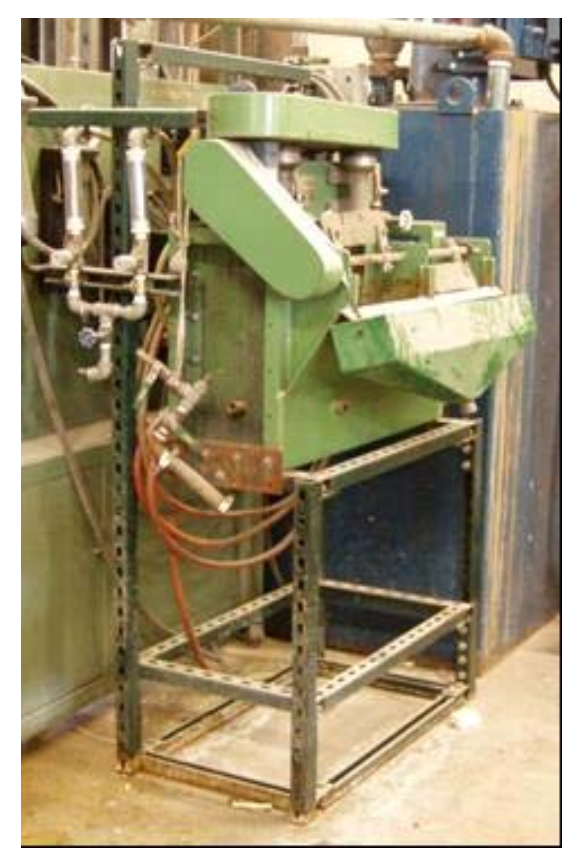

Figure 5. The Fotation Equipment Used for Second Pilot Scale Tests

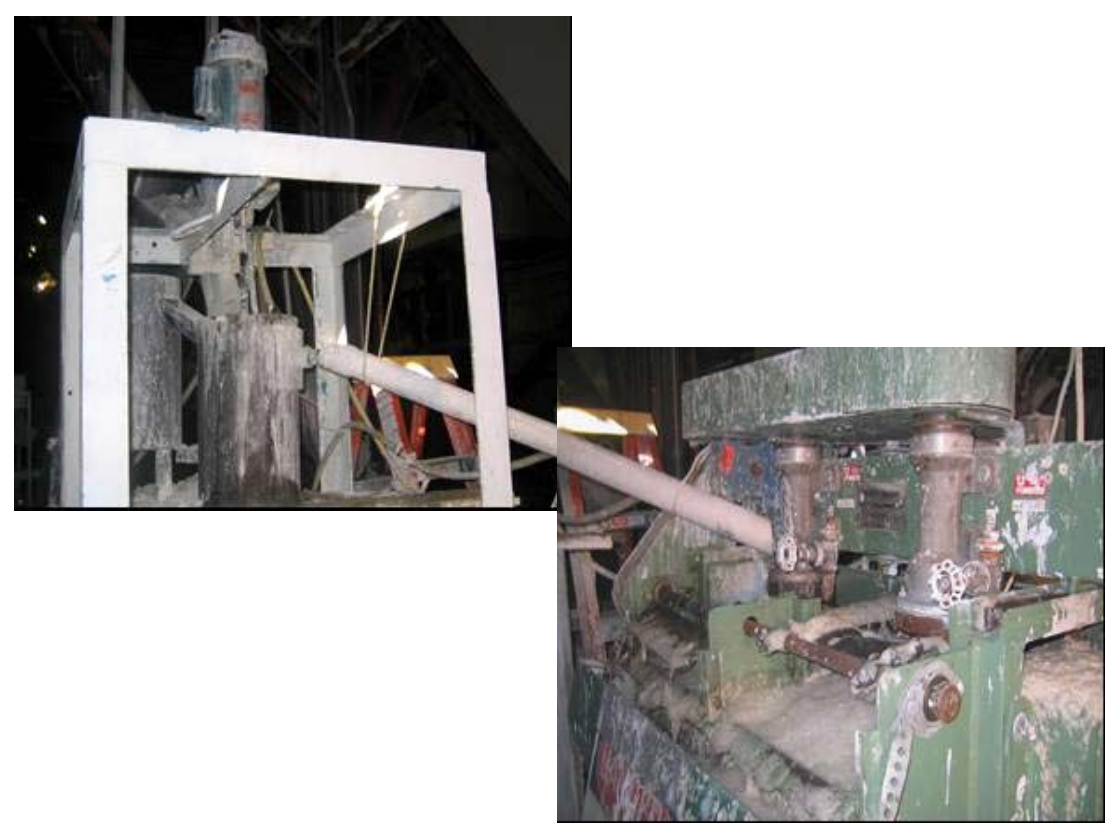

Figure 6. Facilities for the Pilot Scale Flotation Test Campaign at the General Chemical

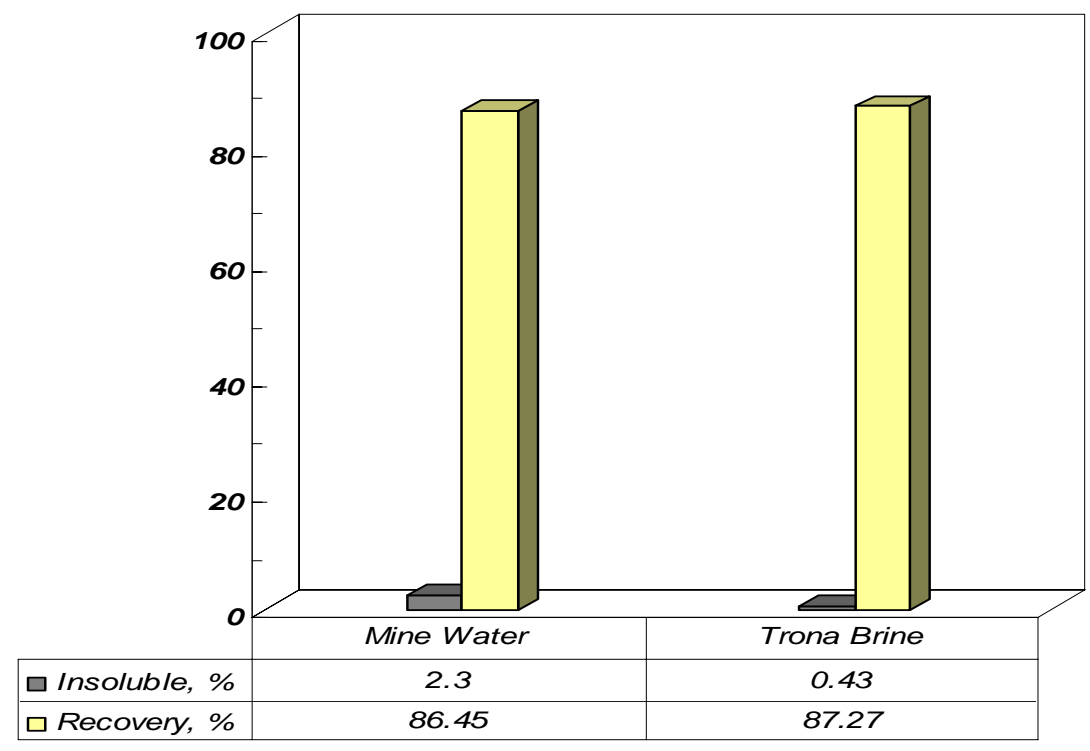

Figure 7. The Effect of Brine on Grade and Recovery 


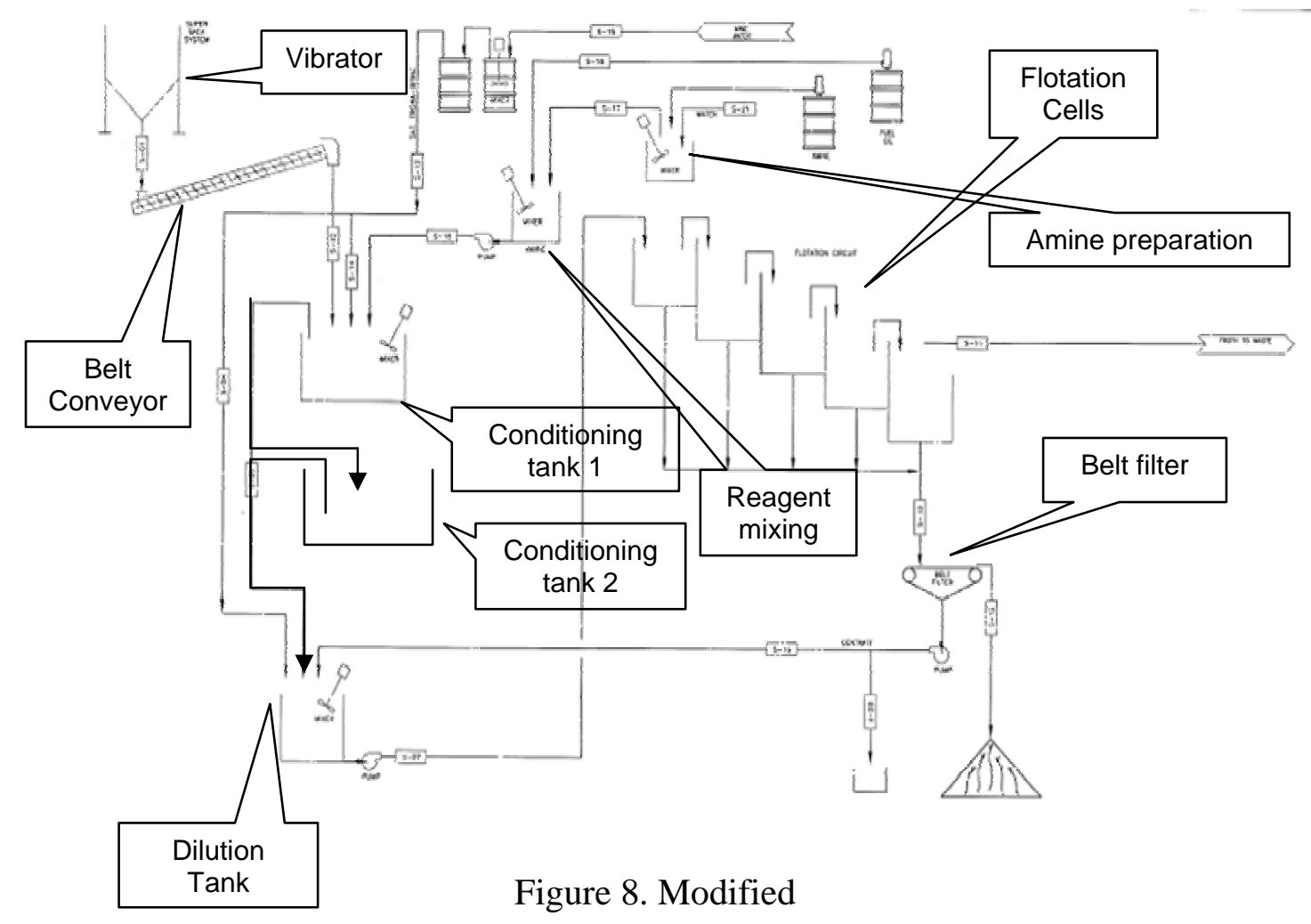


Table 1. Contact Angle Values of Roof Shale as a Function of Amine Concentration

\begin{tabular}{|c|c|}
\hline $\begin{array}{c}\text { Amine } \\
\text { Concentration } \\
(\mathrm{M})\end{array}$ & $\begin{array}{c}\text { Contact Angle } \\
\text { (Degree) }\end{array}$ \\
\hline 0 & 54 \\
\hline $1.10^{-5}$ & 59 \\
\hline $1.10^{-4}$ & 64 \\
\hline $1.10^{-3}$ & 75 \\
\hline
\end{tabular}

Table 2. Flotation Results for $30 \times 200$ Mesh Feed Material at $150 \mathrm{lb} / \mathrm{hr}$ (Mine Water)

\begin{tabular}{|c|c|c|c|c|c|}
\hline Samples & Products & $\begin{array}{c}\text { Weight } \\
(\%)\end{array}$ & $\begin{array}{c}\text { Wt, Insol } \\
(\%)\end{array}$ & $\begin{array}{c}\text { Wt, Trona } \\
(\%)\end{array}$ & $\begin{array}{c}\text { Recovery } \\
(\%)\end{array}$ \\
\hline \hline \multirow{3}{*}{ Unscreened $^{*}$} & Tailing & 42.81 & 16.04 & 83.96 & 39.21 \\
\cline { 2 - 6 } & Concentrate & 57.19 & 2.57 & 97.43 & 60.79 \\
\cline { 2 - 6 } & Total & 100.00 & 8.33 & 91.67 & 100.00 \\
\hline \multirow{3}{*}{ Screened } & Tailing & 20.61 & 41.01 & 58.99 & 13.55 \\
\cline { 2 - 6 } & Concentrate & 79.39 & 2.30 & 97.70 & 86.45 \\
\cline { 2 - 6 } & Total & 100.00 & 10.27 & 89.73 & 100.00 \\
\hline
\end{tabular}

"Unscreened feed means the crushed sample (supposedly -30+200 mesh size) used directly from super sacks had about $50 \%$ fine particles (-200mesh).

Table 3. Flotation Results for $30 \times 200$ Mesh Feed Material at $150 \mathrm{lb} / \mathrm{hr}$ (Trona Brine)

\begin{tabular}{|c|c|c|c|c|c|}
\hline Samples & Products & $\begin{array}{c}\text { Weight } \\
(\%)\end{array}$ & $\begin{array}{c}\text { Wt, Insol } \\
(\%)\end{array}$ & $\begin{array}{c}\text { Wt, Trona } \\
(\%)\end{array}$ & $\begin{array}{c}\text { Recovery } \\
(\%)\end{array}$ \\
\hline \hline \multirow{3}{*}{ Unscreened $^{*}$} & Tailing & 36.65 & 9.48 & 90.52 & 34.57 \\
\cline { 2 - 6 } & Concentrate & 63.35 & 0.84 & 99.16 & 65.43 \\
\cline { 2 - 6 } & Total & 100.00 & 4.01 & 95.99 & 100.00 \\
\hline \hline \multirow{3}{*}{ Screened } & Tailing & 19.70 & 40.80 & 59.20 & 12.73 \\
\cline { 2 - 6 } & Concentrate & 80.30 & 0.43 & 99.57 & 87.27 \\
\cline { 2 - 6 } & Total & 100.00 & 8.38 & 91.62 & 100.00 \\
\hline
\end{tabular}

*Unscreened feed means the crushed sample (supposedly -30+200 mesh size) used directly from super sacks had about 50\% fine particles (-200mesh). 
Appendix D: VA009 - Flotation Processes/Experiments and Analysis 


\section{TECHNICAL PROGRESS REPORT}

\begin{tabular}{lll}
\hline Contract Title and Number: & Period of Performance: \\
Crosscutting Technology Development at the Center for & Starting Date: & $4 / 1 / 03$ \\
Advanced Separation Technologies (DE-FC26-02NT41607) & Ending Date: & 5/30/05 \\
\hline
\end{tabular}

Sub-Recipient Project Title:

Flotation Processes/ Experiments and Analysis

Principal Investigators:

Demetri P. Telionis and Pavlos P. Vlachos

Contact Address:

Virginia Tech

Engineering Science and Mechanics Dept.

219 Norris Hall

Blacksburg, VA, 24061

Subcontractor Address:

No subcontracts issued.
Report Information:

Type: Semi-Annual

Number: 3

Period: $\quad 4 / 1 / 04$ to $9 / 31 / 04$

Date: $\quad$ November 10, 2004

Code: VA 009

Contact Information:

Phone: 540-231-7492

Fax: $\quad$ 540-231-3867

E-Mail: Telionis@vt.edu

Subcontractor Information:

Phone:

Fax:

E-Mail:

\section{ABSTRACT}

Flotation processes involve complex, three-phase flow interactions between a liquid, bubbles and solid particles. For decades engineers and researchers based their calculations on algebraic formulas that model these interactions. These formulas were derived from simple models, from experimental data or just from arbitrary assumptions. Considerable progress has been made so far but this approach is far for providing a reliable tool for the design of flotation machines.

Most of the experimental data were obtained decades ago with literally primitive methods. Modern experimental tools are employed in this effort to measure with great accuracy the basic features of the motion of all three phases in homogenous isotropic turbulent flow and in a model flotation cell. We will employ a unique in the US Digital Particle Image Velocimeter (DPIV) that can record with great accuracy and $\mathrm{kHz}$ temporal resolution velocity vectors of all three phases, namely the fluid, the solid particles and the air bubbles. We will measure three-phase flow interactions of bubbles and model particles of different hydrophobicity with a turbulent flow field.

An advance model for predicting and quantifying the efficiency of the flotation process will be the final deliverable of this two-year effort. Such a tool will improve the design of flotation systems and/or enhance the performance of existing systems. 


\begin{tabular}{|c|c|}
\hline Nomenclature & \\
\hline$\overline{\text { Subscript p }}$ & particle \\
\hline Subscript b & bubble \\
\hline Subscript l & liquid \\
\hline Superscript * & nondimentional quantity \\
\hline$<>$ & time average \\
\hline $\mathrm{C}_{12}$ & collision frequency coefficient $\left[\mathrm{m}^{3} \cdot \mathrm{s}^{-1}\right]$ \\
\hline$d_{i}$ & diameter of $\mathrm{i}[\mathrm{m}]$ \\
\hline$d_{12}$ & sum of diameters of particle and bubble \\
\hline $\mathrm{N}_{\mathrm{i}}$ & number density of i $\left[\mathrm{m}^{-3}\right]$ \\
\hline $\mathrm{R}_{12}$ & radius of collision $[\mathrm{m}]=\left(\mathrm{d}_{1}+\mathrm{d}_{2}\right) / 2=\mathrm{R}_{1}+\mathrm{R}_{2}$ \\
\hline $\mathrm{u}_{\mathrm{i}}$ & $\mathrm{i}^{\text {th }}$ component of fluctuating velocity \\
\hline${\sqrt{\mathbf{U}_{i}^{2}}}^{2}$ & root-mean-squared velocity of $\mathrm{i}$ with respect to flow $\left[\mathrm{m} \cdot \mathrm{s}^{-1}\right]$ \\
\hline$\overline{\mathbf{U}_{\mathrm{i}}^{2}}$ & variance of i with respect to flow $\left[\mathrm{m}^{2} \cdot \mathrm{s}^{-2}\right]$ \\
\hline $\mathbf{U}^{2}$ & variance of flow velocity \\
\hline $\mathrm{Z}_{12}$ & collision frequency between particle and bubble $\left[\mathrm{m}^{-3} \cdot \mathrm{s}^{-1}\right]$ \\
\hline$\varepsilon$ & Kinetic Energy Dissipation rate $\left[\mathrm{m}^{2} \cdot \mathrm{s}^{-3}\right]$ \\
\hline$v$ & kinematic viscosity $\left[\mathrm{m}^{2} \cdot \mathrm{s}^{-1}\right]$ \\
\hline$\rho_{\mathrm{i}}$ & density of i $\left[\mathrm{kg} \cdot \mathrm{m}^{-3}\right]$ \\
\hline$\tau_{\mathrm{i}}$ & relaxation time of i [s] \\
\hline $\mathrm{L}$ & Characteristic length \\
\hline Uo & Free stream velocity \\
\hline $\operatorname{Re}$ & Reynolds number \\
\hline $\mathrm{T}$ & flow time scale \\
\hline
\end{tabular}

\section{INTRODUCTION}

\section{$\underline{\text { Background }}$}

In our previous progress report we discussed our experimental efforts to monitor three phases, namely water, particles and bubbles in grid turbulence. This was homogeneous, isotropic turbulent flow, which may be realistic in some regions of a flotation cell. Such flows were generated in a water tunnel downstream of a grid. In this report we describe our initial steps in the design, construction and testing of a stirred tank.

There is a wealth of experimental and numerical results of the turbulent characteristics of the flow in stirred tanks. These are cylindrical tanks in which a stirring device generates turbulence. A typical stirrer is the Rushton turbine, which is essentially a set of flat plates with their plane positioned in the radial direction and parallel to the axis of symmetry of the devise. In the tests reported here, we use an impeller type of a stirrer. The aim has always been to measure the basic parameters that characterize turbulence. Recall that each of the models discussed in our previous report, relies on the 
accurate determination of the kinetic energy dissipation rate. Our measurement technique to determine the dissipation rate is now discussed.

Researchers used a variety of methods to record velocity fluctuations in stirred tanks, as for example hot wire velocimetry, (Rao and Brodkey 1972), laser-Doppler velocimetry (Costes and Couderc 1988, Wu et al. 1989, Okamoto et al. 1981, Wu and Patterson 1989) and more recently particle-image velocimetry (Saarenrinne and Piirto 2000). Wu et al. (1989) performed an energy balance on measured turbulent kinetic energy over a control volume to obtain local values of turbulent dissipation. Rao and Brodkey (1972) and Okamoto et al. (1981) applied power spectrum methods, while others (Rao and Brodkey 1972, Wu and Patterson 1989 and Kresta and Wood 1993) estimated the integral scale by integration of the auto-correlation function.

A well-documented approach of the performance of flotation cells is based on analytical or numerical determination of the rate constant (Moon, et al. (2002). An accepted estimate of the collision rate is given by the Abrahamson (1975) equation, which requires the root-mean square of the velocities of phase 1 and 2, here the coal particles and the bubbles relative to the fluid, respectively. Abrahamson's analysis is valid only if the phase density is much larger than the fluid density. This is the case for coal particles but not for bubbles.

Schubert (1999) proposes instead

$$
\overline{U_{i}^{2}}=0.33 \frac{\varepsilon^{4 / 9} d_{i}}{v^{1 / 3}}\left(\frac{\rho_{i}-\rho_{f}}{\rho_{f}}\right)^{2 / 3}
$$

This formulation is an empirical, curve-fitting procedure carried out by Liepe and Moeckel (1976), based on experimental data collected by many authors. All these data were obtained decades ago, with almost primitive tools. Levins and Glastonbury (1972) for example record visual data in a flotation machine, along two planes and then proceed to measure manually thousands of particle-path segments. From such data they then generate the RMS of flow and particle velocity fluctuations.

\section{Objective and Approach}

We are investigating three-phase flow, namely particle-bubble-turbulence interaction via time-resolved digital particle image velocimetry (DPIV). This study is conducted downstream of a grid that generates turbulence. This design provides an approximate but controlled simulation of the motion in a flotation machine, where next to the impeller we find large vortical structures, which again break down, populating the field with smaller vortices and ultimately lead to fully-developed turbulence. We are measuring the spatial and temporal evolution of turbulence properties like length scales, time scales, Reynolds stresses and finally turbulent dissipation, which appears in both the Schubert and the Abrahamson formulations. Our aim here is to compare the performance of different models in isotropic turbulence and extend the work to nonisotropic turbulence. 


\section{PROJECT TASKS}

Work on this project has been progressing for a little more than one year. The following tasks have been defined at the beginning of this project.

\section{$>$ Task 1: Phase velocities}

We employ DPIV to study experimentally the direct interaction of bubbles and particles. The streams are seeded with two types of particles. The first type are particle sizes the order of $100 \mu$ and simulate coal particles. Different levels of hydrophobicity will be tested. The second type of particles are sized down to the order of $1 \mu$ and their purpose is to allow accurate measurements of the instantaneous velocity field around the bubbles. We will document the individual velocities and turbulence fluctuations of each individual phase.

\section{$>$ Task 2: Particle/bubble interaction}

We measured the trajectories and velocities of solid particles traveling around bubbles in homogenous isotropic turbulence. These trajectories were compared with trajectories computed by BBO equation. From the experimental results are computing the energy dissipation rate, which we will be incorporated into Schubert's formulation for the efficiency estimation of flotation processes. We will be extending these measurements to nonisotropic turbulence.

\section{$>$ Task 3: Measurement of collision rates}

By varying parameters like sizes of particles and bubbles, as well as the density and hydrophobicity of particles, we will generate statistical distributions for the probabilities of attachment and detachment. We will thus be able to evaluate the effect of different parameters on flotation efficiency. We found that this task is more difficult than we had anticipated. We are not sure what progress we will be able to make on this task in this project.

\section{$>$ Task 4: Tests in a model flotation machine}

We are continuing our experimental measurements in a model flotation machine. This machine is described in this progress report.

\section{PROGRESS}

\section{Analytical Considerations}

We repeat here for completeness the analytical formulas that we will be testing experimentally.

The knowledge of particle and bubble velocities within a turbulent environment is a basis for understanding what occurs within a flotation cell. This knowledge, along with other relevant parameters, allows the prediction of a rate constant which in turn allows the prediction of recovery and grade of minerals. The flotation process occurs within a highly turbulent three-phase flow, where a detailed understanding of these flows is limited. These velocities are used to model collision frequencies which are in the form

$$
\mathbf{Z}_{12}=\mathbf{C}_{12} \mathbf{N}_{1} \mathbf{N}_{2} \mathbf{R}_{12}^{2}
$$

where $\mathrm{Z}_{12}$ is a collision frequency coefficient and contains the relevant velocities.

Saffman and Turner (ref) proposed two collision models both assuming Stokes numbers below 1 . The first took into account only the shear mechanism for collision and assumes a Stokes number of zero. 


$$
\mathbf{Z}_{12}=\sqrt{\frac{8 \pi}{15}} \mathbf{R}_{12}^{3} \mathbf{N}_{1} \mathbf{N}_{2} \sqrt{\frac{\varepsilon}{v}}
$$

The second accounted for inertial differences due to gravity and turbulent accelerations.

$$
\mathbf{Z}_{12}=\sqrt{8 \pi} \mathbf{R}_{12}^{2} \mathbf{N}_{1} \mathbf{N}_{2}\left(\left(1-\rho_{12} / \rho_{\mathbf{l}}\right)^{2}\left(\tau_{1}-\tau_{2}\right)^{2}\left(1.3 \sqrt{\frac{\varepsilon^{3}}{v}}+\frac{1}{3} \mathbf{g}^{2}\right)+\frac{1}{9} \mathbf{R}_{12}^{2} \frac{\varepsilon}{v}\right)
$$

Abrahamson (1975) then came up with a collision frequency where the Stokes number of the colliding particles is infinite, essentially assuming the motion of the bubbles and particles is completely uncorrelated with the flow. This frequency only accounted for the accelerative mechanism for collisions.

$$
\mathbf{Z}_{12}=2^{3 / 2} \pi^{1 / 2} \mathbf{N}_{1} \mathbf{N}_{2} \mathbf{d}_{12}^{2} \sqrt{\left(\overline{\mathbf{U}_{1}^{2}}+\overline{\mathbf{U}_{2}^{2}}\right)}
$$

There are various methods to calculate the RMS of the particle and bubble velocities, $\overline{\mathbf{U}_{\mathbf{i}}^{2}}$. One such method is a derivation from the BBO equation by Levins and Glastonbury (1972) that assumed single frequency oscillations,

$$
\begin{aligned}
\frac{\overline{\mathbf{U}_{\mathbf{i}}^{2}}}{\overline{\mathbf{U}^{2}}}=\frac{(1-\mathbf{b})^{2}}{\mathbf{a T}+1} & \mathbf{b}=\frac{3 \mathbf{p}_{\mathbf{f}}}{2 \mathbf{p}_{\mathbf{i}}+\mathbf{p}_{\mathbf{f}}} .
\end{aligned}
$$

Abrahamson also included a simplification to Equation 4 by assuming solid particles in a gas $\left(b=0, a=1 / \tau_{p}\right)$ and calculating the time scale, $\mathbf{T}_{\mathbf{L}}=0 . \overline{\mathbf{U}^{2}} / \varepsilon$, therefore reducing to equation 5 , which is a common formula used in the flotation industry,

$$
\overline{\left(\mathbf{U}_{\mathbf{i}}^{2}\right)_{\mathbf{a b s}}}=\frac{\overline{\mathbf{U}^{2}}}{1+1.5 \tau_{\mathbf{i}} \varepsilon / \overline{\mathbf{U}^{2}}} .
$$

The most common form used in the flotation industry is a combination of the collision frequency given by Abrahamson and the particle root-mean-squared velocity with respect to the flow given by Liepe and Mockel (1976).

$$
\sqrt{\overline{\mathbf{U}_{\mathbf{i}}^{2}}}=0.33 \frac{\varepsilon^{4 / 9} \mathbf{d}_{\mathbf{i}}^{7 / 9}}{v^{1 / 3}}\left(\frac{\rho_{\mathbf{i}}-\rho_{\mathbf{l}}}{\rho_{\mathbf{l}}}\right)^{2 / 3}
$$

This velocity was experimentally developed and is valid at intermediate Stokes numbers where the flotation process occurs.

There are limitations to all of these models for flotation. The velocity components of Saffman and Turner's models assume Stokes numbers of 1 or less while Abrahamson assumes Stokes numbers of infinity. Neither of these conditions is valid within the flotation environment over the particle sizes that are significant. Liepe and Mockel's model should be valid for particles at intermediate Stokes numbers. The 
limitation on this is the assumption that the density of the particle is greater than that of the fluid, which is not the case with air bubbles. To determine how greatly these limitations affect their collision frequencies, fluid velocity measurements have been recorded in grid turbulence. The velocity at the Kolmogorov scale, $U=(v \varepsilon)^{1 / 4}$, has been determined from these and compared against the RMS velocities predicted by the three models described above. The nondimentionalized forms of the Levins and Glastonbury, and Shubert models respectively are shown in Equations 6 and 7. These comparisons will show how well each predicts small particle flow.

$$
\begin{gathered}
\frac{\overline{\mathbf{U}^{*^{2}}}}{\overline{\mathbf{U}^{* 2}}}=\frac{(1-\mathbf{b})^{2}}{\mathbf{a} \mathbf{T}^{*} \mathbf{L} / \mathbf{U}_{\mathbf{0}}+1} \\
\sqrt{\overline{\mathbf{U}_{\mathbf{i}}^{* 2}}}=0.33 \mathbf{R e}^{1 / 3} \varepsilon^{* 4 / 9} \mathbf{d}_{\mathbf{i}}^{* 7 / 9}\left(\frac{\rho_{\mathbf{i}}-\rho_{\mathbf{f}}}{\rho_{\mathbf{f}}}\right)^{2 / 3}
\end{gathered}
$$

The main objective of this project is to record the fluctuations of particles in a homogenous turbulent flow field. The RMS of theses velocity fluctuations corresponding to the Kolmogorov micro scale will then be calculated in order to confirm or modify accordingly the Schubert equation given in Equation 7, where $\overline{U_{i}^{2}}$ is the RMS of the velocity fluctuation of species $i$, with respect to the flow. In addition, the measured particle velocity fluctuations will be compared to those presented by Levins and Glastonbury (Equation 6).

Each of these models are dependent upon the kinetic energy dissipation rate, which has been shown to determine the degree of droplet and bubble break up and rates of chemical reactions. Direct approximation of the dissipation rate from the definition,

$$
\varepsilon=\frac{v}{2}\left\langle\left(\frac{\partial \mathbf{u}_{\mathbf{i}}^{\prime}}{\partial \mathbf{x}_{\mathbf{j}}}+\frac{\partial \mathbf{u}_{\mathbf{j}}^{\prime}}{\partial \mathbf{x}_{\mathbf{i}}}\right)^{2}\right\rangle
$$

requires the evaluation of the strain rate fields at a spatial resolution less than the Kolmogorov length scale. So far, there are no experimental methods available that can fully resolve the dissipation rate directly. However, implementing Taylor's frozen turbulence hypothesis allows the special derivatives to be represented by time derivatives (Sheng et. Al. 2000),

$$
\left\langle\left(\frac{\partial \mathbf{u}_{\mathbf{i}}^{\prime}}{\partial \mathbf{x}_{\mathbf{i}}}\right)^{2}\right\rangle=\frac{1}{\overline{\mathbf{U}}_{1}^{2}}\left\langle\left(\frac{\partial \mathbf{u}_{\mathbf{i}}^{\prime}}{\partial \mathbf{t}}\right)^{2}\right\rangle
$$

This relationship can be used to determine the dissipation rate (Hinze 1994),

$$
\varepsilon=\frac{15 v}{\overline{\mathbf{U}}^{2}}\left\langle\left(\frac{\partial \mathbf{u}_{1}^{\prime}}{\partial \mathbf{t}}\right)^{2}\right\rangle
$$

which will be the evaluated form used in this study through means of Particle Image Velocimetry. 


\section{Facilities and Instrumentation}

Experiments to characterize the particle interaction with turbulence were performed and descried in our previous progress report. . A small-scale water tunnel has been constructed in which we generate homogenous isotropic turbulence (Figure 1. The design allows quick change of the fluid/particle mixture and flushing of the system for more tests. The facility is appropriate for mixing different sizes of particles with different densities, as well as generating air bubbles of different sizes. Homogeneous isotropic turbulence is generated by grids. This is the simplest reproducible and repeatable example of turbulence. Moreover, the multi-phase flow data thus generated can be compared with the results of other investigators.

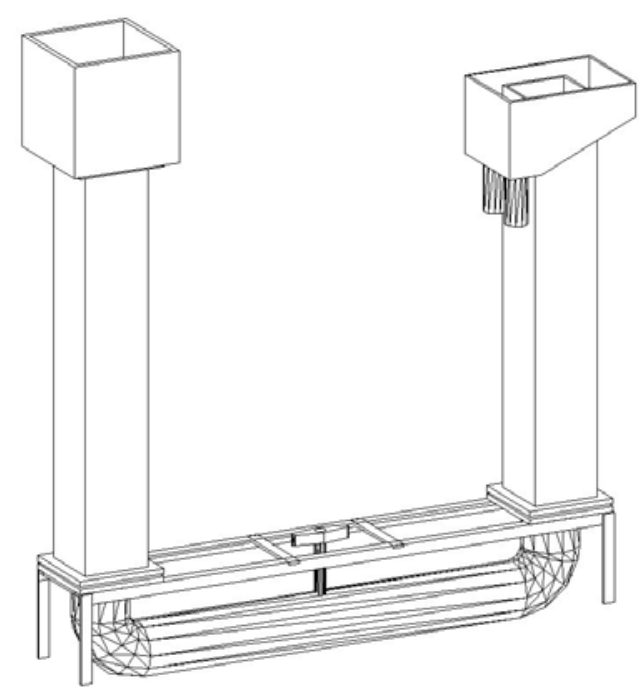

Figure 1: Schematic representation of the isotropic turbulence water tunnel
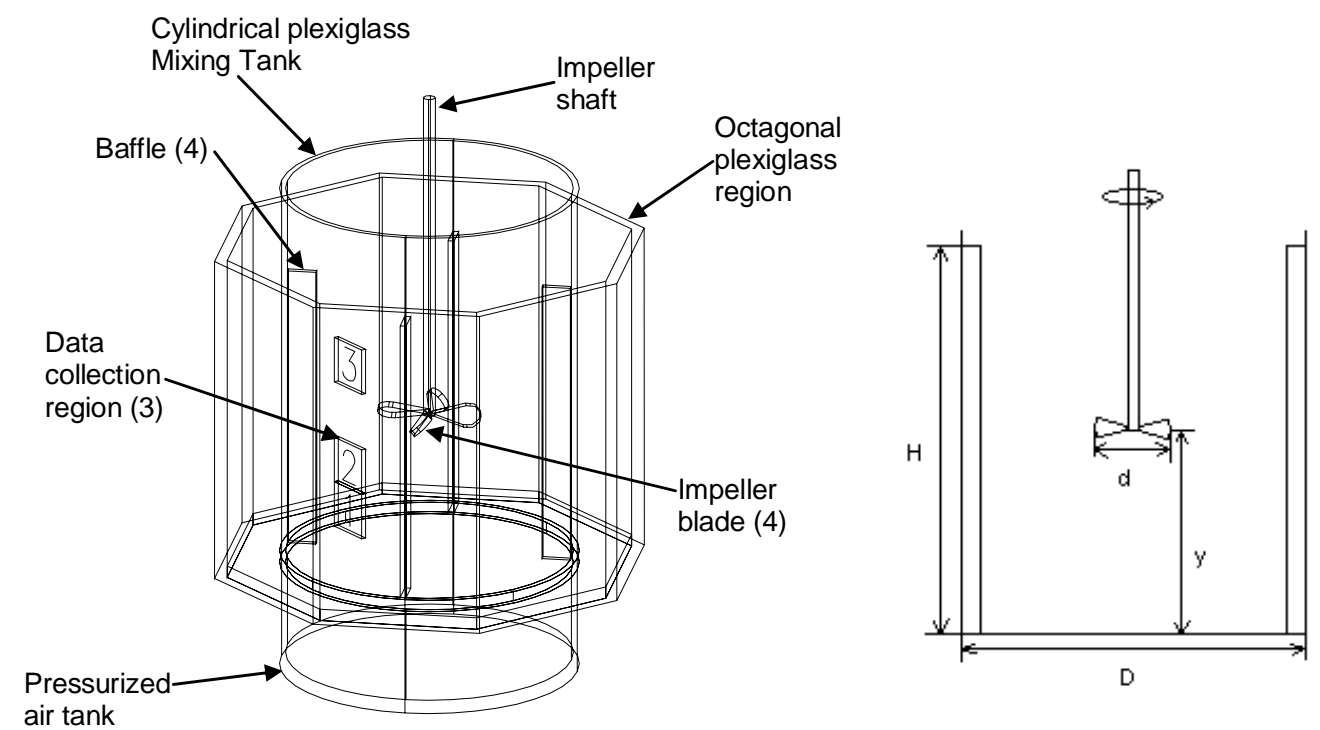

Figure 2 - Schematic of stirred tank

Such data are used to obtain relationships, including the RMS of the bubble/particle velocity fluctuations in terms of the fluid velocity fluctuations. This allows us to generate new and more reliable data to corroborate or to replace Schubert's equation.

Since the last progress report, we designed and constructed a mixing tank. This tank consisted of a small-scale cylindrical, baffled vessel made of Plexiglas with diameter $D=0.1504 \mathrm{~m}$ as it shown in Fig. 2 . Four axial baffles with width $\left(w_{b}\right)$ one tenth of the tank diameter were mounted along the wall. An impeller with four blades was located at a 
height $0.0762 \mathrm{~m}$ from the bottom and was driven at $225 \mathrm{rpm}$. The ratio between the vessel and the impeller diameter was $d / D=1 / 3$. The ratio of blade width $\left(w_{i}\right)$ to the impeller diameter $(D)$ was 0.25 . The tank was open at the top and was filled with filtered water as the working fluid. The height of the water was maintained at $0.1504 \mathrm{~m}$, equal to the tank diameter. The cylindrical tank was housed in an outer octagon tank filled with water to eliminate the optical distortion of light beams passing a curved boundary of media with different indices of refraction. The flow was seeded with $6 \mu \mathrm{m}$ diameter spherical fluorescent tracers made of polystyrene. In the present paper we studied two cases. One only with the seed particles so we can examine the flow field of the mixing and one in which we added glass particles (specific gravity 3.6) with diameter of $86 \mu \mathrm{m}$ to simulate coal particles. The aim is to determine the trajectories and slip velocities of the coal particles and relate them to the local flow properties.

The Reynolds number is calculated $\mathrm{Re}=N \cdot d^{2} / v$ based on the impeller diameter and was about 9677 . The Kolmogorov length scale can be calculated from $\eta=d \cdot(\mathrm{Re})^{-3 / 4}$ and was in the order of $50 \mu \mathrm{m}$, and the corresponding time scale was 0.267 .The experiments were performed with sampling frequency $1000 \mathrm{~Hz}$ and a spatial resolution of 49.8 microns/pixel.

\section{Results}

Non invasive optical flow diagnostics measurements were performed in order to characterize the particle and/or bubble interactions within homogeneous isotropic turbulence. Digital particle-image velocimetry (DPIV) is employed. This method records the instantaneous flow field in a plane and has been recently employed by the authors to monitor two-phase flows. DPIV requires a plane sheet of intense laser light. This sheet cuts the domain of interest along planes of interest. A CMOS digital camera is then employed to record the instantaneous position of different objects in the flow field. Recording the position of seed particles that follow the flow, allows us to calculate the instantaneous velocity field. Over the past few years, we were able to improve this method by increasing the frequency response by two orders of magnitude over commercially available systems. We have also employed this method to record two-phase flows, namely spray flows or bubbly flows.

Digital Particle Image Velocimetry (DPIV) is the most established global flowfield measurement technique, however, time-resolved measurements with simultaneous velocity, shape and size characterization of multiple phases remains a great challenge. In the current effort, we integrate the appropriate hardware and software components necessary to perform such measurements. A Vision Research Phantom-IV camera with frame rate up to 1000 frames per second (fps) and spatial resolution of 512x512 is employed using single laser exposure per frame for the recording of the DPIV images. The camera is synchronized with a high repetition rate Copper-Vapor pulsing laser with emission wavelengths at $511 \mathrm{~nm}$ and $578 \mathrm{~nm}$. The pulse duration is in the order of 25nsecs is sufficient for performing measurements for low and moderate speeds. 
For multi-phase flows, saturation of the image from overexposure of bubbles or droplets is a detrimental parameter for carrying out accurate quantitative measurements. Conventional DPIV systems employ CCD cameras, which suffer from leakage effects, namely, the excessive charge from overexposed pixels, leaks to the neighboring ones saturating the whole area. In contrast, CMOS sensors isolate the individual pixels behaving as a cut-off filter without leaking the energy. Therefore, by employing CMOS technology we eliminate the blooming effect, allowing resolution of a multi-phase flow

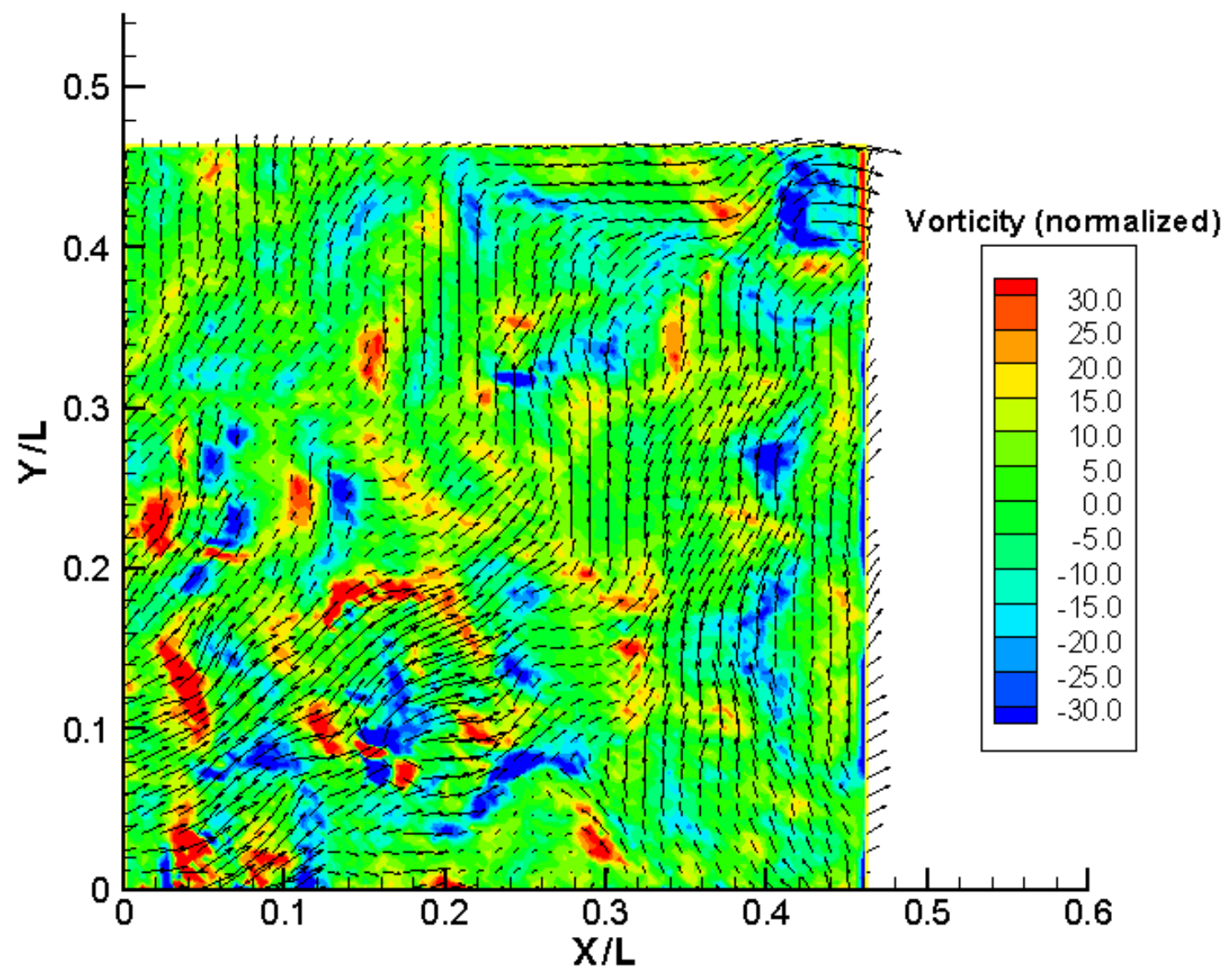

Fig. 3. Instantaneous velocity vectors and vorticity contours

with direct imaging within a laser sheet. This feature is of great importance since it simplifies the experimental setup, enhances the signal-to-noise ratio, and more importantly allows accurate shape and size quantification of particles or bubbles present in the flow. In addition, it improves the performance of the centroid Gaussian estimator, which is essential for the performance of the particle tracking methodology. Details on the performance characteristics and accuracy of the system can be found in Abiven and Vlachos (2002)

Very small particles at the asymptotic limit of the Stokes number less than 1 behave as fluid elements responding to all the fluctuations of the flow. At that level the Urms corresponding to the particle motion will be the one defined by the velocity at the level of 
the Kolmogorov micro scale for homogeneous isotropic turbulence, $\mathbf{U}=(\varepsilon v)^{\frac{1}{4}}$. In Fig. 3 we display a typical snapshot of the flow, showing instantaneous velocity vectors in a frame immediately above the impeller. The color contours represent the magnitude of the

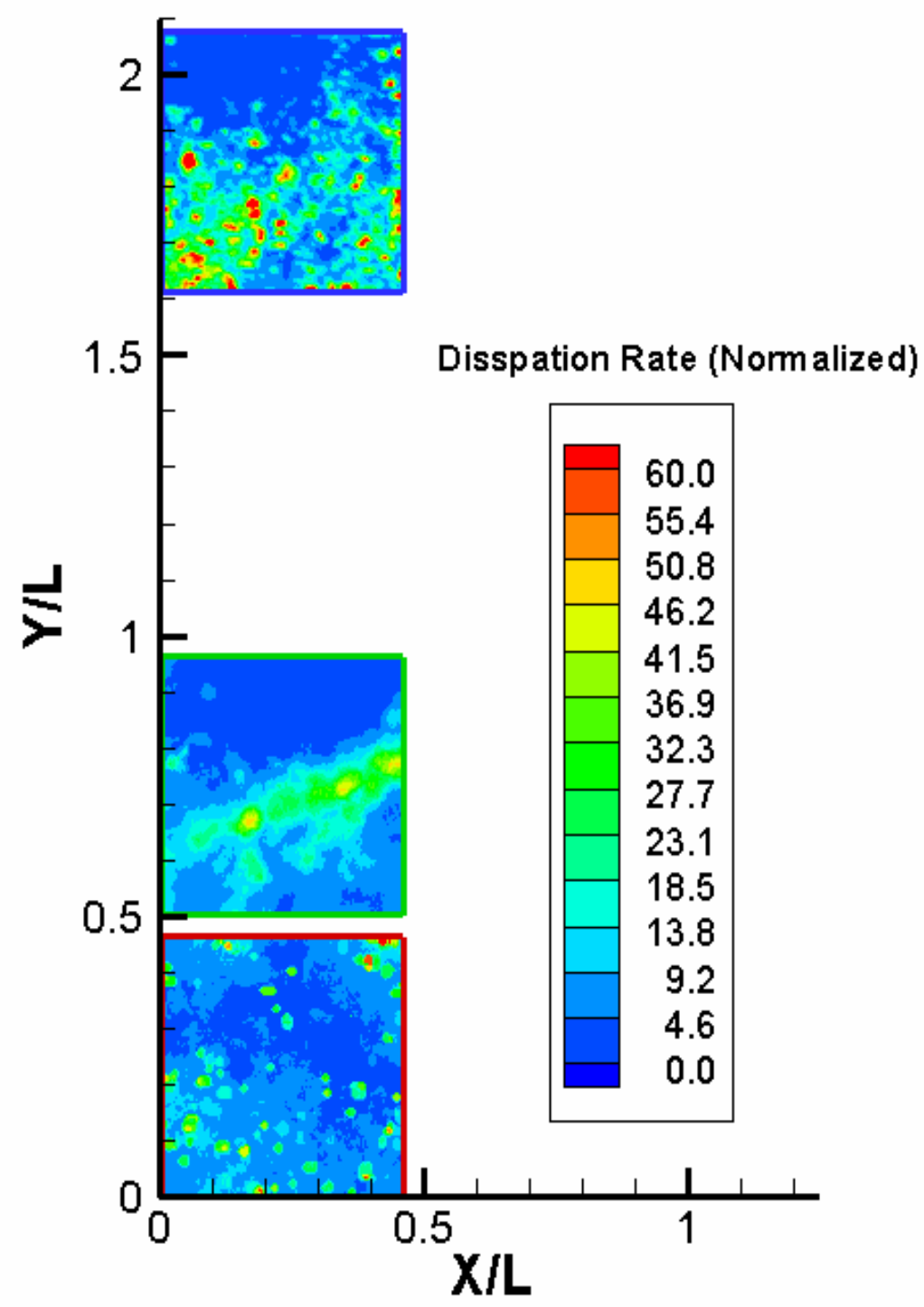

vorticity vector normal to the plane of measurement.

The dissipation rate computed was computed using Taylor's hypothesis of frozen-turbulence, Equation 10. In Fig. 4 we display the dissipation rates on three consecutive frames above the impeller. It should be noted that the plane of measurement is off the axis by about on impeller diameter. This is therefore in the nearly dead zone between tow opposing streams. Immediately above the impeller the flow is moving downward, driven by the impeller. Away from the cylindrical control volume with diameter equal to the impeller diameter, the flow is moving upward, to complete the

Fig. 4. Dissipation rates above the impeller.

recirculation in the tank. Our measurements were obtained at about the space between these regions. This explains the fact we find dissipation rates higher away from the impeller.

Finally in Fig. 5, we present vorticity contours along the same frames as in Fig. 4. 


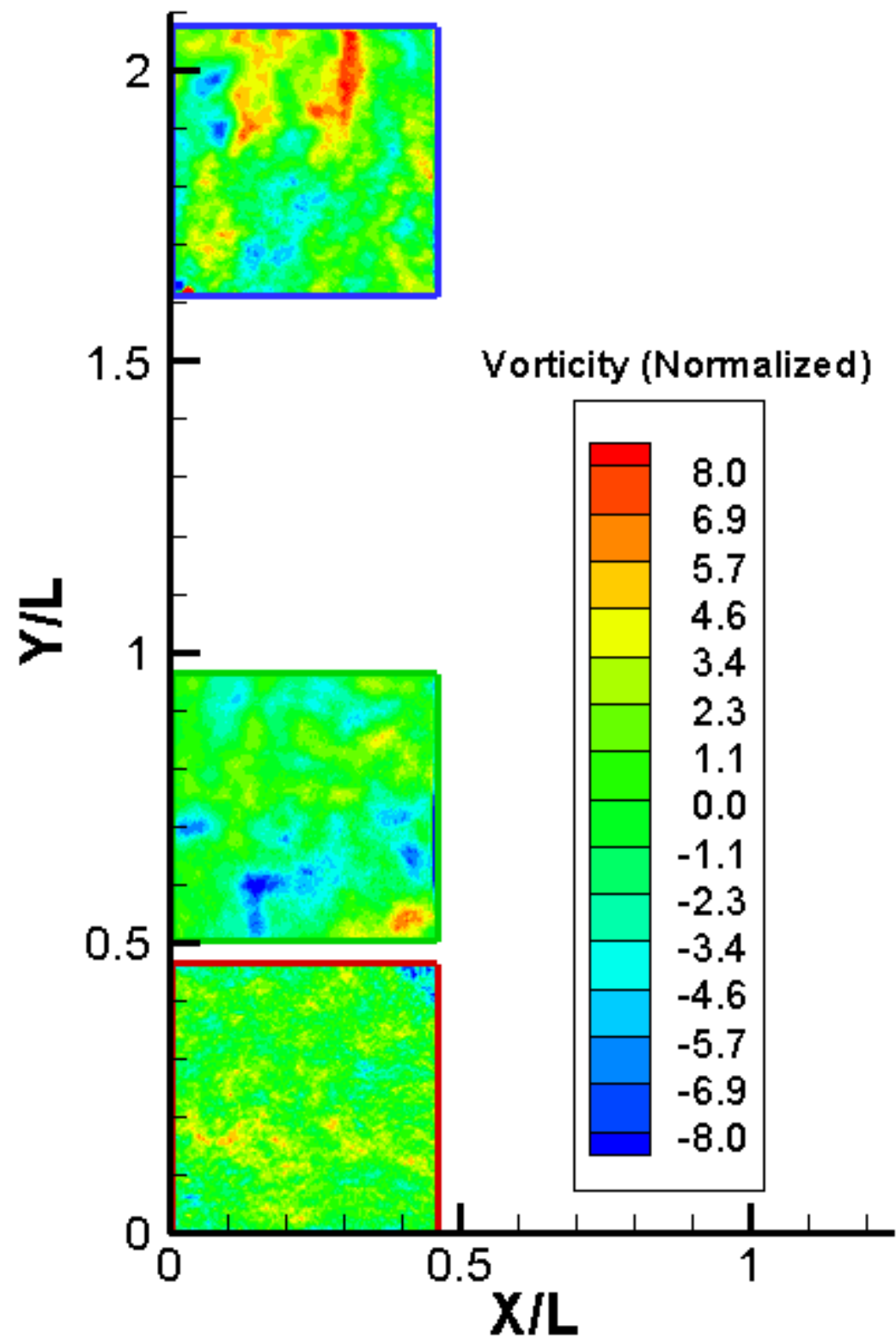

\section{SUMMARY}

In our previous report, we reported on measurements obtained in homogeneous isotropic turbulence. Our aim now is to simulate the anisotropy and nonhomogeneity found in a flotation cell. The turbulent dissipation rate was measured using a cross correlation based Particle Image Velocimeter. Particle Tracking Velocimetry will be used to determine the velocity fluctuations of the solid particles relative to the fluid phase. RMS velocities of the particles were calculated and compared to experimental and theoretical models that are based on the dissipation rate.

Fig. 5 Vorticity Contours 


\section{FUTURE WORK}

As described above, we have completed the design and made great progress on Task 1, as described above. We have some preliminary data but we need to define a detailed set of experiments that will have to be conducted. These will require taking data along vertical planes that pass through the axis of the impeller. These will provide velocity components in the radial and axial direction and their fluctuations. We will then take data along planes normal to the impeller axis. These will provide components in the radial and circumferential direction.

The outside walls of the tank have an octagonal shape. This was chosen specifically to accommodate two cameras that will allow us to record three components of the velocity. It is not clear that we will be able to complete this phase of the work, which was not included in our original proposal.

Work on this effort will combine detailed theoretical analysis and modeling with state-of-the-art, global, multi-phase flow measurements to quantify the effects of the various hydrodynamic parameters on the flotation process. Our modeling approach will incorporate all physical parameters that affect the collision efficiency of coal particles and flotation bubbles and the probabilities of attachment and detachment. We will deliver global, time-resolved velocity distributions and turbulence characteristics for each phase. All the experimental results will be compared with their modeled counterparts.

\section{REFERENCES}

Abiven, C, Vlachos, P P, 2002. Comparative study of established DPIV algorithms for planar velocity measurements ASME IMECE, IMECE2002-33170.

Abrahamson, J, 1975. Collision rates of small particles in a vigorously turbulent fluid, Chemical Engineering Science, 30, 1371-1379.

Adrian, R J, 1991: Particle-imaging techniques for experimental fluid mechanics. ARFM, 23, 261-304.

Adrian, R J, 1997: Dynamic ranges of velocity and spatial resolution of particle image velocimetry, Measurement Science and Technology, 8 1393-1398.

Adrian, R J, Yao, C-S, 1985: Pulsed laser technique application to liquid and gaseous flows and the scattering power of seed materials, App Optics, 24, 44-52.

Boedec, T, Simoens, S, 2001: Instantaneous and simultaneous planar velocity field measurements of two phases for turbulent mixing of high pressure sprays. Experiments in Fluids, 31, 506-518.

Costes, J and Couderc, J P, 1988. Study by laser dopper anemometry of the turbulenct flow induced by a rushton turbine in a stirred tank: influence of the size of the units- 1 . Mean flow and turbulence, Chemical Engineering Science, 43:2751-2764. 
Cowen, B and Monismith, S, 1997: A hybrid digital particle tracking velocimetry technique. Experiments in Fluids, 22, 199-211.

Guezennec, Y G and Kiritsis, N, 1990. Statistical investigation of errors in particle image velocimetry. Experiments in Fluids, 10, 138-146

Hinze, J O, 1994. Turbulence. New York: McGraw-Hill, Inc.

Höfken, M, Schäfer, M and Durst, F, 1996. Detaillierte Untersuchung des Strömungsfeldes innerhalb eines Sechs-Blatt-Scheibenrührers, Chemie Ingenieur Technik, 68:803-809.

Huang, H T and Gharib, M, 1997: Processing error in digital particle image velocimetry, FEDSM97-3068.

Huang, H T, Dabiri, D and Gharib, M 1997: On Errors of digital particle image velocimetry, Meas. Science and Technology, .8, 1427-1440.

Khalitov, D A, Longmire, E K, 2002: Simultaneous two-phase PIV by two-parameter phase discrimination, Experiments in Fluids, 32, 252-268.

Kresta, A M and Wood, P E, 1993. The flow field produced by a pitched blade turbine: characterization of the turbulence and estimation of the dissipation rate, Chemical Engineering Science, 48:1761-1774.

Laufhütte, H D andMersmann, A, 1985. Proceedings of $5^{\text {th }}$ European Conference on Mixing, 331 (BHRA Fluid Eng., Cranfield, England).

Lecordier, B and Trinite, M, 1999: Time resolved PIV measurements for high speed flows,

Third International Workshop on Particle Image Velocimetry. (Santa Barbara, 16-18 Sept 1999).

Lee, C A and Erickson, L E. Bubble breakup and coalescence in turbulent gas-liquid dispersions, Chemical eng. comm. 59(1-6), 65-84.

Levins, B E and Glastonbury, J R, 1972. Trans. Instn. Chem. Engr., 50, 32, 132.

Levins, D M, Glastonbury, J R, 1972. Particle-liquid hydrodynamics and mass transfer in a stirred vessel, Part I-particle-liquid vessel, Trans. Instn. Chem. Engrs., 40:32-41.

Liepe, F-M, Hans, O, 1976. Untersuchungen zum Stoffvereinigen in Flüssiger Phase, Chem. Techn., 28, Jg., Heft 4. 
Okamoto, Y, Nishikawa, N and Hashimoto, K, 1981. Energy dissipation rate distribution in mixing vessels and its effects on liquid-liquid dispersion and solid-liquid mass transfer, International Chemical Engineering, 21:88-94.

Rao, M A and Brodkey, R S, 1972. Continuous flow stirred tank turbulence parameters in the impeller stream, Chemical Engineering Science, 27:137-156.

Saffman, PG, Turner, J S, 1956. On the collision of drops in turbulent clouds. Journal of Fluid Mechanics, 1, 16-30

Scarano, F and Rieuthmuller, M L, 1999: Iterative multigrid approach in PIV image processing with discrete window offset, Experiments in Fluids, 26, 513-523.

Schubert, H, 1999. On the Turbulence-Controlled Microprocesses in Flotation Machines. Int. J. Mier. Process., 56, 257-276.

Sheng, J, Meng, H and Fox, R O, 2000. A large eddy PIV method for turbulence dissipation rate estimation, Chemical Engineering Science, 55:4423-4434.

Upatnieks, A, Laberteaux, K, Ceccio, S L, 2002:A kilohertz frame rate cinematographic PIV system for laboratory-scale turbulent and unsteady flows, Experiments in Fluids, 32, 87-98.

Vlachos, P, 2000: A spatio-temporal analysis of separated flows over bluff bodies using quantitative flow visualization. PhD. Dissertation, Department of Engineering Science and Mechanics, Virginia Polytechnic Institute and State University, Blacksburg, VA

Wereley, S T, Meinhart, C D, 2001: Second-order accurate particle image velocimetry. Experiments in Fluids, 31, 258-268.

Westerweel, J, 1993a. Digital Particle Image Velocimetry, Theory and Application, Delft University Press, Delft, The Netherlands.

Westerweel, J, 1993b. Analysis of PIV interrogation with low pixel resolution. In Optical diagnostics in fluid and thermal flow, (ed) Trolinger J. D., Proc SPIE Vol. 2005, pp. 624635.(San Diego July 1993).

Wu, H and Patterson, G K, 1989. Laser-doppler measurements of turbulent-flow parameters in a stirred mixer, Chemical Engineering Science, 44:2207-2221.

\section{PUBLICATIONS/PRESENTATIONS}


“Turbulent Particle Bubble Interactions Measured by Particle Image Velocimetry”. By Mike Brady, Demetri Telionis, Pavlos Vlachos, Ian Sherrell and Roe-Hoan Yoon. Presented at the SME Conference. Denver Colorado, February 2004. 
Appendix E: WV007 - Column Flotation of Relative Coarse and Fine Dolomitic Phosphate Pebbles 


\section{TECHNICAL PROGRESS REPORT}

Contract Title and Number:

Crosscutting Technology Development at the Center for

Advanced Separation Technologies

(DE-FC26-02NT41607)
Period of Performance:

Starting Date: 10/1/02

Ending Date: 5/31/05
Sub-Recipient Project Title:

Column Flotation of Relatively Coarse and Fine

Dolomitic Phosphate Pebbles

Principal Investigators:

Felicia Peng

Contact Address:

365 Mineral Resources Building

Minig Engineering Dept., West Virginia University

Morgantown, WV 26506-6070

Subcontractor Address:

No subcontracts issued.
Report Information:

Type: Semi-Annual

Number: R03

Period: 4/30/04 - 9/30/04

Date: $\quad 9 / 30 / 04$

Code: WV007-R03

Contact Information:

Phone: $\quad 304-293-7860$ x-3308

Fax: $\quad 304-293-5708$

E-Mail: ffpeng@mail.wvu.edu

Subcontractor Information:

Phone:

Fax:

E-Mail:

\section{ABSTRACT}

The size distribution and liberation characteristics were determined for the dolomitic phosphate pebble sample obtained from IMC Phosphates MP, Inc., FL. Four different fatty acid or soap types of dolomite collectors were evaluated at $\mathrm{pH} 5.1$, using the mixture of 1:1 phosphoric acid and sulfuric acid as $\mathrm{pH}$ modifier and depressant. The fatty acid type collectors used were PA-31, USPA-31, S-500 and FAS-40A. The tests results show that the increase in collector dosages can removal of 60-75\% $\mathrm{MgO}$ at $78 \%-90 \% \mathrm{P}_{2} \mathrm{O}_{5}$ recovery, from the feed with $2.9 \% \mathrm{MgO}$ and $24.2 \% \mathrm{P}_{2} \mathrm{O}_{5}$ dolomitic phosphate pebble samples for the size range of $-0.25 \mathrm{~mm}+0.15 \mathrm{~mm}(-60+100$ mesh).

\section{INTRODUCTION}

\section{Background}

High dolomite content in the phosphate flotation concentrates causes to consume higher sulfuric acid, reduce filtration rates and lower the $\mathrm{P}_{2} \mathrm{O}_{5}$ content of the final product in fertilizer manufacturing process. Removal of dolomite from phosphate minerals is difficult because both dolomite and phosphate particles have close relative density, and are oxide type minerals with the same cationic component. They show similar electrokinetic, adsorptive and 
desorptive behavior in flotation process. It was found that dolomite is liberated from phosphate at relatively coarser particle size range. Various flotation processes have been developed, but none is quite satisfactory due to either high MgO content and relatively low $\mathrm{P}_{2} \mathrm{O}_{5}$ recovery in the final phosphate concentrate at the relative coarse size fraction. Most of the investigations focus on utilizing fatty acid type collectors and phosphoric acid as depressant, with or without dispersant for fine dolomite flotation. Better collectors for dolomite particles and depressants for phosphate particles need to be investigated and used to lower $\mathrm{MgO}$ content and increase $\mathrm{P}_{2} \mathrm{O}_{5}$ recovery in the final phosphate product of relatively coarse size fraction.

\section{Objective and Approach}

The objectives of this project are to separate dolomite from Florida dolomitic phosphate pebbles at relatively coarser size fraction. The separation performance will be evaluated, using selected fatty acid or soap collectors, and appropriate mixtures of phosphoric acid/sulfuric acid as depressant. Optimum $\mathrm{pH}$ and collector dosages for dolomite flotation will be determined to produce the phosphate concentrate with low $\mathrm{MgO}$ content at high $\mathrm{P}_{2} \mathrm{O}_{5}$ recoveries from Florida low grade dolomitic phosphate pebbles.

\section{PROJECT TASKS}

The Dolomitic phosphate sample is obtained from IMC Phoshphates MP, Inc., Mulberry, FL. The size distribution and chemical analysis of the as-received dolomitic phosphate pebble sample is given in Table 1. It indicates that the as received sample contains $24.16 \% \mathrm{P}_{2} \mathrm{O}_{5}, 2.88 \% \mathrm{MgO}$ and $11.56 \%$ insolubles. This dolomitic phosphate pebble sample has high content of $\mathrm{MgO}$.

Table 1 Size distribution and chemical analysis of the as-received dolomitic phosphate pebble sample

\begin{tabular}{|c|r|r|r|r|r|r|r|}
\hline \multirow{2}{*}{$\begin{array}{c}\text { Size } \\
(\mathrm{mm})\end{array}$} & \multirow{2}{*}{$\mathrm{Wt} \%$} & \multicolumn{6}{|c|}{ Assay, \% } \\
\cline { 3 - 8 } & $\mathrm{P}_{2} \mathrm{O}_{5}$ & \multicolumn{1}{c|}{$\mathrm{CaO}$} & $\mathrm{Fe}_{2} \mathrm{O}_{3}$ & $\mathrm{Al}_{2} \mathrm{O}_{3}$ & \multicolumn{1}{c|}{$\mathrm{MgO}$} & Insoluble \\
\hline+6.35 & 44.84 & 23.4 & 39.20 & 0.87 & 0.76 & 3.17 & 10.53 \\
\hline$-6.35+4.0$ & 32.53 & 24.5 & 41.16 & 0.81 & 0.93 & 3.12 & 10.26 \\
\hline$-4.0+2.38$ & 8.86 & 26.6 & 40.89 & 0.81 & 1.00 & 2.13 & 9.93 \\
\hline$-2.38+1.0$ & 7.84 & 27.5 & 39.33 & 0.73 & 0.95 & 1.16 & 15.47 \\
\hline$-1.0+0.5$ & 1.48 & 25.9 & 38.30 & 0.78 & 0.99 & 1.31 & 18.23 \\
\hline$-0.5+0.1$ & 1.38 & 17.2 & 24.53 & 0.59 & 0.74 & 0.99 & 47.95 \\
\hline-0.1 & 3.06 & 18.2 & 33.50 & 1.74 & 1.81 & 4.41 & 15.34 \\
\hline Total & 100.00 & 24.16 & 39.61 & 0.85 & 0.88 & 2.88 & 11.56 \\
\hline
\end{tabular}

To examine the liberations of both dolomite and phosphate from the dolomitic phosphate pebbles, the sample was double-roll crushed to minus $1.4 \mathrm{~mm}$ (-14 mesh) with the size and chemical analyses. The analysis results indicated that the $\mathrm{P}_{2} \mathrm{O}_{5}$ and $\mathrm{MgO}$ are evenly distributed in every size fraction except the lower $\mathrm{P}_{2} \mathrm{O}_{5}$ and higher $\mathrm{MgO}$ in minus $37 \mu \mathrm{m} \mathrm{(-}$ $400 \mathrm{mesh})$ fines. The minus $1.4 \mathrm{~mm}$ sample was further wet ground to minus $250 \mu \mathrm{m}$ (-60 mesh) for liberating dolomite from phosphate in a rod mill. Each batch sample weighs 300 grams and has $60 \%$ solids. It can be seen in Table 2 that the average $\mathrm{P}_{2} \mathrm{O}_{5}$ content is $22.7 \%$, 
while $\mathrm{MgO}$ content is $2.93 \%$. The minus $37 \mu \mathrm{m}$ (-400 mesh) size fraction contains as high as $4.9 \% \mathrm{MgO}$ at $20.5 \% \mathrm{P}_{2} \mathrm{O}_{5}$ after grinding.

Table 2 Size distribution and chemical analysis of minus $250 \mu$ m (-60 mesh) ground dolomitic phosphate pebble sample

\begin{tabular}{|c|r|r|r|r|r|r|r|}
\hline \multirow{2}{*}{$\begin{array}{c}\text { Size } \\
(\mathrm{mm})\end{array}$} & $\mathrm{Wt} \%$ & \multicolumn{6}{|c|}{ Assay, \% } \\
\cline { 3 - 8 } & \multicolumn{1}{|c|}{$\mathrm{P}_{2} \mathrm{O}_{5}$} & \multicolumn{1}{c|}{$\mathrm{CaO}$} & $\mathrm{Fe}_{2} \mathrm{O}_{3}$ & $\mathrm{Al}_{2} \mathrm{O}_{3}$ & \multicolumn{1}{c|}{$\mathrm{MgO}$} & Insoluble \\
\hline$-60+100$ & 4.62 & 24.1 & 37.5 & 0.71 & 0.57 & 1.22 & 17.84 \\
\hline $100+200$ & 35.83 & 23.9 & 36.76 & 0.75 & 0.65 & 1.78 & 14.66 \\
\hline$-200+400$ & 19.77 & 24.4 & 36.86 & 0.79 & 0.68 & 2.25 & 11.68 \\
\hline-400 & 39.78 & 20.5 & 35.28 & 0.87 & 0.81 & 4.5 & 6.08 \\
\hline & 100.00 & 22.66 & 36.23 & 0.80 & 0.72 & 2.93 & 10.80 \\
\hline
\end{tabular}

The flotation tests were conducted for minus $0.25 \mathrm{~mm}$ (-60 mesh) sample in Denver machine with 1.2 L stirred-tank flotation cell. In flotation, the mixture of 1:1 phosphoric acid and sulfuric acid was used as $\mathrm{pH}$ modifier, and different type of fatty acids, or soaps were used as dolomite collectors. The flotation feed sample was first conditioned in acid mixtures to depress the phosphate particles for 1 minute, then in a selected collect and dosage for another 1 minute. After the conditioned pulp was aerated for 1 minute, the froth was skimmed off, filtered, dried and analyzed. The aeration was continued during froth skimming. The effect of $\mathrm{pH}$ was evaluated using 1.5kg/t of USPA-31 (Hwang, et al., 2003) as dolomite collector. The optimum flotation is determined at $\mathrm{pH} 5.1$ with $1.6 \% \mathrm{MgO}$ and $91.8 \% \mathrm{P}_{2} \mathrm{O}_{5}$ recovery, from the feed of 2.9\% MgO content and 24.2\% $\mathrm{P}_{2} \mathrm{O}_{5}$, as shown in Table 3.

Table 3 pH effect on dolomite flotation using USPA-31 collector

\begin{tabular}{|c|c|c|c|c|c|c|c|c|c|}
\hline \multirow{2}{*}{$\mathrm{pH}$} & \multirow{2}{*}{$\begin{array}{c}\text { USPA- } \\
31 \\
\mathrm{Kg} / \mathrm{t}\end{array}$} & \multirow{2}{*}{ Product } & \multirow{2}{*}{$\mathrm{Wt} \%$} & \multicolumn{3}{|c|}{ Grade, \% } & \multicolumn{3}{|c|}{ Recovery, \% } \\
\hline & & & & $\mathrm{P}_{2} \mathrm{O}_{5}$ & $\mathrm{MgO}$ & Insol. & $\mathrm{P}_{2} \mathrm{O}_{5}$ & $\mathrm{MgO}$ & Insol. \\
\hline \multirow{3}{*}{5.5} & \multirow{3}{*}{1.5} & Float & 20.55 & 15.62 & 7.99 & 5.23 & 13.68 & 56.07 & 9.85 \\
\hline & & Sink & 79.45 & 25.50 & 1.62 & 12.38 & 86.32 & 43.93 & 90.15 \\
\hline & & Feed & 100.00 & 23.47 & 2.93 & 10.91 & 100.00 & 100.00 & 100.00 \\
\hline \multirow{3}{*}{5.1} & \multirow{3}{*}{1.5} & Float & 17.80 & 10.76 & 8.97 & 3.92 & 8.20 & 54.68 & 6.30 \\
\hline & & Sink & 82.20 & 26.10 & 1.61 & 12.63 & 91.80 & 45.32 & 93.70 \\
\hline & & Feed & 100.00 & 23.37 & 2.92 & 11.08 & 100.00 & 100.00 & 100.00 \\
\hline \multirow{3}{*}{4.8} & \multirow{3}{*}{1.5} & Float & 18.52 & 12.71 & 8.33 & 5.10 & 9.96 & 52.10 & 8.59 \\
\hline & & Sink & 81.48 & 26.10 & 1.74 & 12.34 & 90.04 & 47.90 & 91.41 \\
\hline & & Feed & 100.00 & 23.62 & 2.96 & 11.00 & 100.00 & 100.00 & 100.00 \\
\hline \multirow{3}{*}{4.5} & \multirow{3}{*}{1.5} & Float & 17.51 & 10.65 & 9.01 & 4.89 & 7.97 & 54.21 & 7.82 \\
\hline & & Sink & 82.49 & 26.12 & 1.62 & 12.24 & 92.03 & 45.79 & 92.18 \\
\hline & & Feed & 100.00 & 23.41 & 2.91 & 10.95 & 100.00 & 100.00 & 100.00 \\
\hline
\end{tabular}

At $\mathrm{pH}$ 5.1, four different types of fatty acid collector for dolomite particles were tested, including S-500, FAS-40A, PA-31, and USPA-31. The reagents are supplied by IMC Phosphates MP, Inc., Mulberry, FL. The flotation results are presented in Tables 4, 5, 6 and 7 , respectively. 
Table 4 S-500 dosage effect on dolomite flotation at pH 5.1

\begin{tabular}{|c|c|c|c|c|c|c|c|c|c|}
\hline \multirow{2}{*}{$\mathrm{pH}$} & \multirow{2}{*}{$\begin{array}{c}\mathrm{S}-500 \\
\mathrm{Kg} / \mathrm{t}\end{array}$} & \multirow{2}{*}{ Product } & \multirow{2}{*}{$\mathrm{Wt} \%$} & \multicolumn{3}{|c|}{ Grade, \% } & \multicolumn{3}{|c|}{ Recovery, \% } \\
\hline & & & & $\mathrm{P}_{2} \mathrm{O}_{5}$ & $\mathrm{MgO}$ & Insol. & $\mathrm{P}_{2} \mathrm{O}_{5}$ & $\mathrm{MgO}$ & Insol. \\
\hline \multirow{3}{*}{5.1} & \multirow{3}{*}{1} & Float & 24.18 & 15.45 & 7.28 & 4.86 & 15.93 & 59.77 & 11.46 \\
\hline & & Sink & 75.82 & 26.00 & 1.56 & 11.98 & 84.07 & 40.23 & 88.54 \\
\hline & & Feed & 100.00 & 23.45 & 2.95 & 10.26 & 100.00 & 100.00 & 100.00 \\
\hline \multirow{3}{*}{5.1} & \multirow{3}{*}{0.75} & Float & 19.03 & 15.82 & 6.49 & 5.67 & 12.73 & 45.52 & 10.07 \\
\hline & & Sink & 80.97 & 25.50 & 1.83 & 11.90 & 87.27 & 54.48 & 89.93 \\
\hline & & Feed & 100.00 & 23.66 & 2.71 & 10.71 & 100.00 & 100.00 & 100.00 \\
\hline \multirow{3}{*}{5.1} & \multirow{3}{*}{0.5} & Float & 11.75 & 15.49 & 6.93 & 4.94 & 7.71 & 30.11 & 5.28 \\
\hline & & Sink & 88.25 & 24.70 & 2.14 & 11.79 & 92.29 & 69.89 & 94.72 \\
\hline & & Feed & 100.00 & 23.62 & 2.70 & 10.98 & 100.00 & 100.00 & 100.00 \\
\hline
\end{tabular}

Table 5 FAS-40A dosage effect on dolomite flotation at pH 5.1

\begin{tabular}{|c|c|c|c|c|c|c|c|c|c|}
\hline \multirow{2}{*}{$\mathrm{pH}$} & \multirow{2}{*}{$\begin{array}{c}\text { FAS- } \\
40 \mathrm{~A} \\
\mathrm{Kg} / \mathrm{t} \\
\end{array}$} & \multirow{2}{*}{ Product } & \multirow{2}{*}{$\mathrm{Wt} \%$} & \multicolumn{3}{|c|}{ Grade, \% } & \multicolumn{3}{|c|}{ Recovery, \% } \\
\hline & & & & $\mathrm{P}_{2} \mathrm{O}_{5}$ & $\mathrm{MgO}$ & Insol. & $\mathrm{P}_{2} \mathrm{O}_{5}$ & $\mathrm{MgO}$ & Insol. \\
\hline \multirow[t]{3}{*}{5.1} & 1 & Float & 13.74 & 10.82 & 8.31 & 4.37 & 8.56 & 43.63 & 5.32 \\
\hline & & Sink & 86.26 & 26.19 & 1.71 & 12.39 & 91.44 & 56.37 & 94.68 \\
\hline & & Feed & 100.00 & 24.07 & 2.62 & 11.29 & 100.00 & 100.00 & 100.00 \\
\hline \multirow[t]{3}{*}{5.1} & 1.5 & Float & 15.62 & 15.00 & 8.39 & 3.95 & 9.87 & 46.32 & 5.64 \\
\hline & & Sink & 84.38 & 25.36 & 1.80 & 12.22 & 90.13 & 53.68 & 94.36 \\
\hline & & Feed & 100.00 & 23.74 & 2.83 & 10.93 & 100.00 & 100.00 & 100.00 \\
\hline \multirow[t]{3}{*}{5.1} & 2 & Float & 17.50 & 11.00 & 9.81 & 3.77 & 8.35 & 58.11 & 5.99 \\
\hline & & Sink & 82.50 & 25.60 & 1.50 & 12.56 & 91.65 & 41.89 & 94.01 \\
\hline & & Feed & 100.00 & 23.05 & 2.95 & 11.02 & 100.00 & 100.00 & 100.00 \\
\hline \multirow[t]{3}{*}{5.1} & 2.5 & Float & 25.65 & 13.60 & 8.63 & 4.56 & 15.09 & 68.67 & 10.73 \\
\hline & & Sink & 74.35 & 26.40 & 1.36 & 13.09 & 84.91 & 31.33 & 89.27 \\
\hline & & Feed & 100.00 & 23.12 & 3.22 & 10.90 & 100.00 & 100.00 & 100.00 \\
\hline \multirow[t]{3}{*}{5.1} & 3 & Float & 28.54 & 14.60 & 8.00 & 5.18 & 18.09 & 71.64 & 13.29 \\
\hline & & Sink & 71.46 & 26.40 & 1.26 & 13.50 & 81.91 & 28.36 & 86.71 \\
\hline & & Feed & 100.00 & 23.03 & 3.19 & 11.13 & 100.00 & 100.00 & 100.00 \\
\hline
\end{tabular}

Table 6 PA-31 dosage effect on dolomite flotation at $\mathrm{pH} 5.1$

\begin{tabular}{|c|c|c|c|c|c|c|c|c|c|}
\hline \multirow{2}{*}{$\mathrm{pH}$} & \multirow{2}{*}{$\begin{array}{c}\mathrm{PA}-31 \\
\mathrm{Kg} / \mathrm{t}\end{array}$} & \multirow{2}{*}{ Product } & \multirow{2}{*}{$\mathrm{Wt} \%$} & \multicolumn{3}{|c|}{ Grade, \% } & \multicolumn{3}{|c|}{ Recovery, \% } \\
\hline & & & & $\mathrm{P}_{2} \mathrm{O}_{5}$ & $\mathrm{MgO}$ & Insol. & $\mathrm{P}_{2} \mathrm{O}_{5}$ & $\mathrm{MgO}$ & Insol. \\
\hline \multirow{3}{*}{5.1} & \multirow{3}{*}{1.5} & Float & 34.72 & 16.20 & 6.62 & 5.80 & 24.54 & 78.23 & 18.81 \\
\hline & & Sink & 65.28 & 26.50 & 0.98 & 13.32 & 75.46 & 21.77 & 81.19 \\
\hline & & Feed & 100.00 & 22.92 & 2.94 & 10.71 & 100.00 & 100.00 & 100.00 \\
\hline \multirow{3}{*}{5.1} & \multirow{3}{*}{0.7} & Float & 21.28 & 15.32 & 8.72 & 5.65 & 14.04 & 63.91 & 10.39 \\
\hline & & Sink & 76.30 & 26.20 & 1.37 & 13.64 & 85.96 & 36.09 & 89.61 \\
\hline & & Feed & 100.00 & 23.25 & 2.90 & 11.61 & 100.00 & 100.00 & 100.00 \\
\hline
\end{tabular}


Table 7 USPA-31 dosage effect on dolomite flotation

\begin{tabular}{|c|c|c|c|c|c|c|c|c|c|}
\hline \multirow{2}{*}{$\mathrm{pH}$} & \multirow{2}{*}{$\begin{array}{c}\text { USPA } \\
\mathrm{Kg} / \mathrm{t}\end{array}$} & \multirow{2}{*}{ Product } & \multirow{2}{*}{$\mathrm{Wt} \%$} & \multicolumn{3}{|c|}{ Grade, \% } & \multicolumn{3}{|c|}{ Recovery, \% } \\
\hline & & & & $\mathrm{P}_{2} \mathrm{O}_{5}$ & $\mathrm{MgO}$ & Insol. & $\mathrm{P}_{2} \mathrm{O}_{5}$ & $\mathrm{MgO}$ & Insol. \\
\hline \multirow{3}{*}{5.1} & \multirow{3}{*}{1.5} & Float & 17.80 & 10.76 & 8.97 & 3.92 & 8.20 & 54.68 & 6.30 \\
\hline & & Sink & 82.20 & 26.10 & 1.61 & 12.63 & 91.80 & 45.32 & 93.70 \\
\hline & & Feed & 100.00 & 23.37 & 2.92 & 11.08 & 100.00 & 100.00 & 100.00 \\
\hline \multirow{3}{*}{5.1} & \multirow{3}{*}{2.7} & Float & 21.53 & 11.07 & 8.59 & 3.53 & 10.26 & 66.03 & 6.68 \\
\hline & & Sink & 78.48 & 26.60 & 1.21 & 13.48 & 89.74 & 33.97 & 93.32 \\
\hline & & Feed & 100.00 & 23.26 & 2.80 & 11.34 & 100.00 & 100.00 & 100.00 \\
\hline
\end{tabular}

\section{SUMMARY}

The dolomitic phosphate pebble sample were supplied by IMC Phosphates MP, Inc., Mulberry, FL. The study of size distribution and chemical analysis showed that the sample is a high MgO contant sample ranged from 1.22-4.5\% MgO for minus $0.25 \mathrm{~mm}$ (-60 mesh) size fraction. Four different fatty acid or soap types of dolomite collectors were evaluated at $\mathrm{pH} 5.1$ using the mixture of 1:1 phosphoric acid and sulfuric acid as $\mathrm{pH}$ modifier and depressant for size fraction of for $-0.25 \mathrm{~mm}+0.15 \mathrm{~mm}(-60+100 \mathrm{mesh})$ size fraction. The fatty acid collectors for dolomite are PA-31, USPA-31, S-500 and FAS-40A supplied by IMC Phosphates. The tests results show that the increase in collector dosages can removal of $60-75 \% \mathrm{MgO}$ at $78 \%-90 \% \mathrm{P}_{2} \mathrm{O}_{5}$ recovery, from the feed with average $2.9 \% \mathrm{MgO}$ and $24.2 \%$ $\mathrm{P}_{2} \mathrm{O}_{5}$ dolomitic phosphate pebble samples.

\section{FUTURE WORK}

The tests results show that the increased in collector dosages can removal of $60-75 \%$ of $\mathrm{MgO}$ in the float, at $80 \%-92 \% \mathrm{P}_{2} \mathrm{O}_{5}$ recovery in the sink. However, the loss of $\mathrm{P}_{2} \mathrm{O}_{5}$ in the sink due to increase in dolomite collector dosages are also observed. In order to improve the removal of $\mathrm{MgO}$ and minimize the loss of $\mathrm{P}_{2} \mathrm{O}_{5}$ recovery, the selected depressants will be used for the evaluation. The feed for the flotation tests will also be increased to relatively coarser size range of $-0.43 \mathrm{~mm}+0.15 \mathrm{~mm}$. The delaying in the progress is due to take at least 2-4 weeks to receive the analysis results for the tested dolomite phosphate samples from the Analytical Lab of NRCCE. We can not make the determination of the flotation test conditions without the analysis results from the Lab. We have made the request to the Lab to place our sample analysis jobs at the top of their analysis priority list.

\section{REFERENCES}

Huang, C., Guan, C., Gao, Z., Zhang S., and Xu, Q., "Optimizing the Formulation for Dolomite Collector “PA-31” Using Raw Materials from the United States,” Final Report No. 0215-197, FIPR, FL

\section{PUBLICATIONS/PRESENTATIONS}

None 
Appendix F: KY002 - Improving Densification of Fine Coal Refuse Slurries to Eliminate Slurry Ponds 


\section{TECHNICAL PROGRESS REPORT}

Contract Title and Number: $\quad$ Period of Performance:

Crosscutting Technology Development at the Center for Starting Date: 4/1/03

Advanced Separation Technologies

(DE-FC26-02NT41607)

Sub-Recipient Project Title:

Improving Densification of Fine Coal Refuse to

Eliminate Slurry Ponds.

Principal Investigators:

B.K.Parekh

\section{Contact Address:}

Center for Applied Energy Research

University of Kentucky

2540 Research Park dr.

Lexington, KY 40511

Subcontractor Address:

"No subcontracts issued."
Ending Date: 5/30/05

Report Information:

Type: Semi-Annual

Number: 3

Period: $\quad 4 / 2004$ to $09 / 2004$

Date: $\quad$ September 30,2004

Code: $\quad 8001$

Contact Information:

Phone: 859-257-0239

Fax: 859-257-0302

E-Mail: parekh@caer.uky.edu

Subcontractor Information:

Phone:

Fax:

E-Mail: 


\begin{abstract}
During this reporting period, characterization, flocculation and settling studies were conducted on the thickener underflow obtained from the Arch coal of WV, located near Logan. The combined use of anionic and cationic flocculent was found to be more effective in providing higher settling flux and settled percent solids compared to using anionic flocculant alone. The flocculation studies were conducted with diluted slurry (10\% solids) to facilitate the observation of the settling characteristics. Using only anionic flocculant (400 $\mathrm{g} / \mathrm{t}$ ), the settling flux and settled percent solids were 2.38 tonnes $/ \mathrm{hr} / \mathrm{m}^{2}$ and $30 \%$ respectively. Addition of cationic flocculant at a dosage of $100 \mathrm{~g} / \mathrm{t}$ to the slurry treated with anionic flocculant (400 g/t) improved the settling flux to 4.39 tonnes $/ \mathrm{hr} / \mathrm{m}^{2}$ and settled percent solids to $35 \%$. The factorial design experimental study was carried out to optimize the flocculent dosages and to find out their interactions. Preliminary study with the T-Floc apparatus indicated that using the "as received" slurry containing 35\% solids, an underflow concentration of $57 \%$ solids could be achieved using the dual flocculation system.
\end{abstract}

\title{
INTRODUCTION
}

\section{Background}

Increased mechanization in the underground coal mining industry has decreased selectivity and increased the volume of refuse. Coal preparation separates non-combustibles material from coal. Thus, a coal preparation plant separates the material it receives into a product stream and a reject stream, which may be further divided into coarse and fine refuse streams. Depending on the source, 20 to 50 percent of the run-of-mine material ends up in reject stream. One of the reject streams is fine waste slurry, which is a blend of water, coal fines, silt, sand, and clay particles, and is commonly disposed of in an impoundment. A recent study conducted by the National Research Council defined the impoundment problem in detail and provided several recommendations to avoid the slurry spillage. One of the recommendations referred to utilizing advanced dewatering technology, which would reduce or eliminate discharge of slurry.

An advanced thickening technique known as "Paste Thickening Technology" marketed by Dorr-Oliver EIMCO has been successfully applied in alumina processing industry, for dewatering 'red mud' a most difficult material to dewater. The technique utilizes DEEP CONE Thickener specially designed, holds a bright prospect of dewatering the fine coal refuse tailings to a high percent solids so it could discharge as a paste. The thickened material could be stacked at a low angle of repose rather than stored in a pond. Thus, the fine refuse slurry ponds could be completely eliminated. Even though the "Paste Thickening Technology" is being used in the alumina industry, no basic rheological or other data exists on fine coal tailings. The project addresses the need to develop a process alternate to conventional ponding of the waste slurry. This semi-annual report summarizes laboratory data on the Arch Coal of W.Va's refuse slurry. 


\section{Objective and Approach}

The main objective of the proposed program is to evaluate the application of DEEP CONE technology for the disposal of the fine coal refuse. The program includes study of the basic rheological properties of the flocculated fine refuse solids for producing highly thickened solids capable of disposing as a paste. It is also the objective of the proposed research to utilize the rheological data obtained in pilot-scale testing of the "DEEP CONE thickener to obtain technical and economic data for a commercial operation. The technique will be evaluated on the thickener feed slurry (pre-flocculated) as well as flocculated slurry obtained from a thickener underflow.

\section{PROJECT TASKS}

\section{Task 1. Acquisition and Characterization of Samples:}

Four fifty-five gallons drums of thickener underflow slurry were collected from the Arch Coal of W.V. A representative sample of the slurry obtained using the Carpco Rotary Slurry Sampler was characterized for $\mathrm{pH}$, particle size distribution, solid and ash contents and mineralogy. The solids content of the slurry was $35.12 \%$. The $\mathrm{pH}$ of the slurry was 7.72 with ash and sulfur contents of $47.69 \%$ and $0.44 \%$ respectively. The chemical analysis of the slurry (Table 1) indicates that about $88 \%$ weight percent of the sample is composed of $\mathrm{SiO}_{2}$ and $\mathrm{Al}_{2} \mathrm{O}_{3}$. X-ray diffraction study showed that the ash fraction consisted of kaolin, quartz and magnetite...

Table 1: Chemical analysis of the thickener underflow sample of Arch coal of WV.

\begin{tabular}{|c|c|c|c|c|c|c|c|c|c|}
\hline$\% \mathrm{SiO} 2$ & $\% \mathrm{Al} 2 \mathrm{O} 3$ & $\% \mathrm{Fe} 2 \mathrm{O} 3$ & $\% \mathrm{CaO}$ & $\% \mathrm{MgO}$ & $\% \mathrm{Na} 2 \mathrm{O}$ & $\% \mathrm{~K} 2 \mathrm{O}$ & $\% \mathrm{P} 2 \mathrm{O} 5$ & $\% \mathrm{TiO} 2$ & $\% \mathrm{SO} 3$ \\
\hline 62.44 & 25.68 & 5.07 & 0.66 & 1.14 & 0.18 & 4.05 & 0.09 & 1.4 & 0.33 \\
\hline
\end{tabular}

The particle size distribution of the -100 mesh fraction obtained using the Cilas Laser Particle Size Analyzer showed that 50\% of particles are finer than 17.33 microns and $90 \%$ finer than 76.06 microns. The percent solids in -100 mesh fraction was 6.6 with an ash content of $57.71 \%$.

\section{Task 2. Flocculation and Rheological Studies}

In this task, detailed flocculation study of the slurry was conducted to identify the optimum conditions to maximize the settling rate and percent solids of the flocculated slurry. For the flocculation studies, the Nalco cationic (9850) and anionic (83949) flocculants were utilized. The polymer stock solution of $0.2 \mathrm{~g} / \mathrm{l}$ was prepared and used within three days of preparation.

Flocculation and settling tests were conducted using a 2 liter cylinder and the procedure developed by the Dorr-Oliver Eimco Company. In order to determine the optimum flocculant dosage providing higher settling flux and percent solids, flocculation tests were conducted with the thickener underflow slurry diluted from $35 \%$ to $10 \%$ solids to facilitate the observation of the settling of flocculated solids. Table 2 shows the settling flux and settled 
percent solids using only the anionic flocculant. A maximum settling flux of 2.38 tonnes $/ \mathrm{hr} / \mathrm{m}^{2}$ can be achieved with $30 \%$ settled percent solids at an anionic flocculant dosage of $400 \mathrm{~g} / \mathrm{t}$. Further increase in flocculant dosage did not significantly improve the settling flux and percent solids of the settled sediment.

Preliminary flocculation tests were conducted with combined addition of flocculants in a beaker to determine the mode of addition and the dosage required. It was observed that using cationic flocculant alone at a dosage of greater than $300 \mathrm{~g} / \mathrm{t}$ had adverse effect on the settling characteristics of flocs. A flocculant dosage of $100 \mathrm{~g} / \mathrm{t}$ was sufficient to achieve good flocculation and clear supernatant. Further settling tests were conducted using the following experimental conditions.

12 liter of the slurry was preconditioned with a known quantity of anionic flocculant followed by the addition of cationic flocculant. The anionic flocculant concentration was varied, while a constant concentration of cationic flocculant (100 g/t) was used for all tests.

22 liter of the slurry was preconditioned with a known quantity of cationic flocculant followed by the addition of anionic flocculant. The cationic flocculant concentration was varied, while a constant concentration of anionic flocculant (400 g/t) was used for all tests.

Table 2: Effect of addition of anionic flocculant alone and combined anionic and cationic flocculants on the settling flux and settled percent solids. (Feed slurry solids 10\%).

\begin{tabular}{|c|c|c|c|c|c|c|}
\hline $\begin{array}{l}\text { Flocculant } \begin{array}{l}\text { Dosage } \\
\text { (g/t) }\end{array} \\
\text { Anionic Flocculant }\end{array}$ & \multicolumn{2}{|l|}{$\begin{array}{l}\text { Anionic followed by a } \\
\text { constant dosage of } \\
\text { Cationic flocculant (100 } \\
\text { g/t) }\end{array}$} & \multicolumn{2}{l|}{$\begin{array}{l}\text { Cationic followed by a } \\
\text { constant dosage of } \\
\text { anionic flocculant (400 } \\
\text { g/t) }\end{array}$} \\
\cline { 2 - 7 } & Settling Flux & \% Solids & Settling Flux & \% Solids & Settling Flux & \% Solids \\
\hline 100 & 0.49 & 15.23 & 1.18 & 23.98 & 2.92 & 31.03 \\
\hline 150 & 0.71 & 19.34 & 1.25 & 31.90 & 1.39 & 32.78 \\
\hline 200 & 0.77 & 23.34 & 1.40 & 33.45 & 0.62 & 30.09 \\
\hline 250 & 0.85 & 25.13 & 2.44 & 34.12 & 0.64 & 28.90 \\
\hline 300 & 1.12 & 27.89 & 3.23 & 35.02 & 0.59 & 29.21 \\
\hline 400 & 2.38 & 30.34 & 4.39 & 35.87 & 0.58 & 27.89 \\
\hline 600 & 2.40 & 31.12 & 2.72 & 34.99 & 0.52 & 26.23 \\
\hline 800 & - & - & 2.60 & 35.90 & 0.51 & 27.01 \\
\hline
\end{tabular}

Table 2 also shows the effect of addition of constant amount of the cationic flocculant (100 $\mathrm{g} / \mathrm{t}$ ) to the slurry flocculated with varying amount of the anionic flocculant. As the anionic flocculant dosage increases, there is a gradual increase in the settling flux till $400 \mathrm{~g} / \mathrm{t}$ and an increase in percent settled solids. Further increase in anionic flocculant dosage decreases the settling flux without much change in the percent solids. At $400 \mathrm{~g} / \mathrm{t}$ anionic flocculant dosage, the settling flux and percent solids increased from 2.38 to 4.39 tonnes $/ \mathrm{hr} / \mathrm{m}^{2}$ and $30 \%$ to $35 \%$ respectively. 
The results of the effect of addition of a constant amount of the anionic flocculant to the slurry preconditioned with varying amount of the cationic flocculant are also shown in Table 2. The anionic dosage was kept constant at $400 \mathrm{~g} / \mathrm{t}$ while varying the cationic flocculant dosage from $100 \mathrm{~g} / \mathrm{t}$ to $800 \mathrm{~g} / \mathrm{t}$. The settling flux sharply decreased to 0.62 tonnes $/ \mathrm{hr} / \mathrm{m}^{2}$ and percent solids to $28 \%$ at a cationic flcocculant dosage of $200 \mathrm{~g} / \mathrm{t}$. These results clearly show that the usage of cationic flocculant after the treatment of slurry with anionic flocculant stabilizes the system instead of improving the flocculation. This effect probably may due to the presence of residual anionic flocculant present of the particle surface, as the sample used in the present study is flocculated thickener under flow.

The results clearly show that pretreatment of slurry with anionic flocculant before the addition of cationic flocculant improves the settling flux and percent solids. It was decided therefore, to study the interactions of anionic and cationic flocculants using factorial design experiments. A three level factorial design experiments was designed using anionic and cationic flocculant dosages as factors and settling flux and settled solids as responses. The analysis revealed that anionic flocculant dosage produces a large effect compared to cationic flocculant dosage.

Preliminary refuse thickening tests were conducted using the as received slurry, with the Dorr-Oliver Eimco's designed T-floc apparatus (Figure 1) in a batch mode, using anionic $(400 \mathrm{~g} / \mathrm{t})$ and cationic $(100 \mathrm{~g} / \mathrm{t})$ flocculent. After 4 hours residence time, the underflow solids concentration reached $57 \%$ solids, which clearly indicated that the refuse slurry could be thickened as a paste.

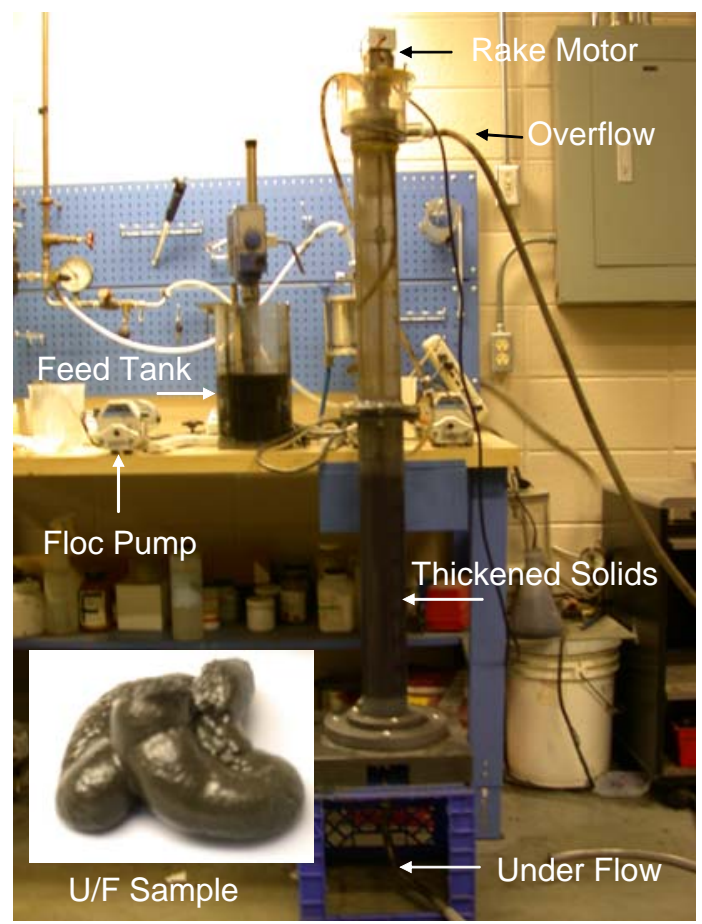

Figure 1: T-Floc apparatus setup showing settled solids and clear supernatant 


\section{Task 3: Pilot-Scale Testing and Process Optimization Studies:}

We are in the process of installing the Dorr-Oliver Eimco's pilot-scale unit at the Arch Coal Co.. Detailed information on the unit was provided in the first annual report. It is anticipated that the pilot-scale testing will provide data obtained in a continuous mode in the plant operating conditions.

\section{SUMMARY}

The fine coal slurry from the Arch Coal Preparation Plant, WA was characterized for particle size distribution, percent solids, ash content and mineralogy. The combined addition of anionic flocculant followed by cationic flocculant was adopted for effective flocculation of the slurry. Preliminary tests conducted with the T-floc apparatus provided an underflow slurry concentration of $57 \%$.

\section{FUTURE WORK}

Additional flocculation/settling tests to simulate Deep Cone thickener will be conducted using the T-Floc. A factorial design of experiments will be carried out to optimize settling parameters in the T-Floc apparatus. The underflow from the T-Floc apparatus will be characterized for yield stress and percent solids. Pilot-scale testing will be conducted at the Arch Coal of W.Va.

\section{PUBLICATIONS/PRESENTATIONS:}

“Thickening of fine coal refuse” IX World Filtration Congress Meeting, New Orleans, LA. April 2004.

“Paste Thickening-An Alternate to Impounding” Proc. Coal Preparation, Lexington, KY May 2004.

"Paste Thickening-An Alternate to Impounding” Proc. Particle Size Enlargement in Mineral Processing”, Met Soc. Of Canada, Hamilton, Canada, pp. 319-328, 2004 
Appendix G: VA010 - Development and Testing of a Horizontal Pressure Belt Filter 


\section{TECHNICAL PROGRESS REPORT}

Contract Title and Number:

Crosscutting Technology Development at the Center for

Advanced Separation Technologies

(DE-FC26-02NT41607)
Period of Performance:

Starting Date: 4/01/03

Ending Date: 5/30/05
Sub-Recipient Project Title:

Development and Testing of a Horizontal Pressure Belt

Filter

Principal Investigators:

Gerald H. Luttrell and Roe-Hoan Yoon

Contact Address:

146 Holden Hall

Virginia Tech, Blacksburg, VA 24061

Subcontractor Address:

No subcontracts issued.
Report Information:

Type: Semi-Annual

Number: 1

Period: $\quad 4 / 1 / 04-9 / 30 / 04$

Date: $\quad 11 / 22 / 04$

Code: VA010

Contact Information:

Phone: (540) 231-4508

Fax: (540) 231-3948

E-Mail:_cast@vt.edu

Subcontractor Information:

Phone:

Fax:

E-Mail:

\section{ABSTRACT}

A variety of mechanical processes are available for dewatering fine particles in the coal and mineral processing industries. Unfortunately, many of these processes suffer from major shortcomings such as poor dewatering performance, low throughput capacity, and high capital and operating costs. This project seeks to overcome these problems by developing a new type of dewatering process that combines the operational flexibility of a continuous belt filter with the dewatering efficiency of a batch pressure filter. The proposed project involves the design, construction, testing, and evaluation of a prototype unit and pilot-scale test circuit having a production capacity of approximately $100 \mathrm{lb} / \mathrm{hr}$. Test data obtained from the project will be used to promote the engineering development of a full-scale commercial unit. Work completed during this reporting period has focused primarily on the design of the prototype unit and procurement of the parts required for construction of the prototype test unit. 


\section{INTRODUCTION}

\section{Background}

Filtration processes are commonly used in the coal and minerals processing industry to remove excess moisture from the surfaces of fine particles. However, in order to overcome difficulties associated with the poor performance, extensive maintenance requirements, and high capital/operating costs of existing filter designs, a tremendous incentive exists to develop a filtration system. Ideally, the new filtration system needs to (i) make use of a high differential pressure, (ii) operate in a continuous mode, (iii) minimize filter cloth blinding while avoiding blow back of moisture, and (iv) offer operational flexibility in terms of independent control of cake thickness and drying cycle time. A process that is capable of meeting all of these criteria is a horizontal belt pressure filter. This new technology is very similar in design to that of a conventional horizontal belt vacuum filter, except the filtering mechanism is enclosed inside a pressurized chamber. During operation, feed is injected into the pressured chamber at the head of the filter belt. The high pressure drives the water through the filter cloth/belt where it is discharged into an effluent collection chamber maintained at atmospheric conditions. The filter cake is dropped into an air lock that sequentially opens and closes to continuously discharge the dried solids. Because of the high pressure differential, the filter cake produced by the new filter would be significantly drier than that obtained using disc or belt vacuum filters that are limited to a practical maximum differential pressure of approximately $0.8 \mathrm{~atm}$. The elimination of the blow back of moisture during cake removal ensures that the driest possible cake is produced. Also, the capital cost of the compressor or staged blower can be less than $20 \%$ of the cost of a vacuum pump with an equivalent volumetric capacity. This difference would significantly reduce the cost of the proposed belt filtration system in comparison to vacuum based filters.

\section{$\underline{\text { Objective and Approach }}$}

The primary objective of this project is to develop and test a horizontal belt pressure filter that is capable of efficiently dewatering fine coal in a cost effective manner. The new filter combines the operational benefits of a continuous belt filter with the dewatering efficiency of a batch pressure filter. The proposed project activities include project planning, equipment design/construction, shakedown testing, and detailed testing. In addition, a complete technical and economic evaluation of the new technology will be performed after the proposed experimental work has been completed.

\section{PROJECT TASKS}

\section{Task 1 - Equipment Design/Construction}

The work conducted during this reporting period was associated primarily with the design of the prototype horizontal belt pressure filter and associated test circuit. The filter was designed to provide a feed capacity of $25-100 \mathrm{lb} / \mathrm{hr}$ with a cake thickness of $0.25-1.00$ inches and cycle time of 60-360 sec. To achieve these targets, the unit has been designed with a 2-inch wide belt capable of running between 1 to $6 \mathrm{ft} / \mathrm{min}$ via a variable-speed drive. 

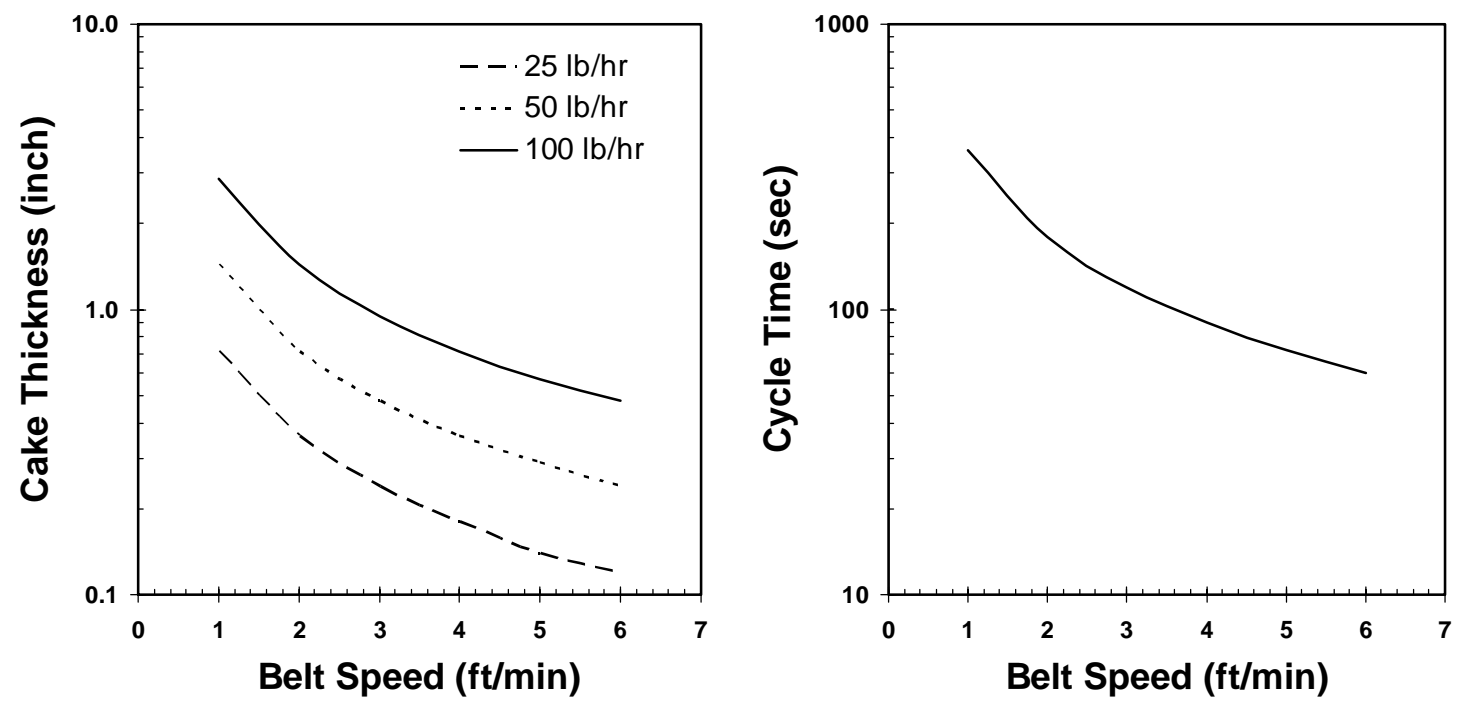

Figure 1. Expected range of operating conditions for the prototype bench-scale horizontal belt pressure filter (2-inch wide by 6-ft long).

(see Figure 1) An overview of the design features for the prototype has been provided in a previous technical project report. Important considerations included the design of the collection box, pressure seal, pressure chamber, and cake discharge system. Fabrication schematics for the bench-scale unit are attached as the final pages to this report.

All project tasks were temporarily placed on hold during the past four months due to delays associated with the fabrication of the bench-scale unit. These delays were created by problems associated with the breakdown of machine shop equipment and work stoppages created by an administrative postponement in replacing the skilled machinist originally dedicated to this effort. In light of this problem, a no-cost time extension was requested to provide the time necessary to resolve these problems. No project funds were expended during the work stoppage. The aforementioned problems responsible for the delays have now been successfully corrected and construction activities are now being restarted for this project.

\section{SUMMARY}

The basic design of a prototype horizontal belt pressure filter has been completed. The 2-inch wide by 6-ft long prototype has been designed to provide a throughput capacity of up to $100 \mathrm{lb} / \mathrm{hr}$ of dry solids. Unfortunately, problems associated with machine shop equipment and personnel caused a temporary delay in completing the construction of this prototype. These problems have now been resolved and work is now underway to procure the necessary construction materials and to complete the fabrication of the test unit. 


\section{FUTURE WORK}

Work during the next reporting period will focus primarily on the completion of construction activities. The machine work is expected to require approximately 3 months of dedicated shop time to complete. Shakedown tests will begin immediately after the construction work is finished. This work will be followed by a detailed test program and economic evaluation. The detailed test program will include a study of key operating variables including feed flow rate, feed solids content, feed size distribution, filter belt speed, filter cloth mesh size, and applied pressure.

\section{REFERENCES}

“Advances in Solid-Liquid Separation,” (H. Muralidhara, Ed.), Distributed by the Royal Society of Chemistry, Burlington House, London, England, Battelle Press Publishing, Columbus, Richmond, England, 1986, 485 pp.

“SME Mineral Processing Handbook,” (N. Weiss, Ed.), American Institute of Mining, Metallurgical, and Petroleum Engineers, Inc., Kingsport Press Publishers, Kingsport, Tennessee, 1985, pp. 9-14-9-26.

\section{PUBLICATIONS/PRESENTATIONS} period.

None publications or presentations have been given during the current reporting 


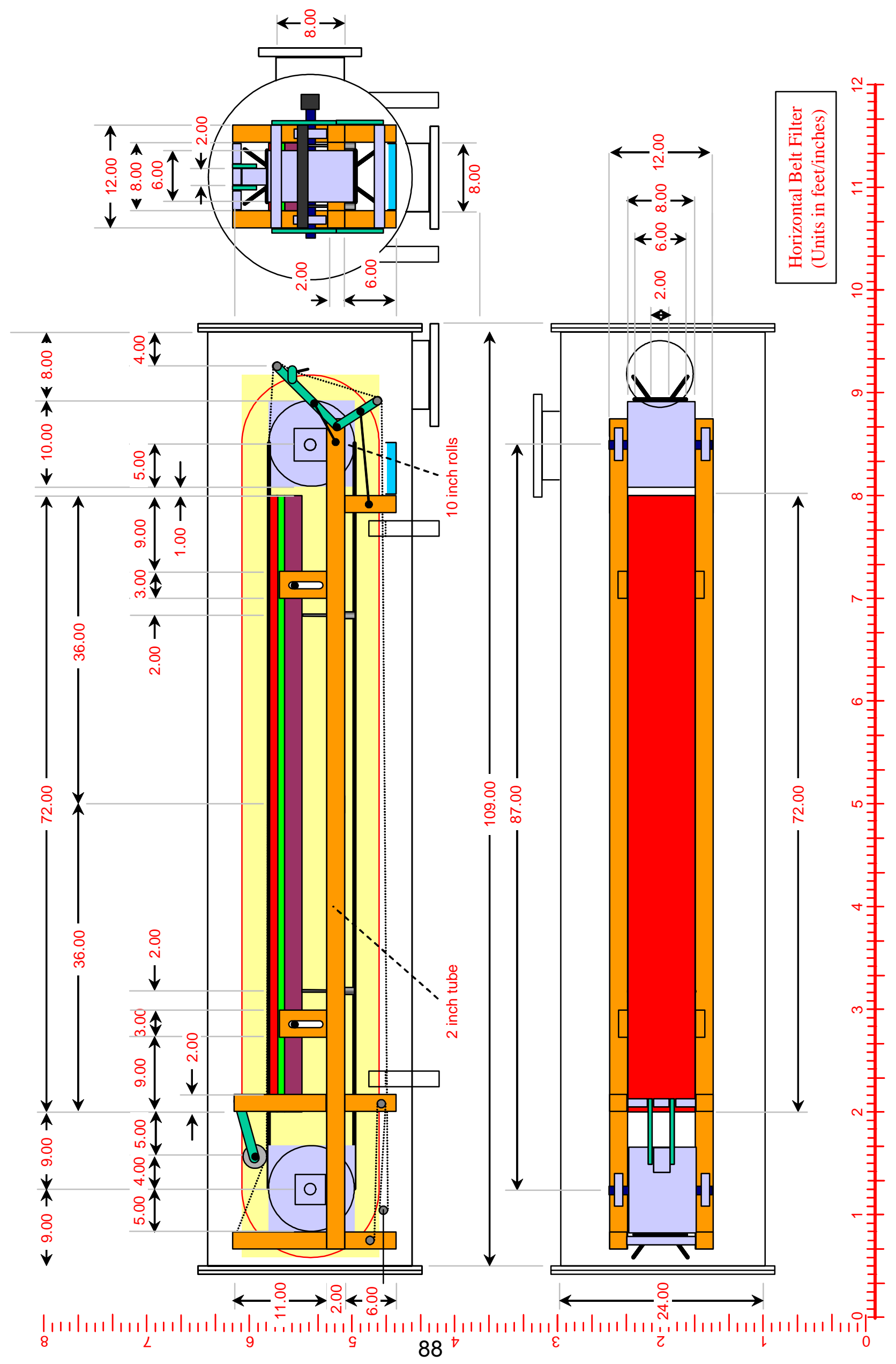


Appendix H: UT002 - Bio-Assisted Heap Leaching of Nickel Laterites for the Development of a Domestic Nickel Industry 
The project was terminated early and a Final report is to be issued. 


\section{Appendix I: MT001 - The Development and Utilization of Alkaline Sulfide Leaching and Recovery of Gold}




\section{TECHNICAL PROGRESS REPORT}

Contract Title and Number:

Crosscutting Technology Development at the Center for

Advanced Separation Technologies

(DE-FC26-02NT41607)
Period of Performance:

Starting Date: Apr. 1, 2003

Ending Date: Sept. 1, 2005
Sub-Recipient Project Title:

DEVELOPMENT OF ALKALINE SULFIDE

LEACHING AND RECOVERY OF GOLD

Principal Investigators:

Corby Anderson

Larry G. Twidwell

Contact Address:

Room 221, ELC Building

1300 West Park Street

Butte, MT 59701-8997

Subcontractor Address:

"No subcontracts issued."
Report Information:

Type: Semi-Annual

Number: 3

Period: $\quad$ Apr. 1 - Sept. 30

Date: Sept. 30, 2004

Code: $\quad$ MT001

Contact Information:

Phone: (406) 496-4794

Fax: $\quad$ (406) 496-4512

E-Mail: canderson@mtech.edu

Subcontractor Information:

Phone:

Fax:

E-Mail:

\section{ABSTRACT}

Progress was made in all aspects of the proposed tasks during this reporting period. Specifically, progress was made determining the optimum leaching conditions (Task 2) and characterizing the leaching system kinetics (Task 3). These tasks were completed predominantly by using a quartz crystal microbalance set to monitor the gold leaching rate. Additionally, leaching tests to verify the repeatability of leaching and solution treatment tests were performed.

\section{INTRODUCTION}

\section{Background}

An alternative, non-cyanide gold leaching process based on the use of environmentally benign sulfur compounds as both the oxidant and lixiviant components of the leach solution is currently underdevelopment. The use of non-cyanide reagents has become particularly relevant in light of recent public concerns involving the use of cyanide for gold production. Furthermore, the development of an alkaline sulfide based leaching processes is particularly well suited for treatment of sulfide gold ores pretreated with low 
temperature pressure oxidation whereby the majority of gold tends to accumulate in the elemental sulfur produced. Additional potential advantages of this process include the production of value added byproducts and improved public perception of gold mining through the use of an environmentally benign leaching process.

The technological issues that are currently hindering the use of alkaline sulfide leaching are a lack of basic understanding of the leaching chemistry and thermodynamics associated with the process. Thus, this study was undertaken to develop an understanding of the basic reaction chemistry which occurs in the alkaline sulfide leaching process and to establish a thermodynamic model in order to predict optimum leaching conditions under various conditions.

\section{Objectives and Approach}

The objectives of this project:

\section{Phase I/Year 1}

- Task 1 - Develop a thermodynamic model of the alkaline sulfide leaching system;

- Task 2 - Optimize the chemistry of the alkaline sulfide gold leaching process; and,

- Task 3 - Study the optimized leaching system kinetics.

Phase II/Year 2

- Task 1 - Recovery of gold from an alkaline sulfide solution;

- Task 2 - Production of sodium sulfate as a treatment method for alkaline sulfide solutions; and,

- Task 3 - Application of the alkaline sulfide leaching system to refractory gold ores and concentrates.

The general approach taken for accomplishing Task 1 consisted of performing a literature search for relevant thermodynamic data. Once the appropriate thermodynamic data were compiled, they were modeled with STABCAL, a thermodynamic modeling program. Because a majority of the data were compiled at $25^{\circ} \mathrm{C}$ or $30^{\circ} \mathrm{C}$ modeling at elevated temperatures will be performed by calculating the free energies with the Helgeson-KirkhamFlowers (HKF) Equations of State or the Criss-Cobble Correspondence Principle. Optimized gold leaching conditions are being developed as part of Task 2. Statistically designed experiments are being used in order to efficiently find conditions conducive to producing an alkaline sulfide lixiviant that is both stable and rapidly leaches gold. A quartz crystal microbalance equipped with a gold coated quartz crystal was also used for developing optimized gold leaching conditions. The kinetic aspects of the optimized gold leaching conditions are being evaluated by analyzing the gold concentration as a function of time while conducting the lixiviant optimizing experiments. The data collected with the quartz crystal microbalance is also being used to characterize the kinetics of the leaching system. 


\section{PROJECT TASKS}

\section{Task 2 (Phase I)}

Experiments were performed using a quartz crystal microbalance (QCM) to help elucidate the optimum conditions for the alkaline sulfide leaching system. The QCM set-up enables quantitative monitoring of the amount of gold that is leached by measuring the change in frequency associated with the change in weight of a quartz crystal coated with gold. The primary advantage of the QCM is the ability to collect only gold leaching data, thereby isolating the leaching reaction from other electrochemical reactions that may occur in traditional electrochemical tests. Several experiments were conducted and the following parameters were studied:

- $\quad$ sulfide concentration (0.25M to $2.0 \mathrm{M})$;

- hydrosulfide concentration (0.0 to $2.0 \mathrm{M})$;

- polysulfide concentration (adjusted by varying the sulfur concentration from 0.0 to 3.0M);

- hydroxide concentration (0.0 to 3.0M);

- temperature $\left(30^{\circ} \mathrm{C}\right.$ to $\left.60^{\circ} \mathrm{C}\right)$; and,

- gold purity (adjusted by adding $2 \%$ to $5 \%$ by weight silver).

Figure 1 shows the effect of increasing the sulfide concentration on the ability of the alkaline sulfide system to leach gold. As the sulfide concentration is increased, a greater amount of gold is leached at lower potentials. Similarly, (as shown in Figure 2) the addition of sodium hydroxide to the alkaline sulfide leaching system results in a greater amount of gold dissolution at lower potentials. It is important to note that the current flow is calculated from the measured change in mass of the gold coated quartz crystal.

Experiments were also performed to verify the repeatability of the leaching tests. The results from one series of experiments are presented in Table I. From the data presented in Table I, a percent difference of $12 \%$ was calculated based on the maximum and minimum average trial values relative to the minimum average trial value (Trial \#3).

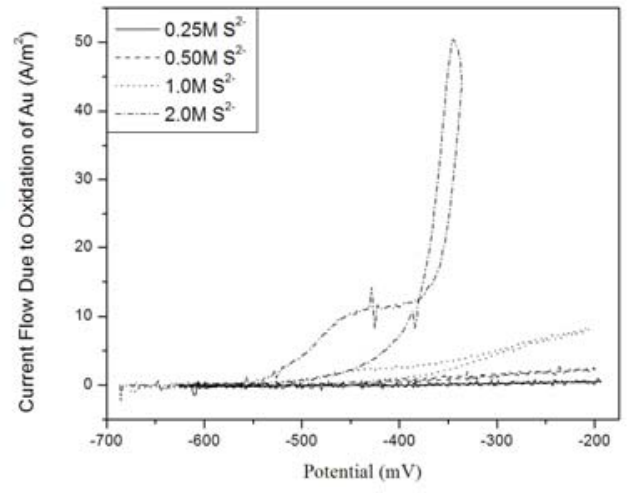

Figure 1. Plot showing the calculated current flow as a function of potential at different sulfide concentrations.

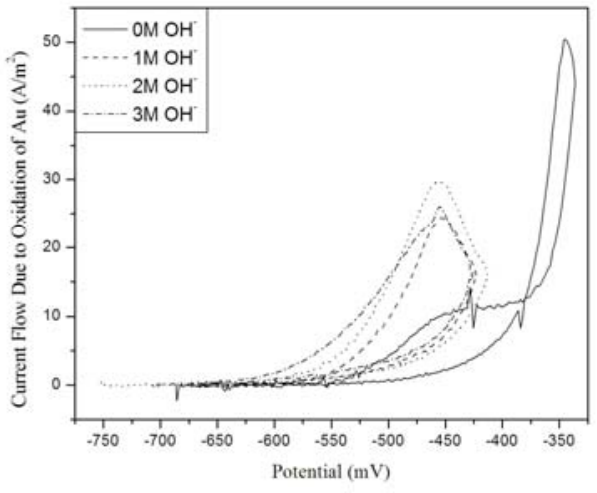

Figure 2. Plot showing the calculated current flow as a function of potential at different hydroxide concentrations. 
Table I. Results of Repeatability Leaching Test

\begin{tabular}{|l|r|r|r|}
\hline & \multicolumn{1}{|c|}{ Trial \#1 } & \multicolumn{1}{c|}{ Trial \#2 } & \multicolumn{1}{c|}{ Trial \#3 } \\
\hline & $(\mathrm{mg} / \mathrm{L})$ & $(\mathrm{mg} / \mathrm{L})$ & $(\mathrm{mg} / \mathrm{L})$ \\
\hline & 59.09 & 61.66 & 55.09 \\
\hline & 61.63 & 63.01 & 56.31 \\
\hline \hline & 61.83 & 62.72 & 55.64 \\
\hline Average & 60.85 & 62.46 & 55.68 \\
\hline
\end{tabular}

\section{Task 3 (Phase I)}

Experiments were performed to determine the effects various solution and temperature parameters had on the kinetics of the alkaline sulfide leaching system. The QCM was also used for this series of experiments because leaching data as a function of time could be collected. Figure 3 shows gold is leached faster as a result of increasing the sulfur concentration in the alkaline sulfide solution. Increasing the sulfur concentration increases the polysulfide concentration in the leaching solution. Thus, the enhanced leaching rate can be attributed to a greater polysulfide ion concentration. The plot shown in Figure 4 shows that increasing the leaching temperature from $30^{\circ} \mathrm{C}$ to $40^{\circ} \mathrm{C}$ has a minimal effect on the leaching rate. However, increasing the temperature to $50^{\circ} \mathrm{C}$ resulted in a dramatically increased leaching rate. Based on these results, further gold leaching experiments at higher temperatures are planned.

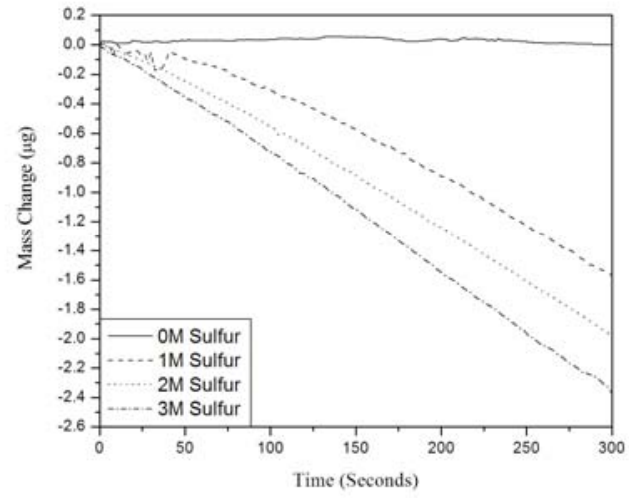

Figure 3. Plot showing the change in mass of the gold coated quartz crystal as a function of time at different sulfur concentrations.

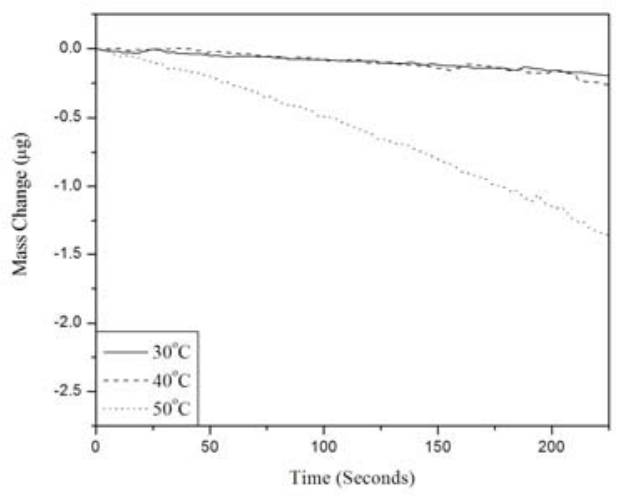

Figure 4. Plot showing the change in mass of the gold coated quartz crystal as a function of time at different temperatures.

\section{SUMMARY}

During this reporting period, progress was made on both Task 2 (Phase I) and Task 3 (Phase I). Data that allowed optimization of alkaline sulfide leaching system chemistry and characterized the kinetics of the alkaline sulfide leaching system were collected with a quartz crystal microbalance. It was found that increasing either the sulfide or hydroxide 
concentration resulted in greater amounts of gold dissolution at lower potentials. Additionally, it was found that increasing the polysulfide ion concentration in the alkaline sulfide solution (by adding sulfur) resulted in faster leaching rates. The gold leaching rate was characterized at different temperatures. Increasing the temperature to $50^{\circ} \mathrm{C}$ resulted in a significant increase in the gold leaching rate. Thus, further leaching experiments at higher temperatures utilizing the quartz crystal microbalance are planned.

\section{FUTURE WORK}

Work will begin on Phase II tasks during the next reporting periods. Some initial work on these tasks was performed in the previous reporting periods. Based on the positive results obtained, more work will be completed. In particular, work focusing on recovering gold from an alkaline sulfide solution with a modified carbon adsorption process, ion exchange, electrowinning, and reduction of gold by the addition of a reducing agent to the solution will be pursued in the next reporting period as part of Task 1/Phase II. Additionally, Task 2 (Phase II) objectives will be completed by performing high temperature/pressure oxidation of the alkaline sulfide solution in an autoclave followed by treatment of the solution with lime. Optimum conditions are expected to produce a sodium sulfate and gypsum product. Finally, work will be performed on leaching refractory gold ores and concentrates Task 3 (Phase II). The general approach that will be taken to accomplish Task 3 (Phase II) will consist of applying the optimum leaching conditions developed as part of Task 1 and Task 2 (Phase I).

\section{PUBLICATIONS/PRESENTATIONS}

In the past reporting period, parts of this research were presented at the Advances in Mineral Resources Management and Environmental Geotechnology conference in Hania, Greece. The presentation was titled "Alkaline sulfide hydrometallurgical recovery of gold utilizing on refractory ores and concentrates". Additionally, a paper covering the research presented was published in the conference proceedings. 
Appendix J: NV001 - Hydrometallurgical Processing of Chalcopyrite Concentrates 


\title{
TECHNICAL PROGRESS REPORT
}

Contract Title and Number:

Establishment of the Center for Advanced Separation

Technologies (DE-FC26-01NT41091)

Sub-Recipient Project Title:

Hydrometallurgical Processing of

Chalcopyrite Concentrates

Principal Investigators:

M. C. Fuerstenau

M. Misra

Contact Address:

Metallurgical and Materials Engineering

University of Nevada, Reno

Reno, NV 89557

Subcontractor Address:

University of Nevada, Reno

Reno, NV 89557
Period of Performance:

Starting Date: 4-1-03

Ending Date: 5-30-05

Report Information:

Type: Semi-Annual

Number: 3

Period: 4-1-04 to 10-1-04

Date: 9-16-04

Code: NV001-R01

Contact Information:

Phone: (775) 784-4310

Fax: (775) 327-5059

E-Mail:mcf@unr.edu

Subcontractor Information:

Phone: (775) 784-4312

Fax: (775) 784-6680

E: jerry_best@vpaf.unr.edu

\begin{abstract}
The effect of nanosize particles of silica in chalcopyrite leaching systems is being studied with two techniques: (1) leaching experiments as a function of various leaching parameters and (2) electrochemical impedance spectroscopy (EIS). Leaching experiments are presented showing the important effect of the presence of nanosize silica. Initial electrochemical impedance spectroscopic experiments have been conducted which shows that the sulfur layer that forms on chalcopyrite on leaching first increases in thickness with time and then decreases in thickness in the presence of nanosilica.
\end{abstract}

\section{INTRODUCTION}

Chalcopyrite $\left(\mathrm{CuFeS}_{2}\right)$ is the most abundant and important source of copper metal available in the earth's crust. Over the years considerable research has been devoted to developing hydrometallurgical processes for leaching copper sulfide concentrates, especially chalcopyrite, at moderate temperature and pressure. Impetus for this research has been the desire for an economical alternative to smelting with the attendant generation of sulfur dioxide. 
Widely-used oxidants for the leaching of chalcopyrite are ferric chloride and ferric sulfate in an acidic medium. The ferric chloride leaching reaction can be written as:

$$
\mathrm{CuFeS}_{2}+3.5 \mathrm{FeCl}_{3} \rightarrow 0.5 \mathrm{CuCl}_{2}+0.5 \mathrm{CuCl}+4.5 \mathrm{FeCl}_{2}+\mathrm{S}^{\mathrm{o}}
$$

In sulfuric acid solutions containing ferric sulfate, the reaction is:

$$
\mathrm{CuFeS}_{2}+4 \mathrm{Fe}^{3+} \rightarrow \mathrm{Cu}^{2+}+5 \mathrm{Fe}^{2+}+2 \mathrm{~S}^{0}
$$
sulfur:

In ammoniacal solution the reaction is seen to produce thiosulfate and elemental $\mathrm{CuFeS}_{2}+4 \mathrm{NH}_{3}+6 \mathrm{OH}^{-} \rightarrow \mathrm{Cu}\left(\mathrm{NH}_{3}\right)_{4}{ }^{2+}+1 / 2 \mathrm{~S}_{2} \mathrm{O}_{3}{ }^{2-}+\mathrm{S}^{\mathrm{o}}+\mathrm{Fe}(\mathrm{OH})_{3}+3 / 2 \mathrm{H}_{2}+7 \mathrm{e}$

The sulfur layer that forms on the surface of the chalcopyrite in all of these reactions is passivating and highly protective. The limited leaching response of chalcopyrite under these conditions is due to the passive sulfur layer formation. To increase recovery investigators have tried a number of methods. Munoz et al. (1979) reduced the chalcoypyrite particle size to four microns and achieved about $60 \%$ recovery at $90^{\circ} \mathrm{C}$, $1200 \mathrm{rpm}$ and $1.0 \mathrm{M}$ sulfuric acid. When the particle size was increased to 12 microns, leaching had to be conducted for 100 hours to achieve about the same recovery.

One of the most successful techniques was developed by Miller (1979) using silver catalysis. Recovery was almost $100 \%$, but the economics of using silver to extract copper precludes its use.

Ozone oxidation was tried by Halvik and Skrobian (1990). Again, this process has poor economics and has not been commercialized. Electrochemical oxidation has been tried using chalcopyrite as an anode (Illangovan et al., 1975). This has also not been successfully applied.

\section{Objective and Approach}

The objective of this investigation is to establish conditions under which chalcopyrite can be leached effectively at moderate temperature and pressure. A technique has been developed at the University of Nevada, Reno, that shows great promise for processing at moderate conditions. This involves the addition of nanosize silica to the leaching systems. Two approaches will be used in this investigation: leaching of sized particles of chalcopyrite and electrochemical impedance spectroscopy.

\section{Leaching of Chalcopyrite}

Leaching studies are being carried out with various oxidants, ferric chloride, ferric sulfate and hydrogen peroxide in the absence and presence of nanosilica. Temperatures have been varied from $60^{\circ}$ to $90^{\circ} \mathrm{C}$. 


\section{Electrochemical Impedance Spectroscopic Characterization}

A Schlumberger Model SI 1286 electrochemical interface connected to a Schlumberger Model SI 12650 Gain Phase Analyzer, controlled by a computer, is being used to study the electrochemical reaction of silica-catalyzed chalcopyrite leaching. Polished chalcopyrite samples are attached to a platinum wire using conductivity silver epoxy. Electrochemical experiments are being conducted with various oxidants, silica concentrations and $\mathrm{pH}$.

\section{PROJECT TASKS}

\section{Leaching Experiments}

Leaching of chalcopyrite mineral and flotation concentrate was conducted under a variety of experimental conditions. Ferric chloride, ferric sulfate, and hydrogen peroxide were added as oxidants, and additions of nanosilica, ethylene glycol, sodium chloride and sodium nitrate were made to systems at various pulp densities and temperatures. Examples of some of these results are presented in this report.

The effect of ethylene glycol additions with hydrogen peroxide as oxidant are shown in Table 1.

Table 1. Effect of ethylene glycol on dissolution of chalcopyrite with hydrogen peroxide as oxidant. Conditions: $1.25 \mathrm{~g} / \mathrm{L}$ chalcopyrite $(-37 \mu), 10 \mathrm{ml} / \mathrm{L} \mathrm{H}_{2} \mathrm{O}_{2}, 400-\mathrm{ml} / \mathrm{L}$ $0.5 \mathrm{~N} \mathrm{H}_{2} \mathrm{SO}_{4}, \mathrm{~T}=65^{\circ} \mathrm{C}$, 5-hr leaching.

$\begin{array}{cc}\begin{array}{c}\text { Ethylene Glycol Addition } \\ (\mathrm{ml} / \mathrm{L})\end{array} & \begin{array}{c}\text { Chalcopyrite Dissolution } \\ (\%)\end{array} \\ 0.25 & 20.0 \\ 0.75 & 35.9 \\ 2.50 & 53.1 \\ 5.00 & 57.7 \\ & 59.3\end{array}$

As can be noted, dissolution is increased as the content of ethylene glycol is increased. When the surface of chalcopyrite was scanned with an electron microscope in the presence of hydrogen peroxide as oxidant, a film of sulfur was present on the chalcopyrite surface. When ethylene glycol was added to this system, aggregates of sulfur were noted on the chalcopyrite surface. See Figures 1 and 2.

The beneficial effect of additions of nanosize silica on chalcopyrite dissolution with hydrogen peroxide as oxidant was presented in Progress Report (10-1-03 to 4-31-04). The addition of nanosilica also accelerates chalcopyrite dissolution with ferric chloride or ferric sulfate as oxidant. These data are presented in Figures 3 and 4. 
Sodium nitrate has also been found to increase the rate of chalcopyrite dissolution with both ferric chloride and ferric sulfate as oxidants. These results are listed in Table 2.

Table 2. Effect of sodium nitrate on chalcopyrite dissolution in the presence of ferric sulfate. Conditions:5.0 g/L chalcopyrite concentrate $(-37 \mu)$ 200-ml $0.5 \mathrm{~N} \mathrm{H}_{2} \mathrm{SO}_{4}, 30 \mathrm{~g} / \mathrm{L}$ $\mathrm{Fe}_{2}\left(\mathrm{SO}_{4}\right)_{3}, 17.1 \mathrm{~g} / \mathrm{L}$ nanosilica, $75^{\circ} \mathrm{C}$, 24-hr leaching.

$\begin{array}{cc}\begin{array}{c}\text { Sodium Nitrate Addition } \\ \underline{\mathrm{M}}\end{array} & \begin{array}{c}\text { Chalcopyrite Dissolution } \\ \mathbf{0}\end{array} \\ 0.05 & 31.1 \\ 0.10 & 58.3 \\ \end{array}$

Scanning electron microscopy examination has not been conducted on single large particles of chalcopyrite under these conditions to establish whether phenomena similar to that observed with peroxide and glycol are occurring. It is expected, though, that nitrate additions probably affect the morphology of the sulfur layer formed on the chalcopyrite surface during oxidation.

\section{SUMMARY}

When chalcopyrite is leached with oxidants in acidic medium, sulfur forms as an oxidation on the chalcopyrite surface which inhibits dissolution in a number of systems. The addition of nanosize silica, ethylene glycol and sodium nitrate apparently change the morphology of the sulfur, and dissolution is enhanced at moderate temperature and pressure. Important developments in this time period are the enhancement in dissolution of chalcopyrite that are obtained when ethylene glycol and sodium nitrate are added to these leaching systems.

\section{FUTURE WORK}

Leaching experiments will be continued as a function of chalcopyrite particle size, temperature, oxidant concentration, silica concentration and degree of agitation to establish the reaction kinetics.

Electrochemical impedance spectroscopic measurements will be continued to establish impedance, conductivity and electrochemical parameters and compared with leaching data to determine the roles of silica, ethylene glycol and sodium nitrate leaching of chalcopyrite. 


\section{PUBLICATION}

The paper entitled,” Chalcopyrite Leaching at Moderate Temperature and Ambient Pressure in the Presence of Nanosize Silica,” is in press in Minerals Engineering.

\section{REFERENCES}

Havlik, T., and Skrobian M., 1990, Can. Met. Quart. Vol. 29, p. 133.

Illingovan, S., Nagaraj, D. R., and Vasu, K. I., 1975, J. of Electrochem. Society of India, vol. 24, p. 22.

Miller, J. D., and Portillo, H. Q., 1979, Proceedings of the XIII International Mineral Processing Congress, J. Laskowski, ed., Poland, p. 691.

Munoz, P. B., Miller, J. D., and Wadsworth, M. E., 1979, Metallurgical Transactions B, Vol. 10B, p. 149. 


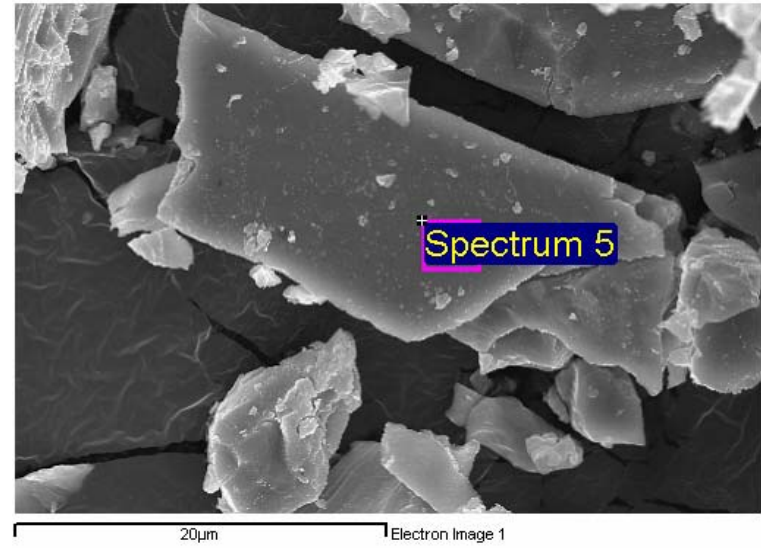

Figure 1. Micrograph of chalcopyrite. $10 \mathrm{ml} / \mathrm{L} \mathrm{H}_{2} \mathrm{O}_{2}$; no glycol

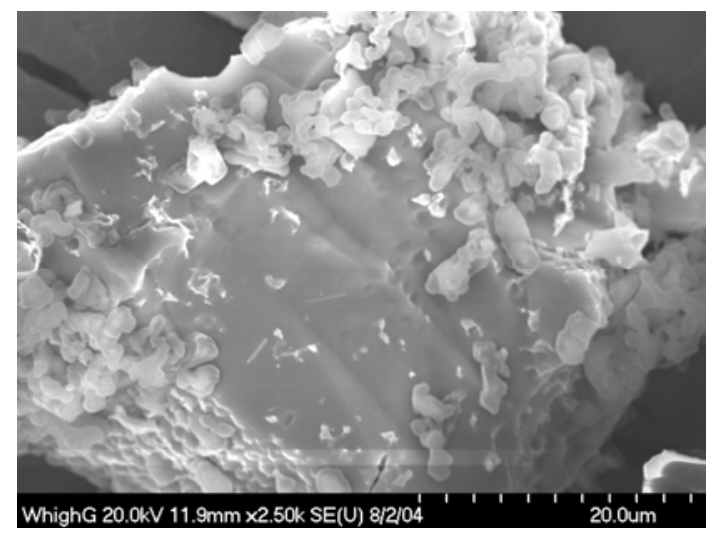

Figure 2. Micrograph of chalcopyrite. $40 \mathrm{ml} / \mathrm{L} \mathrm{H}_{2} \mathrm{O}_{2} ; 1.25 \mathrm{ml} / \mathrm{L}$ glycol

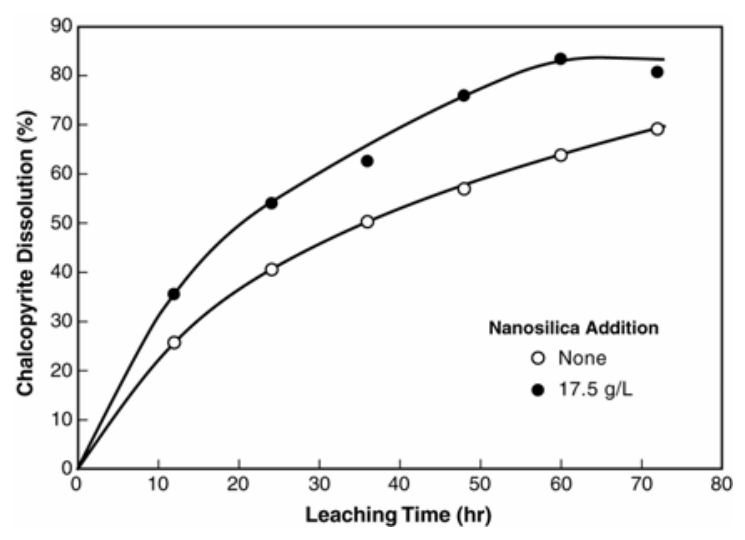

Figure 3. Chalcopyrite concentrate dissolution as a function of time and nanosilica addition. $30 \mathrm{~g} / \mathrm{L} \mathrm{FeCl}_{3}$

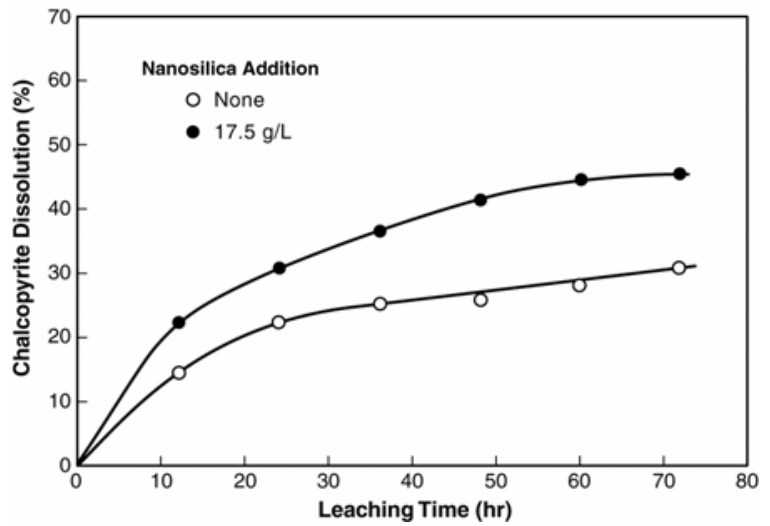

Figure 4. Chalcopyrite concentrate dissolution as a function of time and nanosilica addition. $30 \mathrm{~g} / \mathrm{L} \mathrm{Fe}_{2}\left(\mathrm{SO}_{4}\right)_{3}$ 


\begin{abstract}
Appendix K: MT002 - Simultaneous Electrolysis of Copper and Ferrous Ions to Produce Copper Cathode and to Regenerate Ferric Sulfate - The Lixiviant to Dissolve Copper Sulfide Minerals
\end{abstract}




\section{TECHNICAL PROGRESS REPORT}

Contract Title and Number:

Crosscutting Technology Development at the Center for

Advanced Separation Technologies

(DE-FC26-02NT41607)
Period of Performance:

Starting Date: Apr. 1, 2003

Ending Date: Sept. 1, 2005
Sub-Recipient Project Title:

SIMULTANEOUS COPPER CATHODE PRODUCTION AND FERRIC SULFATE REGENERATION

Principal Investigators:

Courtney Young

Hsin-Hsuing Huang

Contact Address:

ELC Building Room 215

1300 West Park Street

Butte, MT 59701-8997

Subcontractor Address:

"No subcontracts issued."
Report Information:

Type: Semi-Annual

Number: 3

Period: $\quad$ Apr. 1 - Sept. 30

Date: $\quad$ Sept. 30, 2004

Code: $\quad$ MT002

Contact Information:

Phone: (406) 496-4158

Fax: $\quad$ (406) 496-4664

E-Mail: cyoung@mtech.edu

Subcontractor Information:

Phone:

Fax:

E-Mail:

\section{ABSTRACT}

Work was completed on several aspects of the proposed project. Progress was made designing, constructing, testing, and characterizing membrane separated electrolytic cells. Specifically, a new cell that allowed easy membrane and anode changes was constructed and characterized. It was found that high area surface anodes were important to obtain high cell current densities. Preliminary experiments were completed leaching copper concentrate with an acidic ferric sulfate solution. A no-cost extension was granted for year 1 which enabled advancement of all year 1 objectives. Thus, year 2 objectives began Sept 1 .

\section{INTRODUCTION}

\section{$\underline{\text { Background }}$}

An integrated closed-circuit process for treating copper sulfide minerals based on acidic ferric leaching and the subsequent electrolytic recovery of copper is being developed as an alternative low cost method for copper production. The process is based on the simultaneous recovery of copper and regeneration of ferric ions using a membrane separated electrolytic cell divided into an anolyte and catholyte compartment. 
In a conventional copper electrowinning cell, the cathodic reaction is the electrodeposition of copper on a stainless steel or copper starting sheet and the anodic reaction is the dissociation of water into hydrogen ions and oxygen resulting in the production of acid as described by the following electrochemical half-cell reactions:
Cathodic reaction:
$\mathrm{Cu}^{2+}+2 \mathrm{e}^{-} \rightarrow \mathrm{Cu}^{\circ}$
$\mathrm{E}_{\text {cath }}^{\mathrm{o}}=0.337 \mathrm{~V}$
Anodic reaction:
$2 \mathrm{H}_{2} \mathrm{O} \rightarrow 4 \mathrm{H}^{+}+\mathrm{O}_{2}+4 \mathrm{e}^{-}$
$\mathrm{E}_{\text {anod }}^{\mathrm{o}}=1.229 \mathrm{~V}$

From the half-cell reactions, an overall theoretical cell voltage of $0.892 \mathrm{~V}$ was calculated.

Alternatively, the electrochemical reactions occurring in the proposed electrolytic cell would result in the deposition of copper on a stainless steel or copper starting sheet and the oxidation of ferrous ions, produced from the reduction of ferric ions during leaching of the copper sulfide minerals, to ferric ions for recycle as a lixiviant for the dissolution of copper sulfide minerals. The following electrochemical half-cell reactions describe the reactions that would occur in an electrolytic cell separated into an anolyte and catholyte compartment with an ion exchange membrane:
Cathodic reaction:
$\mathrm{Cu}^{2+}+2 \mathrm{e}^{-} \rightarrow \mathrm{Cu}^{0}$
$\mathrm{E}^{\mathrm{o}}{ }_{\mathrm{C}}=0.337 \mathrm{~V}$
Anodic reaction:
$2 \mathrm{Fe}^{2+}+\rightarrow 2 \mathrm{Fe}^{3+}+2 \mathrm{e}^{-}$
$\mathrm{E}_{\mathrm{a}}^{\mathrm{o}}=0.771 \mathrm{~V}$

A theoretical cell voltage of $0.434 \mathrm{~V}$ was calculated when the oxidation of ferrous ions is the anodic reaction compared to $0.892 \mathrm{~V}$ when the dissociation of water is the anodic reaction. Thus, the proposed cell would offer a net reduction in the cell potential of $0.458 \mathrm{~V}$.

\section{Objective and Approach}

The objective of this project is to develop an electrolytic cell divided into two compartments with an ion exchange membrane to allow the simultaneous regeneration of ferric ions and recovery of metallic copper (Year 1) and develop an optimized leaching and electrowinning process for the recovery of copper from copper sulfide minerals (Year 2).

The approach that will be taken to develop the proposed electrolytic cell follows the timetable outlined in the initial proposal. However, because of the extension, the objectives for this reporting period include:

- designing a membrane separated electrolytic cell;

- constructing membrane separated electrolytic cell;

- testing the membrane separated electrolytic cell; and,

- preliminary leach tests of copper concentrate with an acidic ferric sulfate solution.

\section{PROJECT TASKS}

\section{Task 1: Designing Membrane Separated Electrolytic Cell}

A new cell design was adopted due to the difficulty of replacing the membrane in the previously designed membrane separated electrolytic cells. The new cell design was based on an electrolytic cell composed of two parts. The cell was designed to be clamped together 


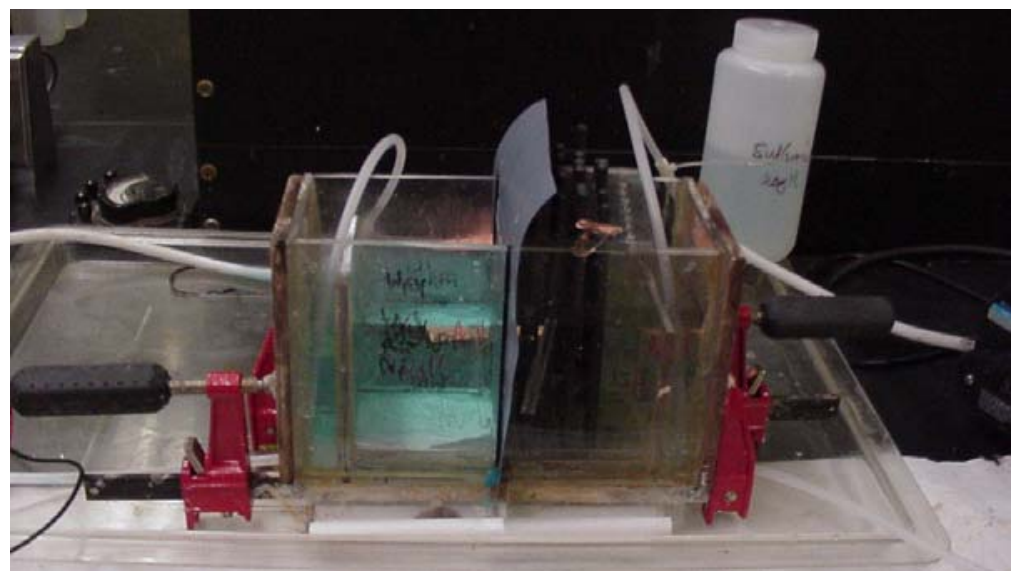

Figure 1. Digital image of the current generation membrane separated electrolytic cell.

with the membrane in between the cell halves. Thus, the membrane was used as a gasket to effectively seal the cell. The new design allowed much quicker membrane replacement and was conducive for performing experiments with different membranes. It is important to note that the two-part cell is designed to function in both continuous and batch operation modes.

\section{Task 2: Constructing the Membrane Separated Electrolytic Cell}

The two-part cell design was constructed from plexi-glass; a digital image of the cell is shown in Figure 1. Plexi-glass was used due to its resilience to an acid environment and because of its favorable fabrication properties. Square cordstock (similar to o-ring material except with a square profile) was used to form a seal between the plexi-glass cell-halves and the membrane. Bar clamps were used to press the membrane separated electrolytic cell halves together creating a watertight seal.

\section{Task 3: Testing and Characterizing of the Membrane Separated Electrolytic Cell}

Experiments were conducted to test and characterize the performance of the two-part membrane separated electrolytic cell. Parameters such as the initial ferrous ion concentration, membrane type, anode type, cathode type, cell agitation, and operating voltage were varied. The amount of current flowing through the cell was monitored as a function of time. From this data, current densities were calculated. Additionally, samples of anolyte and catholyte were collected as a function of time to calculate current efficiencies.

The current flowing through the cell and the ferrous ion concentration are shown plotted as a function of time in Figure 2 for one of the characterizing experiments performed with the two-part membrane separated electrolytic cell. Both the ferrous ion concentration and the current decrease linearly as a function of time. The current decrease was attributed to anodic polarization caused by the decrease in ferrous iron concentration. It should be noted that plot of the ferric ion concentration was also linear but it had a positive rather than negative slope.

Results from an experiment comparing the properties of a commercially available anionic membrane to a commercially available porous membrane are plotted in Figure 3. 


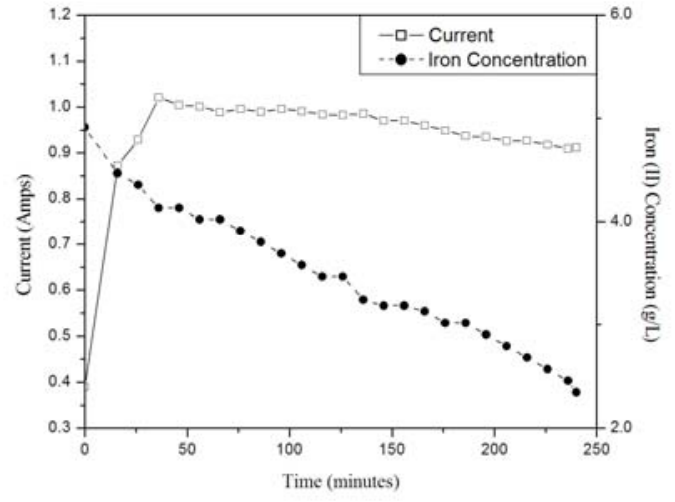

Figure 2. Plot of the current flowing through the membrane separated electrolytic cell and the corresponding decrease of ferrous ions in the anode compartment

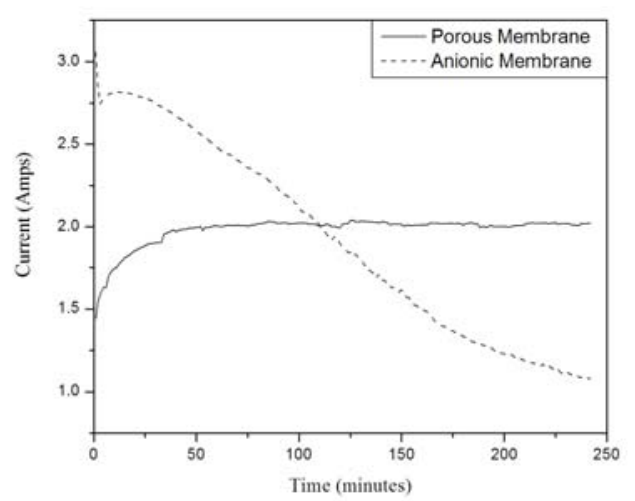

Figure 3. Plot of the current flowing through an electrolytic cell separated by a porous membrane and an anionic membrane.

Although the anionic membrane could sustain higher currents, the membrane tended to breakdown in the acidic sulfate solution. Thus, the porous membrane was adopted for further testing. However, it should be noted that testing of other membranes will be completed during the subsequent reporting periods.

Testing of different types of anode configurations/materials was performed with the two-part membrane separated electrolytic cell. Some of the results are plotted in Figure 4. Carbon rods wired in parallel produced the highest cathode current densities. It should be noted that new cathodes with identical surface areas were used for each test but the anode surface area varied when different anode materials were used. The results obtained from this series of experiments support the theory that high surface area anodes will be required to produce acceptable current densities.

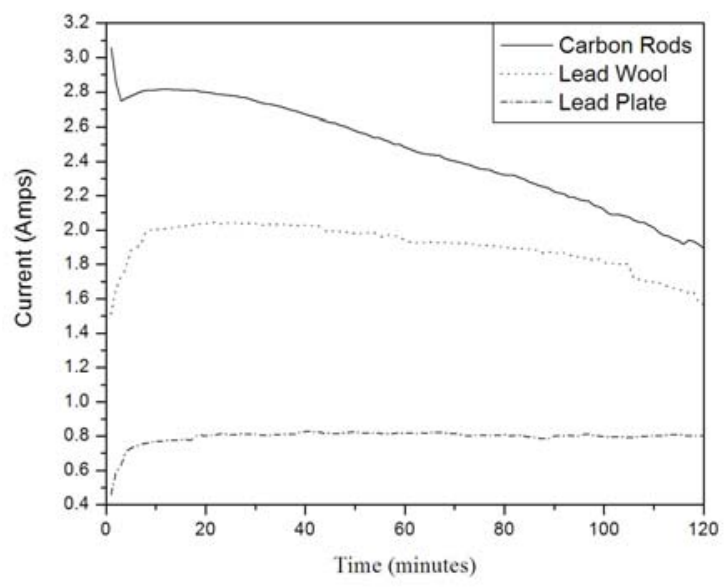

Figure 4. Plot of the current flow in a membrane separated electrolytic cell equipped with different types of anodes. 


\section{Task 4: Preliminary Copper Concentrate Leaching Test}

Preliminary copper concentrate leaching tests were performed. A column type reactor was initially tried in an up-flow and down-flow configuration, but the fineness of the concentrate made the use of a column type reactor unfeasible. Thus, an agitated leaching reactor consisting of a sealed flask, magnetic stir bar, and a magnetic stirrer were used for the copper concentrate leaching tests. More copper was leached from the copper concentrate when it was leached with an acidic sulfate solution that contained ferric ions compared to an acidic sulfate solution that did not contain ferric ions.

\section{SUMMARY}

A new, two-part membrane separated electrolytic cell was designed and constructed this reporting period. The new cell allowed rapid changing of the membrane and resulted in more efficient and reliable experimentation. Several different electrolytic cell parameters were varied including ferrous concentration, anode type, cathode type, and membrane type. The experimental results indicated that the anode type/surface area had a tremendous effect on the cathode current density and that the anodic reactions were the current limiting reactions when a catholyte solution containing typical industry amounts of copper were tested in the cell. The greatest cathode current densities obtained to date were produced when graphite anodes were used. Additionally, comparison of a commercially available anionic exchange membrane to a commercially available porous membrane showed greater current densities could be obtained with the anionic exchange membrane. However, the short life span of the anion exchange membrane in the highly acidic environment would preclude its use in an industrial environment. Preliminary copper concentrate leach tests showed an enhanced leaching rate due to the presence of ferric ions in the acidic sulfate leaching solution. Based on these positive results, further tests are planned with a goal of running a closed circuit leaching/membrane separated electrowinning process to recover copper from both copper sulfide concentrates and ores.

\section{FUTURE WORK}

During the next reporting period further characterization studies will be completed. The experiments will continue to focus on optimizing the current density and current efficiency obtained from the cell. The effect of temperature, anode type, acid concentration, iron concentration, copper concentration, solution flow rate, and membrane life will also be characterized. Comprehensive ore and concentrate leaching studies, utilizing materials obtained from a local copper mine, will also commence to determine the optimum conditions for leaching the copper from sulfide minerals. Additionally, work on a rotating cylinder membrane separated electrolytic cell will also be completed during the next reporting period through collaborative effort with James Cook University in Australia. 
Appendix L: NM002 - Ion Exchange Recovery of Cobalt from Copper Leach Solutions 


\section{TECHNICAL PROGRESS REPORT}

Contract Title and Number: Crosscutting Technology Development at the Center for Advanced Separation Technologies (DE-FC26-02NT41607)

Sub-Recipient Project Title: Ion Exchange Recovery of Cobalt from Copper Leach Solutions

Principal Investigators:

I. Gundiler and M. Hatch

Contact Address:

New Mexico Tech

Bureau of Geology \& Min. Res.

801 Leroy Place

Socorro, NM 87801

Subcontractor Address:

"No subcontracts issued."
Period of Performance:

Starting Date: April 1, 2003

Ending Date: $\quad$ May 30, 2005
Report Information:

Type: Semi-Annual

Number: 3

Period: $\quad$ 04/01/04-09/30/04

Date: $\quad$ 10/06/04

Code: $\quad$ NM002-R03

Contact Information:

Phone: (505) 835-5730

Fax: (505) 835-6333

E-Mail: gundiler@gis.nmt.edu

\section{ABSTRACT}

Two new chelating ion exchange resins have been prepared. The first resin is a highly picolylated diethylenetriamine (CHEL-38) resin. The second resin is a less picolylated diethylenetriamine resin (CHEL-40). These new resins have a somewhat macroporus gel type structure. The resins absorb $\mathrm{Cu}^{2+}$ and $\mathrm{Co}^{2+}$ from weakly acidic $\mathrm{H}_{2} \mathrm{SO}_{4}$ solutions. Moreover, these resins have as good absorption capacities for $\mathrm{Cu}^{2+}$ and they absorb $\mathrm{Co}^{2+}$ better then the commercially available Dow picolylamine type resin, while not absorbing $\mathrm{Fe}^{3+}$ as strongly. In addition, these new resins are stripped and regenerated readily with 1 or 2 M sulfuric acid.

\section{INTRODUCTION}




\section{Background}

Cobalt is a strategic and critical metal which is used in production of super alloys for use in jet engine turbines, wear and corrosion resistant alloys, cutting tools, magnets, and various other alloys and chemicals. It is not mined or refined in the United States; therefore, $80 \%$ of the cobalt consumed in the U.S. is imported. The remaining balance is met with recycled alloys and supplies from stockpiles.

There is a readily available source of cobalt in the southwestern U.S. In the process of hydrometallurgical extraction of copper, leach solutions in large copper mining operations contain $0.03-0.10 \mathrm{Kg} / \mathrm{m}^{3}$ of cobalt. If only a fraction of cobalt can be recovered, New Mexico and eastern Arizona copper leach operations could potentially supply significant portion of the U.S. imports. Currently, the technology to recover the metal from these solutions economically is not available.

Ion exchange processes could recover cobalt present at low concentrations in large volumes of copper leach solutions, however, commercially available resins are either too expensive, or may not function in acidic solutions. Furthermore, solvent extraction process, which is universally used to recover copper from the leach solutions, is also under scrutiny due to large organic inventory involved in the process. Chelating ion exchange resins may also be considered as potential substitutes for the organic liquid extractants used for copper extraction to eliminate fire hazards and potential for ground water pollution.

\section{Objective and Approach}

The objectives of this project are the synthesis and evaluation of new types of chelating ion exchange resins which could potentially be lower priced than the

picolylamine resins, and be effective in absorbing $\mathrm{Cu}^{2+}$ and $\mathrm{Co}^{2+}$ from $\mathrm{pH} 1.5$ to $\mathrm{pH} 3$ solvent extraction raffinates of copper leach solutions.

In addition to three resins that were discussed in the previous report, two new resins now have been synthesized with the objective of increasing cobalt selectivity relative to 
copper, and decreasing the $\mathrm{Fe}^{3+}$ selectivity. These resins are (1) a highly picolylated diethylentriamine resin, and (2) a less picolylated diethylentriamine resin. Small laboratory scale synthesis of the new resins was made. Samples of these resins were then evaluated in small columns by loading and $\mathrm{H}_{2} \mathrm{SO}_{4}$ elution for copper, cobalt, and iron containing solutions at $\mathrm{pH} 1.1$ and $\mathrm{pH} 1.7$.

\section{PROJECT TASKS}

Presently, there are two tasks for this project. They are, 1) to make small samples of the proposed new chelating resins, 2) to run screening tests on these resins with $\mathrm{Cu}$, $\mathrm{Co}$ and Fe containing solutions. These current tasks now have largely been accomplished for the two new picolylated diethylene triamine resins. Standard laboratory ware, heating and stirring equipment, were used in the small-scale preparation of these resins under a chemical hood, as needed. The abilities of these resins for absorption of copper, cobalt and iron were evaluated by small columns performance tests, in comparison with similar mesh-sized commercial resins (Dow) and the original diethylene triamine

\section{Experimental Results:}

The two new resins were synthesized from very finely divided samples of the diethylenetriamine resin, which was made by as described in the previous report. The highly picolylated diethylenetriamine resin (I) was prepared by overnight heating at about $45^{0} \mathrm{C}$ of a stirred slurry in water / ethanol mixture of filtered water-swollen polyamine resin picolylchloride-hydrochloride salt and sodium bicarbonate in weight ratios of approximately 1.0 / 0.65 / 1.7. The less picolylated diethylene triamine resin (II) was made in a similar procedure but using respective weight ratios of about $1.0 / 0.34$ / 1.6 of the reactants as given above.

Small column absorption tests in duplicate were conducted with two new resins in comparison with tested on finely divided commercially resins. The highly picolylated 
(CHEL-38) and less picolylated (CHEL-40) diethylenetriamine resins that were synthesized in our laboratories, and the commercially available Dow resins were hydroxypropyl picolyl amine resin (HPPR), and bis-picolylated polyamine resin (DPAR), which we finely subdivided also. All the resins were water washed and then separately loaded with the test solutions after limited water washing, all the columns except bispicolylamine resin were eluted with $1 \mathrm{M}$ or $2 \mathrm{M} \mathrm{H}_{2} \mathrm{SO}_{4}$. The bis-picolyl amine resin required aqueous ammonia solution for elution. Total absorbed copper ion and cobalt ion concentrations of all eluates were determined separately. These results are tabulated in Tables 1, 2 and 3. Table 1 shows the results for copper and cobalt feed solutions at 38 ppm and $\mathrm{pH} 1.7$.

Using the higher capacity resins (HPPR, CHEL-38, and CHEL-40), column tests were conducted with $190 \mathrm{ppm}$ solutions and at $\mathrm{pH}$ 1.7, and at $\mathrm{pH}$ 1.1. Performance of these resins for copper, cobalt and iron are tabulated in Tables 2. and 3.

For easy comparison, the performance data for all tests is shown in Table-A1, including tests on the carboxymethylated diethylenetriamine resin (CM-DER), which were given in the previous report.

Table-1. Absorption capacity of chelating IX resins for copper (II) and cobalt (II)

\begin{tabular}{|c|l|l|l|l|l|l|}
\hline Resin & $\begin{array}{l}{\left[\mathrm{Cu}^{2+}\right]} \\
{\left[\mathrm{Co}^{2+}\right]} \\
\mathrm{PPM}\end{array}$ & $\begin{array}{l}\mathrm{H}_{2} \mathrm{SO}_{4} \\
\mathrm{ml} / \mathrm{L}\end{array}$ & $\mathrm{H}_{2} \mathrm{SO}_{4} \mathrm{M}$ & $\mathrm{pH}$ & $\begin{array}{c}\text { Capacity } \\
\mathrm{mg} / \mathrm{ml} \\
{\left[\mathrm{Co}^{2+}\right]}\end{array}$ & $\begin{array}{c}\text { Capacity } \\
\mathrm{mg} / \mathrm{ml} \\
{\left[\mathrm{Cu}^{2+}\right]}\end{array}$ \\
\hline CHEL-38 & 38 & 1.00 & 0.018 & 1.7 & 3.8 & 14.4 \\
\hline CHEL-40 & 38 & 1.00 & 0.018 & 1.7 & 1.45 & 14.74 \\
\hline DPAR & 38 & 1.00 & 0.018 & 1.7 & 0.004 & 18.2 \\
\hline HPPR & 38 & 1.00 & 0.018 & 1.7 & 0.04 & 9.4 \\
\hline
\end{tabular}

Feed volumes were about at least 600 bed volumes, and the flow rates were at 0.5 to 1.0 bed volumes per minute. The capacities include approximately $\pm 5 \%$ analytical error. 
Table-2 Absorption of copper cobalt and iron on various resins at $\mathrm{pH} 1.7$

\begin{tabular}{|c|l|l|l|l|l|l|l|}
\hline Resin & $\begin{array}{l}{\left[\mathrm{Cu}^{2+}\right]} \\
{\left[\mathrm{Co}^{2+}\right]} \\
\mathrm{PPM}\end{array}$ & $\begin{array}{l}\mathrm{H}_{2} \mathrm{~S}_{4} \\
\mathrm{ml} / \mathrm{L}\end{array}$ & $\mathrm{H}_{2} \mathrm{~S}_{4} \mathrm{M}$ & $\mathrm{pH}$ & $\begin{array}{l}\text { Capacity } \\
\mathrm{mg} / \mathrm{ml} \\
{\left[\mathrm{Co}^{2+}\right]}\end{array}$ & $\begin{array}{l}\text { Capacity } \\
\mathrm{mg} / \mathrm{ml} \\
{\left[\mathrm{Fe}^{3+}\right]}\end{array}$ & $\begin{array}{l}\text { Capacity } \\
\mathrm{mg} / \mathrm{ml} \\
{\left[\mathrm{Cu}^{2+}\right]}\end{array}$ \\
\hline CHEL-38 & 190 & 1.00 & 0.018 & 1.7 & 4.9 & 2.1 & 25.2 \\
\hline CHEL-40 & 190 & 1.00 & 0.018 & 1.7 & 3.8 & 3.2 & 26.1 \\
\hline DPAR & 190 & 1.00 & 0.018 & 1.7 & 0.008 & 6.5 & 23.6 \\
\hline HPPR & 190 & 1.00 & 0.018 & 1.7 & 0.043 & 3.2 & 18.2 \\
\hline
\end{tabular}

Feed volumes were about at least 400 bed volumes and flow rates were at 0.5 to 1.0 bed volumes per minute. The capacities include approximately $\pm 5 \%$ in experimental error.

Table-3. Absorption capacity of the various resins at $\mathrm{pH} 1.1$

\begin{tabular}{|l|l|c|l|l|c|}
\hline Resin & {$\left[\mathrm{Cu}^{2+}\right] \mathrm{ppm}$} & $\mathrm{H}_{2} \mathrm{~S}_{4} \mathrm{ml} / \mathrm{L}$ & $\mathrm{H}_{2} \mathrm{SO}_{4} \mathrm{M}$ & $\mathrm{pH}$ & $\begin{array}{l}\text { Capacity } \\
\mathrm{mg} / \mathrm{ml}\end{array}$ \\
\hline CHEL-38 & 190 & 4.00 & 0.072 & 1.1 & 12.4 \\
\hline CHEL-40 & 190 & 4.00 & 0.072 & 1.1 & 13.4 \\
\hline HPPR & 190 & 4.00 & 0.072 & 1.1 & 8.8 \\
\hline
\end{tabular}

Feed volumes were about at least 400 bed volumes and flow rates were at 0.5 to 1.0 bed volumes per minute. The capacities include approximately $\pm 5 \%$ in experimental error.

\section{SUMMARY}

In search for new resins to recover copper and cobalt from dilute $\mathrm{H}_{2} \mathrm{SO}_{4}$ solutions, small quantities of two new chelating resins (1) a highly cross-linked, gel-type, and highly picolylated diethylene triamine resin (CHEL-38), and (2) a less picolylated diethylene triamine resins (CHEL-40) were synthesized and evaluated. Small-scale columns tests were made $\mathrm{pH} 1.7$ and pH1.1 solutions containing $\mathrm{Cu}$ (II), Co (II), and Fe (III) ions. Comparison tests were also made with comparable-sized commercially available, hydroxypropyl picolylamine resin (Dow XFS-43084), and bis-picolylated amine resin (Dow XFS-43578). The results indicate that both the highly picolylated diethylene triamine (CHEL-38) and less picolylated diethylene triamine resins were comparable to, or more effective, in absorbing $\mathrm{Cu}^{2+}$ from acidic solutions then the commercial resins. The CHEL-38 resin and the CHEL-40, on the other hand, had cobalt absorption capacities much better than those of the commercial resins. Ferric ion 
absorption on CHEL-38 and CHEL-40, moreover, were comparable to, or less then those of the commercial resins in the test made at $\mathrm{pH} 1.7$ solutions.

\section{FUTURE WORK}

In further laboratory development work we will try to improve the synthesis of the picolylated diethylenetriamine resins (small or intermediate lab-scale). Also we will make further column studies of loading capacity as a function of $\mathrm{pH}$ and of absorption and desorption kinetics, and selectivity for copper and cobalt in the presence of ferric ions. These studies will include mixtures that stimulate the leach solutions from copper mining operations, or with the actual mining liquors if available. If possible, these studies will be made on a larger laboratory scale.

\section{APPENDIX}

Table-A1. Absorption capacities of various resin tabulated together.

\begin{tabular}{|c|c|c|c|c|c|c|}
\hline Resins & $\mathbf{p H}$ & $\begin{array}{l}\mathrm{mg} / \mathrm{ml} \\
\mathrm{Cu}- \\
\text { 38ppm }\end{array}$ & $\begin{array}{l}\mathrm{mg} / \mathrm{ml} \\
\mathrm{Cu}- \\
190 \mathrm{ppm}\end{array}$ & $\begin{array}{l}\mathrm{mg} / \mathrm{ml} \\
\text { Co- } \\
\text { 38ppm }\end{array}$ & $\begin{array}{l}\mathrm{mg} / \mathrm{ml} \\
\text { Co- } \\
\text { 190ppm }\end{array}$ & $\begin{array}{l}\mathrm{mg} / \mathrm{ml} \\
\text { Fe- } \\
\text { 190ppm }\end{array}$ \\
\hline \multirow[b]{2}{*}{ CHEL-38 } & 1.7 & 14.4 & 25.2 & 3.8 & 4.9 & 2.1 \\
\hline & 1.1 & - & 12.4 & & 2.28 & \\
\hline \multirow[b]{2}{*}{ CHEL-40 } & 1.7 & 14.74 & 26.1 & 1.45 & 3.8 & 3.2 \\
\hline & 1.1 & - & 13.4 & & - & - \\
\hline \multirow[b]{2}{*}{ CM-DER } & 1.7 & 11.1 & 16.5 & 0.5 & 1.45 & 20.5 \\
\hline & 1.1 & - & 9 & - & - & - \\
\hline \multirow[b]{2}{*}{ HPPR } & 1.7 & 9 & 18.2 & 0.04 & 0.043 & 3.2 \\
\hline & 1.1 & - & 8.8 & - & - & - \\
\hline \multirow[b]{2}{*}{ DPAR } & 1.7 & 18.2 & 23.6 & 0.004 & 0.008 & 6.4 \\
\hline & 1.1 & - & - & - & - & - \\
\hline
\end{tabular}

Feed volumes were about at least 400 bed volumes and flow rates were at 0.5 to1.0 bed volumes per minute. The capacities include approximately $\pm 5 \%$ error. 


\begin{abstract}
Appendix M: NM003 - The Effect of Diphenyl Oxide Surfactants on Nucleation and Growth of Potassium Sulfate Crystals: Development of Enhanced Surfactants for the Potash Industry
\end{abstract}


TECHNICAL PROGRESS REPORT

\begin{tabular}{|ll|}
\hline Contract Title and Number: & Period of Performance: \\
Crosscutting Technology Development at the Center & Starting Date: April 1, 2004 \\
for Advanced Separation Technologies & Ending Date: May 30, 2005 \\
(DE-FC26-02NT41607) & \\
\hline
\end{tabular}

Sub-Recipient Project Title:

Development of Enhanced Surfactants

for the Potash Industry

Principle Investigators:

M. Wimberly, G. Bond, C. Hockensmith

Contact Address:

New Mexico Tech

Materials Engineering Dept.

Jones Hall, Room 159

Socorro, NM 87801

Subcontractor Address:

"no subcontracts issued"

THE EFFECT OF DIPHENYL OXIDE SURFACTANTS ON NUCLEATION AND GROWTH OF POTASSIUM SULFATE CRYSTALS: DEVELOPMENT OF ENHANCED SURFACTANTS FOR THE POTASH INDUSTRY

\author{
Report Information: \\ Type: Semi-Annual \\ Number: 003 \\ Period: $4-1-04$ to 9-30-04 \\ Date: $9-30-04$ \\ Code: NM003-R01 \\ Contact Information: \\ Phone: (505) 835-5229 \\ Fax: (505) 835-5626 \\ E-Mail: gbond@nmt.edu
}

\title{
M. WIMBERLY, G. BOND, C. HOCKENSMITH
}

\begin{abstract}
A modified MSMPR crystallizer is being used to grow potassium sulfate crystals. Crystal sizes, habits, phases, and growth rates are being evaluated by field-emission scanning electron microscopy, X-ray diffraction, and titration methods. Surfactants are being added with the goal of producing a modest inhibition of nucleation, and hence shifting the crystal size distribution, in order to increase the ratio of granular particles to fines, and thus decrease the costs associated with industrial production of potassium sulfate. Preliminary data obtained with concentrations of Calfax 16L-35 alkyl diphenyl oxide (ADO) surfactant at the critical micelle concentration (CMC) suggest that this ratio may indeed be increased for crystallization at $40^{\circ} \mathrm{C}$. Additional experiments are in progress to verify this result, to provide a better understanding of changes in crystal growth habit and growth rate as a function of surfactant concentration, and to investigate related surfactants.
\end{abstract}




\section{INTRODUCTION}

The aim of the present research is to optimize the surfactants used in production of $\mathrm{K}_{2} \mathrm{SO}_{4}$ fertilizers in the potash industry, in order to minimize the number of small crystals that will pass through the screening process and be reintroduced to the mother liquor. To this end, the influence of alkyl diphenyl oxide (ADO) surfactants on the growth rate, crystal size distribution (CSD), and crystal morphology is determined, for $\mathrm{K}_{2} \mathrm{SO}_{4}$ crystals grown in the presence of $\mathrm{MgSO}_{4}$ as a second solute (as used by Dash et al. (1996) in the growth of $\mathrm{KCl}$ crystals). Initially, a mixed-suspension mixed-product removal (MSMPR) crystallizer was built and used for this purpose. Crystal growth rates and growth characteristics were investigated by means of scanning electron microscopy (SEM), flame atomic absorption spectrometry (AAS), x-ray diffraction (XRD), and Fourier-transform infrared spectrometry (FTIR).

\section{PROJECT TASKS}

The effect of surfactant concentration, particularly around the critical micelle concentration (CMC), is an important factor to determine. Below the CMC, the concentration of single surfactant molecules in the solution increases as further surfactant is added. Above the CMC, however, aggregation of the surfactant occurs, and the concentration of single surfactant molecules remains approximately constant (Israelachvili, 1992). Experiments at concentrations around the CMC were commenced, but a contamination problem arose that reduced the consistency of results, and this problem had to be addressed first. The initial setup that was built for this project consisted of an MSMPR crystallizer, a 19-liter feed tank, and an intermediate dissolution tank; the mother liquor was pumped to the various tanks by means of peristaltic pumps. Unfortunately, a major construction project was started not far from the part of the building in which the apparatus was situated, causing dust to become a major contaminant. The MSMPR design proved particularly susceptible to such contamination, hence introducing additional uncontrolled variables into the experiments.

Several measures have been taken to address these problems and eliminate additional variables. First, the crystallization setup was moved to another laboratory. The new location provides a controlled environment with constant ambient temperature and low humidity, and that is free from dust. The original experimental design has also been modified to provide additional protection against contamination of the mother liquor. As additional precautions, a new source of nano-pure water is being used, and the 98.5\% magnesium sulfate heptahydrate $\left(\mathrm{MgSO}_{4}\right)$ used in the original experiments has now been replaced with $99.5 \%$ magnesium sulfate heptahydrate.

The new experimental system has been compacted to just the MSMPR crystallizer and the cooling/heating bath as shown schematically in Figure 1 (adapted from Dash and Rohani, 1993). At the start of each experiment, one liter of nano-pure water is poured into the MSMPR crystallizer, and the cooling/heating bath is set to $80^{\circ} \mathrm{C}$. A three-bladed 2.5-inch propeller (powered by a $1 / 10 \mathrm{hp}$ motor) is inserted into the crystallizer, and the 
chamber is completely sealed in order to prevent contamination of the water. A thermometer is used to monitor the temperature of the solution. Once the water has reached a temperature of $80^{\circ} \mathrm{C}, 190.3 \mathrm{~g}$ of $\mathrm{K}_{2} \mathrm{SO}_{4}$ and $9.9 \mathrm{~g}$ of $\mathrm{MgSO}_{4}$ are added to the crystallizer, together with the amount and type of surfactant selected for the experiment. The mother liquor is stirred constantly, and is held at $80^{\circ} \mathrm{C}$ until all of the reagents have visibly dissolved. Once dissolution has occurred, a $5 \mathrm{ml}$ sample is removed from the crystallizer and filtered through a $12 \mathrm{ml}$ Whatman autovial syringeless filter that has a 0.2 $\mu \mathrm{m}$ polytetrafluroethylene filter. The filtered sample is poured into a $20 \mathrm{ml}$ glass vial for later analysis. The temperature of the cooling/heating bath is then dropped to $40^{\circ} \mathrm{C}$, and another $5 \mathrm{ml}$ sample is removed from the crystallizer and filtered. The crystallizer is kept at $40^{\circ} \mathrm{C}$ for a 6-hour period, during which a sample is taken every hour.

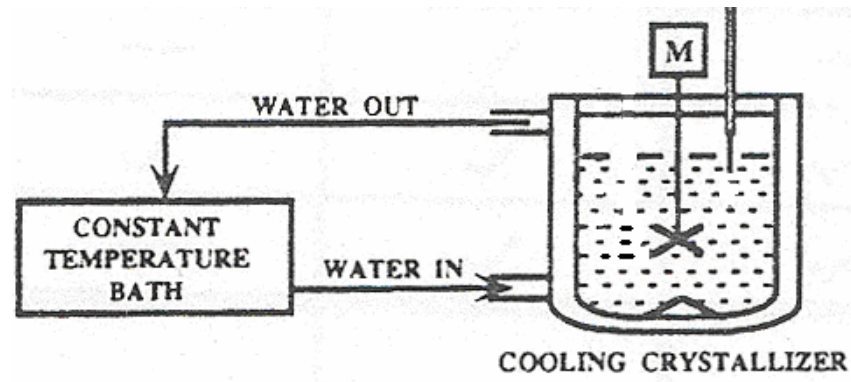

Figure 1: Revised Design of Crystallization System

Crystallization experiments are being performed at $80^{\circ} \mathrm{C}$ and at $40^{\circ} \mathrm{C}$. Experiments with Calfax 16L-35 at and a little below the CMC have already produced encouraging results. Crystals have been characterized by FESEM and XRD, and further CSD studies are underway. Flame AAS is unsuitable for monitoring changes in the growth rates at these concentrations. Thus a titration method is now being applied in this context.

XRD characterization has confirmed that similar phases are precipitated, with or without the presence of surfactant. Crystals were ground to a fine powder, and examined with a standard powder diffractometer (Siemens Model D-500: Cu, $30 \mathrm{~mA}$ and $40 \mathrm{kV}$ ). All data were saved to JADE 3.1 for analysis of the peaks and d-spacings, and the spectra were identified from JCPDF files. A typical spectrum is shown in Figure 2, with the major peaks labeled. It can be seen that the crystal phases present are indeed $\mathrm{K}_{2} \mathrm{SO}_{4}$, $\mathrm{MgSO}_{4}$, and $\mathrm{MgSO}_{4} .7 \mathrm{H}_{2} \mathrm{O}$, as would be expected.

A Hitachi Model S-800 Field Emission Scanning Electron Microscope (FESEM), operating at $15 \mathrm{kV}$, is used to study crystal growth habit, and to obtain an initial indication of CSD. Samples were placed onto a $2 \mu \mathrm{m}$ millipore polycarbonate filter and dried. A small section of the crystal-bearing filter was then mounted and sputter-coated with gold. 


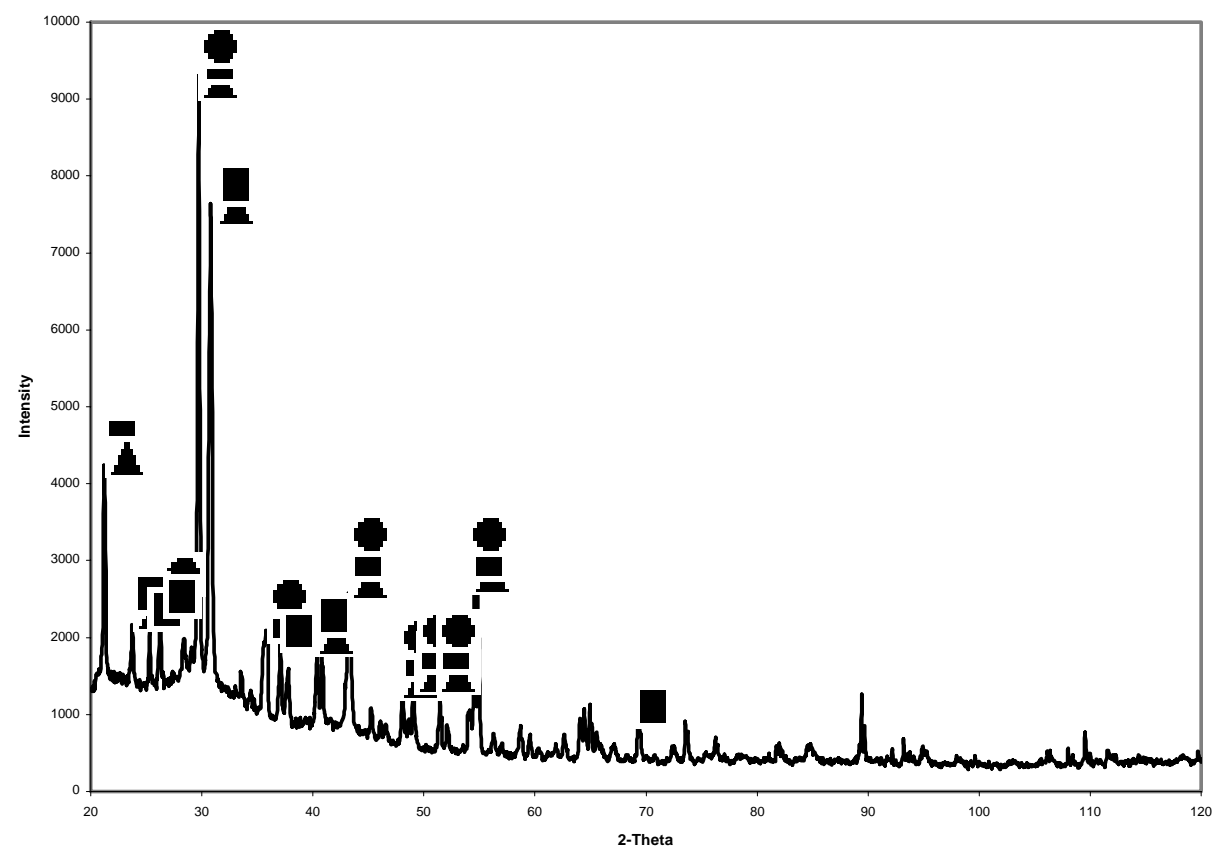

Figure 2. XRD spectrum for crystals grown from mother liquor. Similar spectra were obtained in presence or absence of surfactant. $\square: \mathrm{K}_{2} \mathrm{SO}_{4}, \Delta \mathrm{MgSO}_{4} .7 \mathrm{H}_{2} \mathrm{O}, \bullet \mathrm{MgSO}_{4}$.

FESEM results showed an interesting change in growth habit in the presence of Calfax 16L-35 surfactant. Without surfactant, many of the crystals formed without welldefined crystallographic faces.

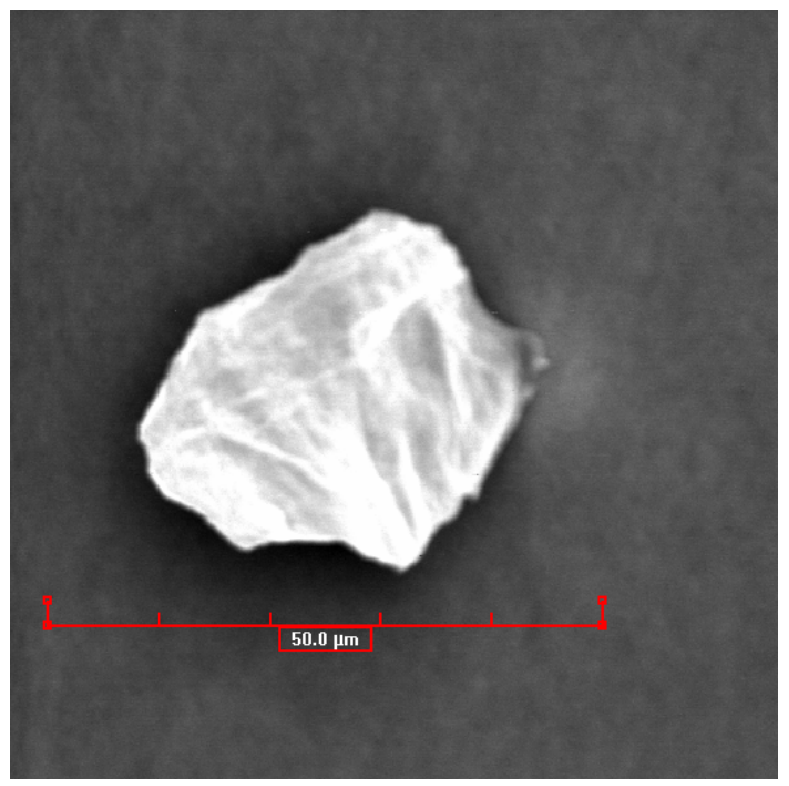

Figure 3. Crystal grown at $80^{\circ} \mathrm{C}$ in absence of surfactant 


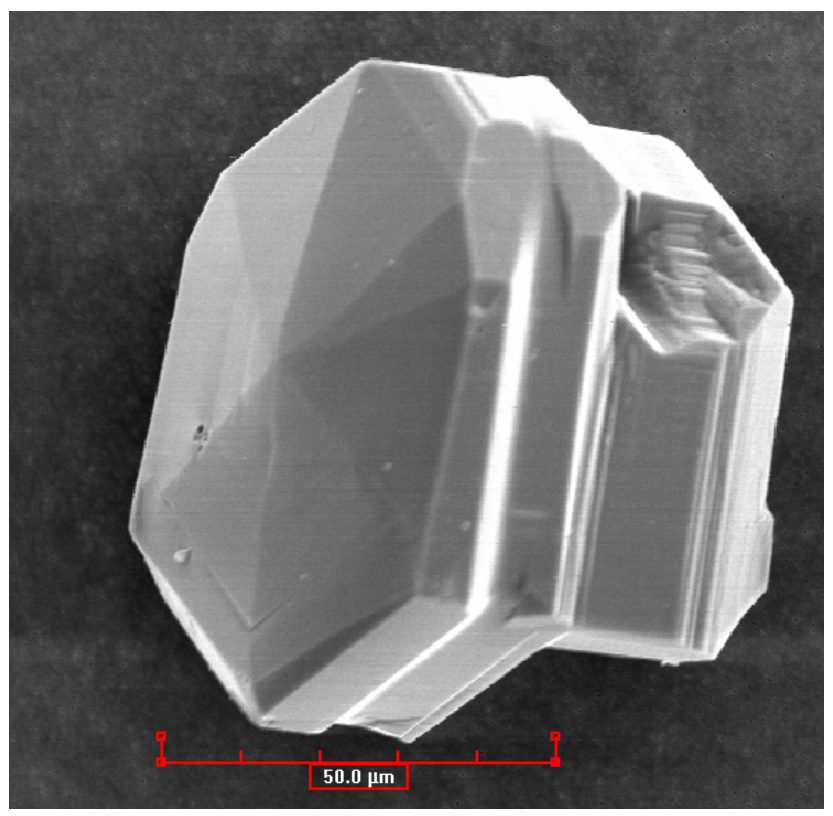

Figure 4. Crystal grown in presence of Calfax 16L-35 surfactant below CMC, at $80^{\circ} \mathrm{C}$

Sizes of crystals grown at $40^{\circ} \mathrm{C}$ ranged, for example, from $\sim 10 \mu \mathrm{m}$ to $2.5 \mathrm{~mm}$ with no surfactant, from $\sim 6 \mu \mathrm{m}$ to $2 \mathrm{~mm}$ at the CMC. The proportion of the mm-scale crystals to the $\mu \mathrm{m}$-scale fines is, however, increased at the CMC, which is the desired effect. Work is continuing, to verify and expand upon this very encouraging result.

\section{FUTURE WORK}

Near-CMC concentrations of Calfax 16L-35 surfactant result in extensive crystallization, with crystals in a size range close to that for crystallization from the mother liquor. Initial data suggest that there may be fewer of the smaller crystals when precipitation occurs in the presence of the surfactant at $40^{\circ} \mathrm{C}$. Additional runs will be performed in order to verify this result. Changes in crystal growth habit and growth rate will be studied further, as a function of surfactant concentration. Analogous studies will also be conducted with related surfactants.

\section{REFERENCES}

Dash, S.R. and S. Rohani (1993). Effect of magnesium and sulfate ions on $\mathrm{KCl}$ crystallization in a continuous cooling MSMPR crystallizer. Chemical Engineering Communications, 125, pp. 211-226.

Dash, S.R., S. Rohani, and S. Sakhansanj (1996). Impurity effects on crystallization of $\mathrm{KCl}$ from aqueous solutions in a MSMPR crystallizer. Canadian Journal of Chemical Engineering, 74, pp. 265-278.

Israelachvili, J. N. (1992). Intermolecular and Surface Forces, $2^{\text {nd }}$ ed. (Academic Press: Amsterdam), pp. 341-394. 
Appendix N: WV008 - Online Monitoring and Diagnosing of Coal Fines During Separation Process 


\section{TECHNICAL PROGRESS REPORT}

Contract Title and Number:
Crosscutting Technology Development at the Center
for Advanced Separation Technologies
(DE-FC26-02NT41607)

Contract Title and Number: (DE-FC26-02NT41607)

Sub-Recipient Project Title:

On-Line Monitoring and Diagnosing of Coal Fines

During Separation Process

Principal Investigators:

Bruce S. Kang and Eric K. Johnson

Contact Address:

Dept. of Mechanical and Aerospace Engineering West Virginia University

P.O. Box 6845

Morgantown, WV 26506

Subcontractor Address:

No subcontracts issued.

\section{Period of Performance:}

Starting Date: 10/01/2002

Ending Date: 05/30/05
Report Information:

Type: Semi-Annual

Number: 3

Period: $\quad 3 / 31 / 03-9 / 31 / 04$

Date: $\quad 10 / 11 / 04$

Code: WV008

Contact Information:

Phone: $\quad 1.304 .293 .3111$

(ext -2316)

Fax: (304)293-6689

E-Mail: Bruce.Kang@mail.wvu.edu

$\underline{\text { Subcontractor Information: }}$

Phone:

Fax:

E-Mail:

\section{ABSTRACT}

The goal of this research program is to develop an on-line, non-contact, elemental analysis of coal fines during solid-solid separation process through the use of LaserInduced Breakdown Spectroscopy (LIBS). Of particular interest is the detection and quantitative measurement of the amount of carbon, sulfur, mercury, and other trace elements in the separated coal fines.

\section{BACKGROUND}

Laser Induced Breakdown Spectroscopy (LIBS) is a technique that uses a powerful laser, to ablate a sample of a desired material. This ablation causes a plasma formation in which the material is broken down into excited ionic and atomic states. The atoms then emit characteristic optical radiation known as an emission spectrum. Collection of the emitted light can be used to provide information on the elemental composition of the material. 
There are several key advantages to LIBS that are beneficial for an on-line monitoring and diagnostic. LIBS is essentially a non-contact, non destructive test; it requires nothing more than the light collected from the plasma created by the laser and ablates and insignificant amount of particles. Because LIBS only requires collection of light to be able to yield sufficient data, it can be used for deployment to hostile or high temperature environments. Also, LIBS requires no sample preparation, which makes it a possible in-situ monitor.

\section{OBJECTIVE AND APPROACH}

LIBS will be applied for on-line elemental analysis and diagnosing of coal fines during solid-solid separation process, i.e. the CFB riser system. The experiment will first be performed in a laboratory environment, away from the riser system. The experiment will be to determine quantitatively the amounts of carbon, sulfur and other trace elements.

Detection and monitoring of mercury will prove to be the most difficult task because of its trace concentrations in coal. A new optical system to optimize light collection efficiency was designed and all the required optical components were purchased. The optical system will be implemented in a laboratory environment by early November, 2004.

Time resolved studies will be conducted to produce the optimal time delay for analysis of the constituents in coal using LIBS. This will be done by synchronization of a Spectra-Physics Quanta Ray DCR 11 Laser and the Princeton Instruments SpectruMM 250 B via a BNC 555 pulse/delay generator, as shown in Figure 1.

\section{RESEARCH PROGRESS}

All experimental components have been either purchased or secured. Only two components (a precision off-axis parabolic mirror and a polygonal scanning mirror apparatus) are yet to be received. These were special custom-ordered items and will be shipped to us by end of October 2004. However, preliminary LIBS tests (without the canning time resolution and synchronization capability) are being conducted on selected elemental samples and NIST coal samples. Also, some of the data collection devices

have been changed since the last report. All of the changes in design are completed and the data collection schematic has been finalized, as shown in Figures 1 and 2.

The new experimental layout will allow optimum signal collection as well as time resolution and synchronization of the LIBS spark of coal. As shown in Figure 2, the laser will fire and ablate the coal particle. Once the laser spark occurs, the light will be collected and collimated by an off-axis parabolic reflector on one side, and a spherical mirror on the other. The collimated light will then go to another off-axis parabolic mirror, which will begin to focus the light down onto a spot on a polygonal scanning mirror. When the spot hits the scanning mirror, it reflects into a collimating lens and is once again collimated. The collimated light then goes through another focusing lens, 
which is focused down on the entrance slit of the spectrometer. Since a spinning mirror reflects the light, there will be a line entering the slit. Each segment of the line will simulate a time delay, which will be read by the CCD detector, thus a temporally resolved LIBS spectrum of the desired material is recorded. The laser, the scanning mirror, and the CCD detector will all be controlled via a PC.

While setting up the new LIBS system, we continue to conduct preliminary LIBS tests. The equipment used for the preliminary LIBS tests include a pulse laser, a $300 \mathrm{~mm}$ focal length spectrometer, an in-house optical collection device with an f/4 fused silica lens as the optical collector and a fused silica focusing lens to focus down onto the fiberoptic, and several EG\&G PARC instruments, which include a model 1460 multi-channel analyzer with a 1463 interface, a 1211 pulse generator to set the delay time and the exposure time of the laser spark, and an optical switch for triggering the data collection.

Samples included a solid iron block, a coal sample obtained from NETL, and a known coal sample from NIST. Other than initial placement into the sample holder, the iron samples and the coal powder from NIST did not have to be prepared in any way. The NETL coal sample was ground into a fine powder. A solid cast iron pipe joint was initially used to take iron measurements, and then was replaced by iron powder.

Figure 4 shows a typical overlaid of iron and coal spectra obtained using LISB. The data from the iron and coal spectra were taken and analyzed in GRAMS/ AI software. The spectra were imported into the software and overlaid for qualitative comparison. With this qualitative comparison, limits of detection can be established with the LIBS technique, which will allow for further optimization of the new LIBS system. It has been established that emission lines from iron, though less intense, can be seen in the coal samples. The fact that not every major iron line corresponded directly onto the coal emission spectrum shows that the concentrations of elements in the coal have a direct effect on each other. The LIBS data analysis is still on-going and will be reported in the next project report.

\section{SUMMARY}

The findings from the preliminary experiments indicated that qualitative analysis of iron and coal sample using LIBS system can be accomplished. Iron was a good candidate to choose for qualitative analysis for two reasons 1.) Iron has many emission lines, which will make it easier to see qualitatively 2.) The MIT wavelength tables show that a few of the iron lines are very close to the mercury lines. If iron can be identified, mercury will be close to it in the spectrum.

A new WVU LIBS system is in the final stage of completion. The new LIBS system (Figures 1 and 2) will allow for time-delayed synchronization and temporal resolution measurement of selected target elements in coal samples such as iron, carbon, sulfur, and mercury. 


\section{FUTURE WORK}

The polygonal scanning mirror and the off-axis parabolic mirror are expected to arrive in late October 2004. Although, the data acquisition for the final laboratory phase was delayed due to technicalities in the procurement process and technical issues with the laser and the spectrometer, a new round of LIBS tests should begin in November 2004 using the new LIBS system. Qualitative analysis of sulfur, carbon, iron, and mercury are expected to be included in the initial LIBS testing.

\section{PUBLICATIONS/PRESENTATIONS}

To date, no publications or presentations have resulted from the project.
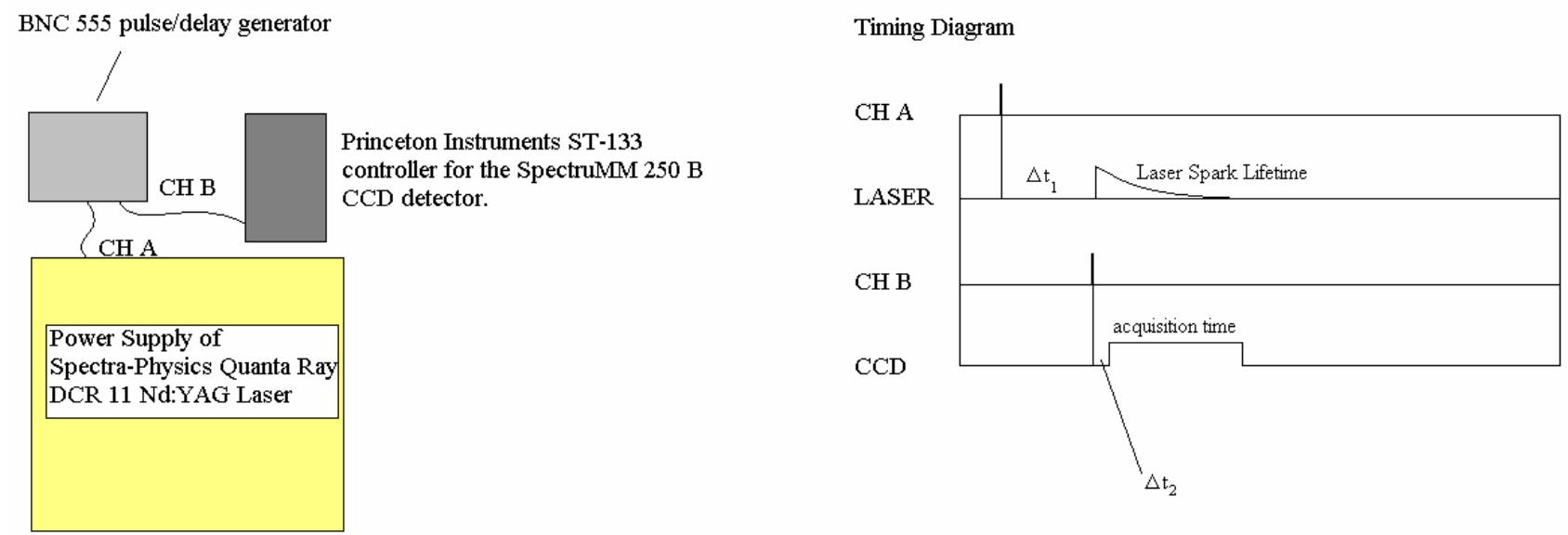

Figure 1 Timing Diagram and Block Diagram of the New WVU LIBS Experiment. 


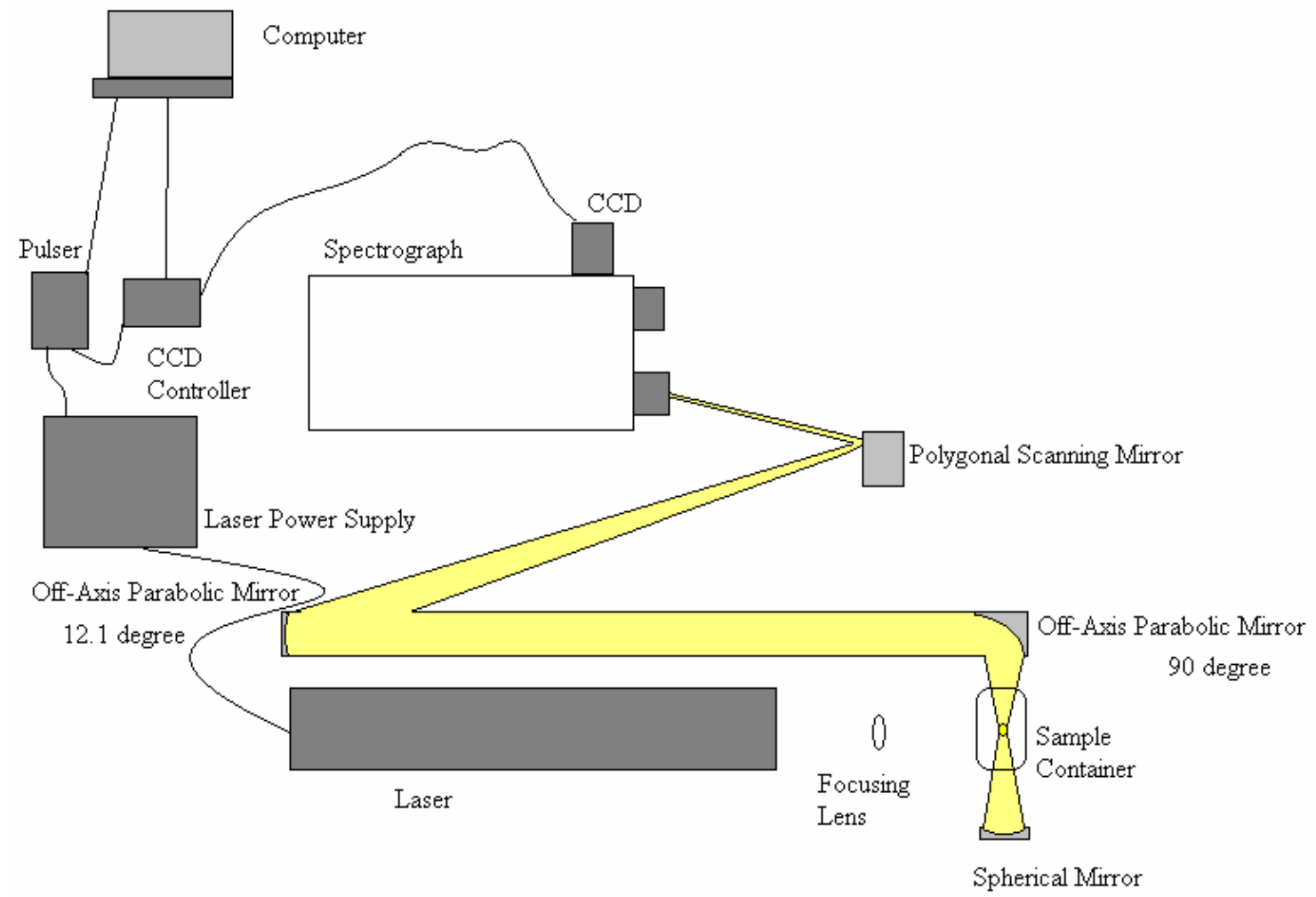

Figure 2 Schematic Optical Setup of the Proposed New WVU LIBS System.

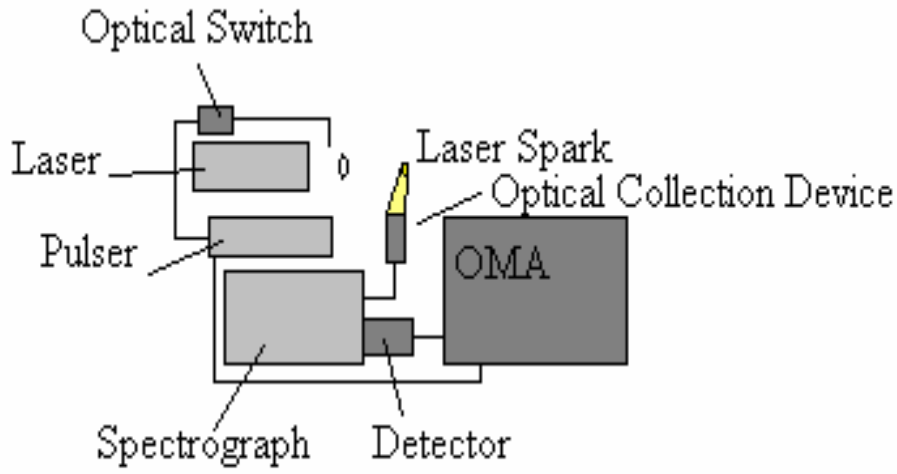

Figure 3 Current Optical Setup for Preliminary LIBS Tests. 


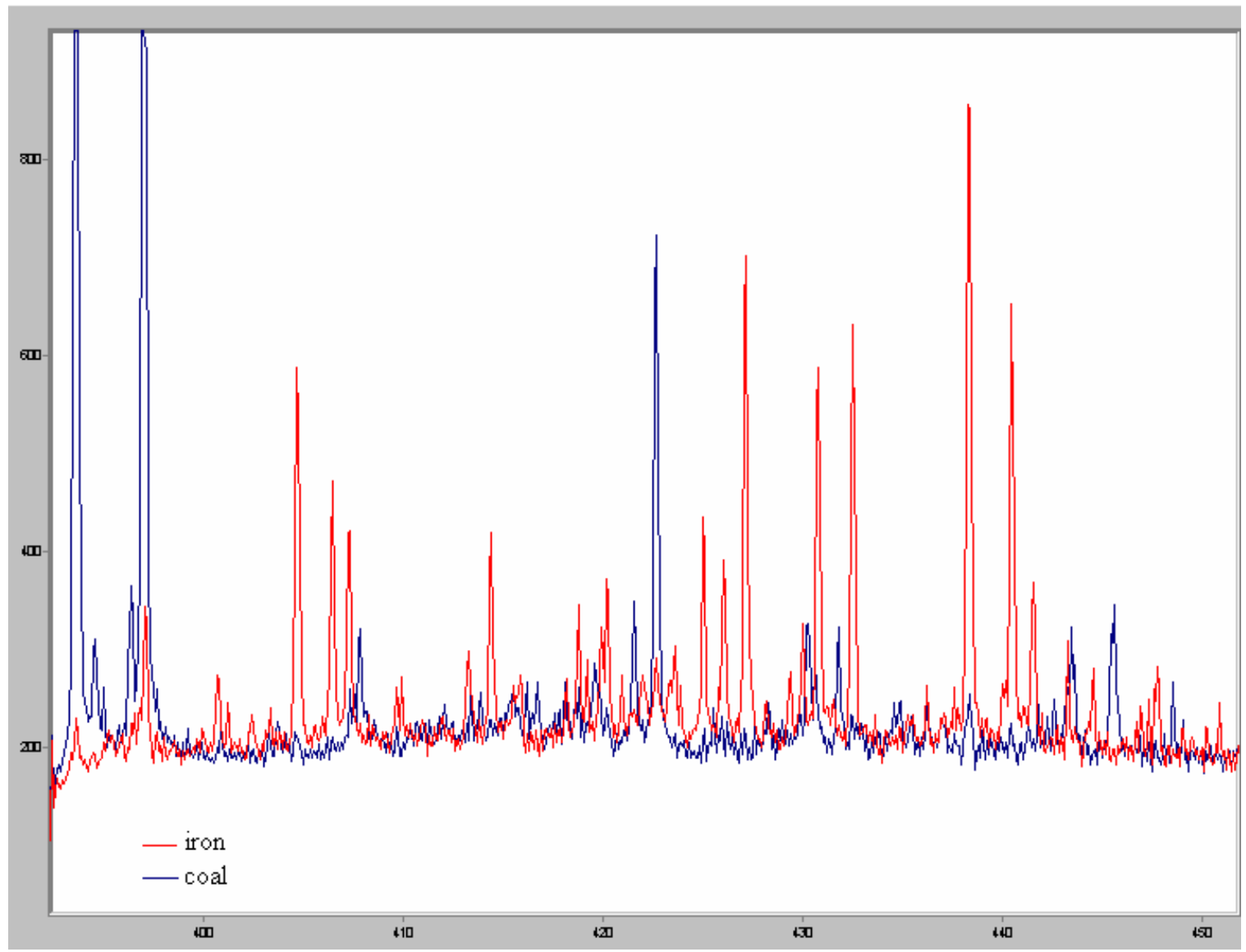

Figure 4 Iron Spectrum and NIST Coal Spectrum overlaid 
Appendix O: KY003 - Development of a Novel Optical Radiation Depolarization Technique for On-Line Measurements of Particle and Bubble Sizes 


\section{TECHNICAL PROGRESS REPORT}

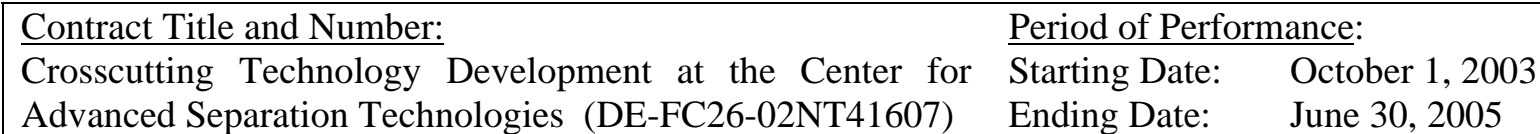

Sub-Recipient Project Title:

Development of A Novel Optical Radiation Depolarization

Technique for On-Line Measurements of Particle And Bubble

Sizes

Principal Investigators:

Daniel Tao, M. Pinar Mengüç, and Czarena Crofcheck

Contact Address:

234E MMRB, University of Kentucky, Lexington, KY 40506
Report Information:

Type: Semi-Annual

Number: 3

Period: $\quad 3 / 31 / 2003-9 / 30 / 2004$

Date: $\quad$ 10/1/2004

Code:

Contact Information:

Phone: (859) 257-2953

Fax: (859) 323-1962

E-Mail: dtao@engr.uky.edu

\section{ABSTRACT}

An elliptically polarized light scattering (EPLS) approach was adapted for monitoring the 3-phase column froth flotation parameters such as bubble size, average gas hold-up and particle size distribution. The results obtained so far show that it is possible to monitor three parameters (bubble size distribution, average gas hold-up, and coal particle size distribution) in the froth flotation process with two different light sensors. The two light scattering based sensors were assembled at two different angular locations of the column: one is to monitor bubble size and gas-hold up at the measurement point and the other is to sense coal particle size distribution in froth flotation column.

\section{INTRODUCTION}

\section{Background}

Grinding and froth flotation are the two most important processes for mineral beneficiation. The importance of grinding is well reflected in the fact that approximately $80 \%$ of beneficiation costs are for grinding, mainly due to high energy consumption. To reduce energy consumed by grinding, fines should be removed quickly from the grinding circuit. This requires a reliable on-line particle size analysis technique. Froth flotation is the most widely used solid-solid separation process for coal and minerals beneficiation and about $90 \%$ of mineral concentrates are produced from froth flotation. It is now recognized that air bubble size distribution plays an important role in flotation separation performance [1]. Optimization of bubble size distribution is possible only if bubble size can be monitored on-line. Obviously, an on-line analysis technique for particle and bubble size is critical for enhanced grinding and flotation process efficiency.

Light scattering is one of the most effective concepts for characterization of particles and bubbles. When either vertically or horizontally polarized light is incident on the medium, it goes through a number of scattering events. Bubbles are considered much larger than the wavelength of the incident light, which is a reasonable approximation even for bubble diameters as small as $5 \mu \mathrm{m}$. A model based on a hybrid Monte Carlo/Ray Tracing technique allows the Fresnel reflections on the bubble-medium interfaces. This algorithm has already been developed and currently is adapted to our experimental system. 


\section{Objective and Approach}

The overall objective of the proposed research program is to develop a novel sensor based on optical radiation depolarization measurement technique for on-line real-time size analysis of grinding and flotation processes to minimize energy consumption during grinding and maximize flotation efficiency. The technique is based on use of angular and radial profiles of reflection and transmission of an object subjected to a collimated, polarized light beam.

\section{PROJECT TASKS}

Task1. Design and Fabrication

Development of a laboratory scale EPLS System for gas-liquid phase was already discussed in the previous report. Since characterization of 3-phase (gas-solidliquid) flow is complex, the best solution to monitor the froth flotation process is to monitor two different two-phases (gas bubbles and coal particles).

We are currently in process of developing a prototype on-line EPLS System, as shown in Fig. 1 in order to monitor the system at two different locations where the flow is essentially two- phase. Details of optical sensors ( 1 and 2 ) were given in the previous report. With two sensors scattered light intensity and polarization information from bubbles and coal particles will be monitored at optimum scattering angles. Based on the scattered light data, size distribution of both bubbles and coal particles and volume fractions of bubbles will be obtained by developed algorithm. Two sensors will

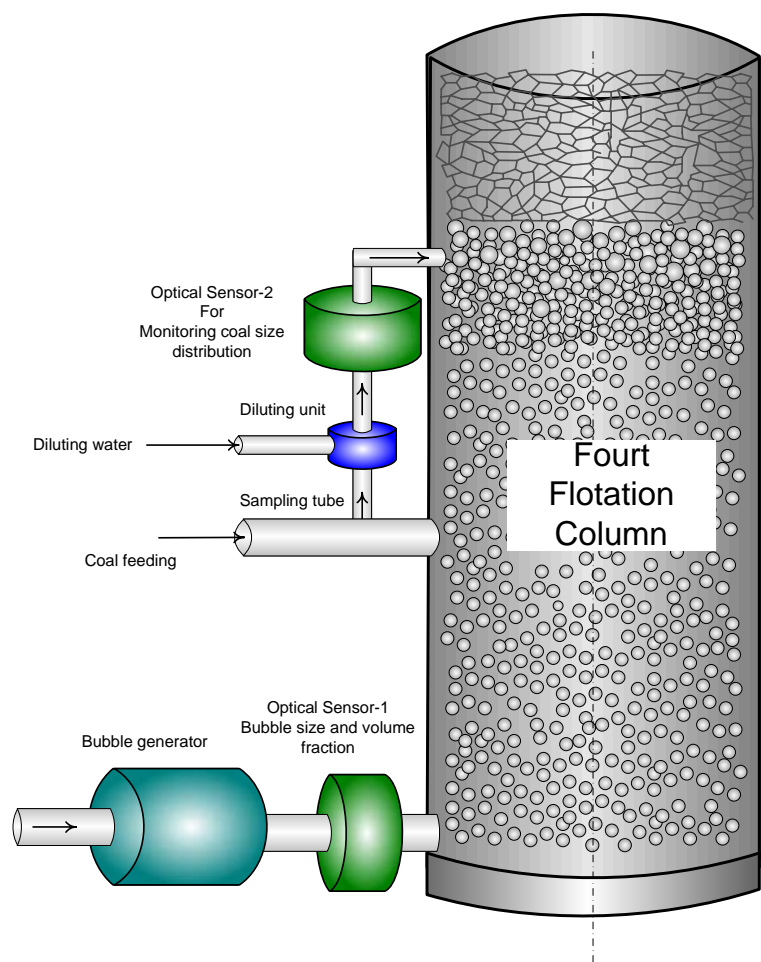

Figure 1. Gas-liquid (bubbles) and solid-liquid (coal particles) monitoring system. allow us to monitor the process in-situ and control the input parameters such as gas flow rate (gas pressure), surfactant concentration, and coal feeding rate.

A simplified EPLS system developed by Aslan et al. [1] will be used for the study of the system shown in Figure 1. A He-Ne laser will be connected to light scattering measurement ring by a fiber optic with a collimator. Scattered light at two different scattering angles will be collected by two polarizationmaintaining fiber-optic to the detector via polarization optics box where scattering light intensity, polarization state and degree are measured. The data are collected using a data acquisition board on a PC. Scattering angles where the measurements are taken can be changed to measure bubble size depending on flow-rate and surfactant ratio by two rotational disks. We expect to have more details about this system in the next report.

\section{Task 2. Customization of Algorithm}

The theoretical models are mostly developed for single scattering. In the independent scattering regime for 2-phase GL flow, the separation distance is much larger than the particle diameter and therefore the interaction of the incident electromagnetic wave with an individual bubble is independent of other bubbles. For these conditions, the Lorenz-Mie solution can be used as a basis for theoretical predictions. However, if the bubbles are separated by smaller distances, the scattering may become dependent and the 
Lorenz-Mie solution may not be applicable. Therefore, experimental conditions over a wide range of scattering regime from single scattering to multiple scattering make it more difficult to compare the results with a single theoretical model. We are continually improving the model to have a direct comparison with the experimental results.

\section{Task 3. Calibration and Verification}

\section{Two Phase Measurements -- Gas Bubbles in Liquid:}

A series of experiments were conducted to understand the relationship between input parameters such as flow rate and surfactant concentrations and scattering matrix elements $\left(M_{\mathrm{ij}}\right)$. Potential of using an elliptically polarized light scattering (EPLS) method to monitor both bubble size and gas hold-up in a bubble laden medium was explored. It is shown that with the use of EPLS, normalized scattering matrix elements $\left(M_{\mathrm{ij}}\right.$ 's) at different side and back scattering angles yielded the desired correlation between the bubble sizes and input parameters, including gas flow rate and surfactant concentrations, for the
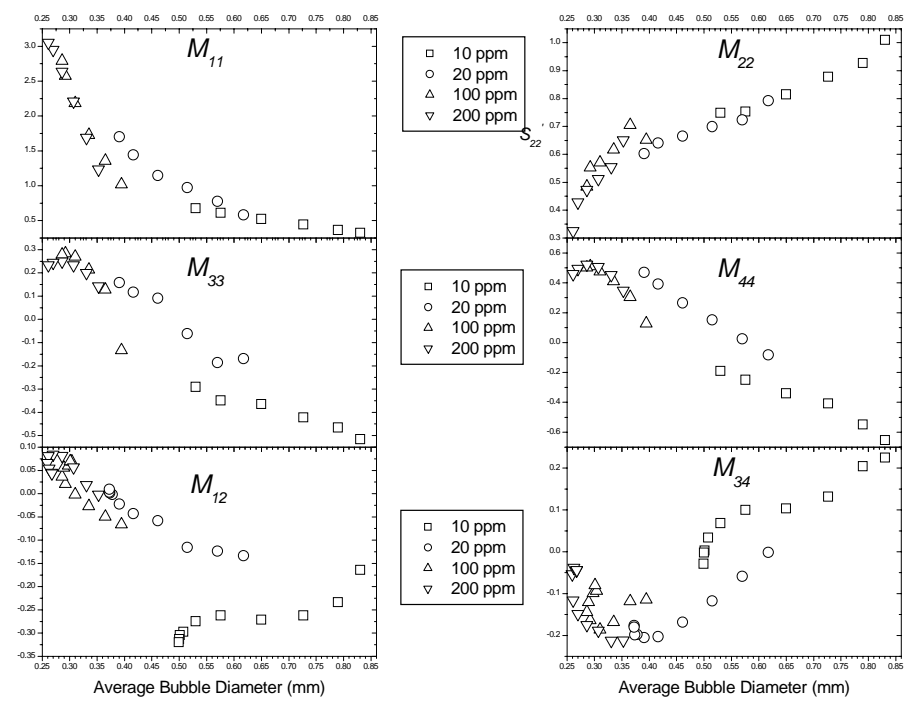

Figure 2. $M_{i j}$ 's at 120 degree as a function of mean bubble diameter.

gas-liquid (GL) column. Experiments were carried out on gas-liquid columns containing different bubble sizes. The bubble size distributions were first evaluated using a digital image processing system at different gas flow rates and surfactant concentrations. Based on these images, bubbles were assumed to be spherical and their scattering matrix elements were calculated using the Lorenz-Mie theory. After the experiments were conducted, scattering matrix elements were determined using the intensity values measured for different polarization settings and the results were compared against the theoretical values. It was observed that the change in the bubble size yielded significant changes in $M_{11}, M_{33}, M_{44}$, and $M_{34}$ profiles at a single angle of $\theta=120^{\circ}$ for gas velocity range of 0.04 to $0.35 \mathrm{~cm} / \mathrm{s}(\mathrm{ID}=4.5 \mathrm{~cm})$. This optimum angle to conduct light scattering measurements depended on frit pore size, column diameter, gas pressure, and surfactant concentration. These results suggest that it is possible to design optical on-line sensors capable of monitoring bubble size and liquid hold-up based on EPLS.

In order to understand relationship between gas velocity and $M_{\mathrm{ij}}$ elements, additional single angle scattered measurements were conducted at $\theta=120^{\circ}$ where separation of gas velocity curves with most of scattering matrix elements is possible. Gas velocities were converted to mean bubble diameter and gas hold-up and plotted against the measured $M_{\mathrm{ij}}$ values, as shown in Figures 2 and 3. Figure 2 depicts that it is possible to predict bubble diameter based on scattering measurements: $M_{11}, M_{22}, M_{33}, M_{44}$, and $M_{34}$ are sensitive to bubble diameter at low gas velocities with medium-low surfactant concentrations. At high superficial gas velocities $\left(v_{\mathrm{g}}>0.2 \mathrm{~cm} / \mathrm{s}\right)$, there is little change in the size of the bubbles as the flow rate increases. 
Gas hold-up is the second parameter that can be related to the gas velocity. Figure 3 shows how the gas fraction in water affects the scattering at $120^{\circ}$. Even though the gas hold-up increases linearly with increasing gas velocity, effect of gas hold-up on $M_{\mathrm{ij}}$ depends on surfactant concentration. For a lowmedium surfactant concentration, $M_{11}, M_{33}$, and $M_{44}$ increase as gas hold-up increases. $M_{12}$ decreases rapidly and $M_{34}$ increases when bubble size increases with increasing flow rate and surfactant concentration. $\quad M_{22}$ changes drastically at higher surfactant concentrations, unlike other scattering matrix elements, because the shape factor of bubbles is decreasing with increasing gas velocity and the number of bubbles increases (multiple scattering regime). $M_{34}$ decreases at single scattering region but it increases in the multiple scattering zone. Monitoring gas hold-up based on $M_{\mathrm{ij}}$ measurements is possible at some gas velocities for known surfactant concentrations. Detailed results of GL-phase measurements are given in Ref [2-3].

\section{Two Phase (SL) Measurements Coal Particles in Liquid:}

There are many parameters that affect solid particle size measurement results in liquid using scattering light: carbon content of the coal mixture, optical property of the coal, shapes of the particles, volume fraction of particle in the water, etc. In this part of the study we addressed each of important parameters.

Sensor 2 in Figure 1 was designed to measure particle size in diluted solution. After the intensity values were measured, they were converted to scattering matrix elements. The corresponding $M_{i j}$ values are plotted in Figure 4 for three different volume fraction of coal particles. Solid curves are for Lorenz-Mie single scattering results obtained for a size distribution of $100 \%$ coal (red solid line) and $100 \%$ mineral (sand \& clay) (black line) particles in water. It shows that pure carbon (coal) concentration in the coal mixture is important for
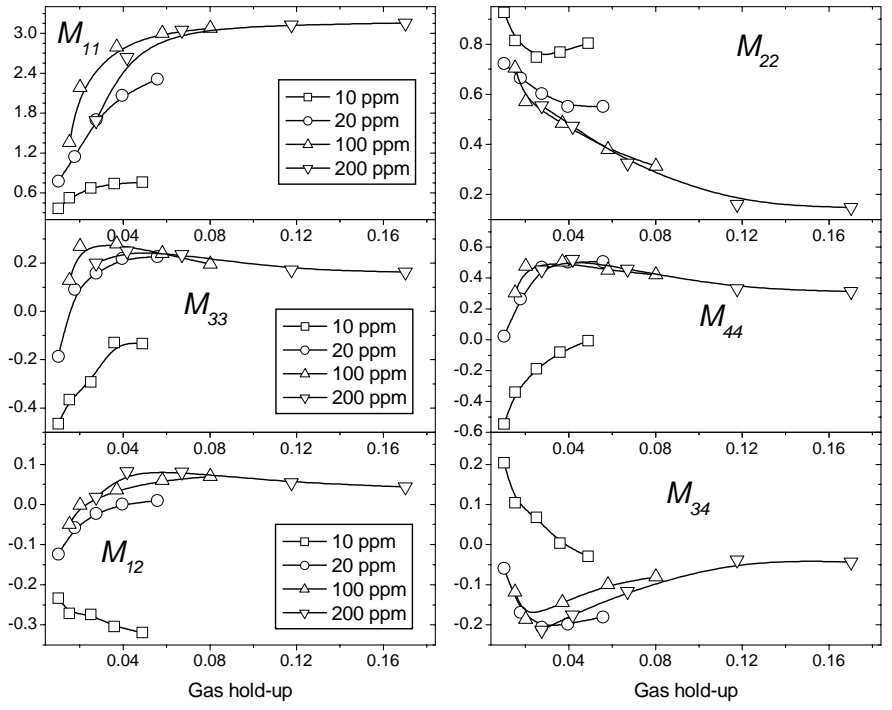

Figure 3. Scattering matrix elements $\left(M_{i j}\right)$ at scattering angle of $120^{\circ}$ as a function of gas hold-up. 
predicting size distribution of particles. The second important parameter is refractive index of coal particles at visible wavelength range. In the literature there is a wide range of refractive index even at a fixed carbon concentration. Figure 5 shows how the normalized scattering matrix elements vary with different complex refractive index of coal particles. $M_{11}$ is sensitive to real part of refractive index and $M_{12}$ is more sensitive to imaginary part of refractive index. The imaginary part changes the type of $M_{34}$ curves significantly but its amplitude is still low.

\section{SUMMARY}

An elliptically polarized light scattering (EPLS) approach was adapted for monitoring the column flotation parameters such as bubble size, average gas hold-up and coal size distribution. In order to monitor two phase flows (GL and SL), two different sensor locations were proposed.

The two-phase GL results show that the present EPLS concept is very promising for characterization of optically thin columns and has many advantages over imaging techniques when in-situ measurement of bubble size are necessary at high flow rates with high surfactant concentrations. For optically-denser bubble laden media, the reliability of this technique can be improved by

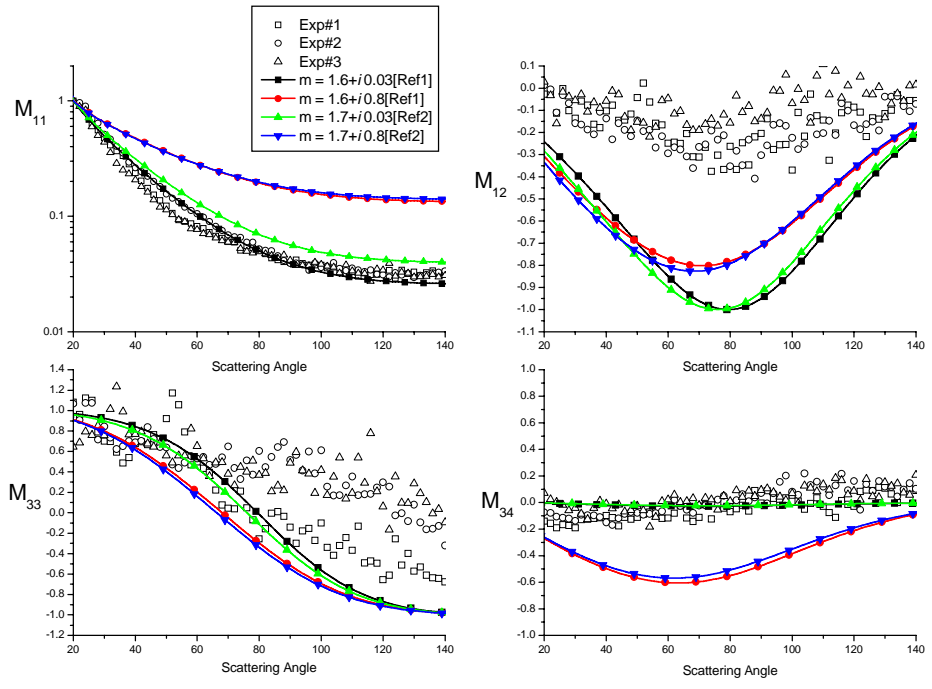

Figure 5. Effect real and imaginary parts of complex refractive index of the coal particles. incorporating multiple scattering algorithms in data reduction.

The two-phase SL experiments show the problem is more complex than GL phase measurements because of composite structure of the coal mixtures and wide range of size distribution. But it is still possible to sense the particle size distribution from the normalized scattering matrix elements.

\section{FUTURE WORK}

1. Define parameter(s) based on scattering matrix elements at highly sensitive scattering angles to study the influence of various input parameters of the froth flotation column on light scattering within the two-phase mediums (GL \& SL).

2. Assemble two sensors for large size columns for online process monitoring.

\section{REFERENCES}

1. Tao D, "Role of bubble size in flotation of coarse and fine particles - A review," Separation Science and Technology 2004; 39: 741-760.

2. Aslan, M.M., Mengüç, M.P., Tao, D., and Crofcheck, C., "Bubble size and gas hold-up detection via Elliptically Polarized Light,” International Symposium on Radiative Transfer, 2004, IstanbulTurkey. (poster presentation).

3. Aslan M.M., Crofcheck C., Tao D., and Mengüç, M.P., 2004 "Evaluation of Micro-Bubble Size and Gas Hold-Up in Two-Phase Gas-Liquid Columns via Scattered Light Measurements," Journal of Quantitative Spectroscopy and Radiative Transfer, (under review for publication). 


\section{Appendix P: UT003 - Electrolytic Solution Purification and Metal Recovery from Metal-Bearing Toxic Waste Streams}


The project has been completed and a Final report is to be issued. 
Appendix Q: MT003 - Determining the Effectiveness of Gold Filters for Removing Mercury from Coal Fired Power Plants 


\title{
TECHNICAL PROGRESS REPORT
}

Contract Title and Number:

Crosscutting Technology Development at the Center for

Advanced Separation Technologies

(DE-FC26-02NT41607)
Period of Performance:

Starting Date: 10/1/03

Ending Date: 5/30/05

Sub-Recipient Project Title:

Report Information:

"Determining the Effectiveness of Gold Filters for Type: Semi-Annual

Removing Mercury from Coal Fired Power Plants” $\quad$ Number: 3

Principal Investigators:

Period: $\quad 3 / 31 / 2004-9 / 30 / 2004$

Dr. Kumar Ganesan

Date: $\quad 9 / 30 / 04$

Code: $\quad$ MT003-R03

Contact Address:

Department of Environmental Engineering

Montana Tech of The University of Montana

1300 West Park Street

Contact Information:

Phone: 406-496-4239

Fax: 406-496-4650

Butte, Montana 59701

E-Mail: kganesan@mtech.edu

Subcontractor Address:

"No subcontracts issued."

Subcontractor Information:

Phone:

Fax:

E-Mail:

\section{DETERMINING THE EFFECTIVENESS OF GOLD FILTERS FOR THE REMOVAL OF MERCURY FROM COAL FIRED POWER PLANTS}

\begin{abstract}
The main objective of this research is to evaluate the effectiveness of gold filter in removing mercury vapor from flue gas. Three gold filters were tested with mercury containing gas stream in the laboratory. The laboratory results indicate that the mercury removal efficiency of the filters is about 85-95 percent. Preliminary tests conducted in a coal fired flue gas stack indicate similar mercury removal efficiency. However, the testing with stack gas needs further sample conditioning and long term testing to confirm the efficiency of the filter. In the laboratory during previous testing periods the spent filters were heated gently to recover the mercury. Over $99 \%$ of the mercury was recovered successfully from the spent filters. Similar procedures will be conducted with the field tested filters. Further tests will be conducted to develop the relationship between the temperature and mercury release rate from the spent filters.
\end{abstract}

\section{INTRODUCTION}

This research project is focused to remove mercury vapor effectively from flue gas in coalfired power plants. The results of this research will help to determine the potential of the 
proposed technology and its viability to use in reducing mercury emissions from power plants. This report highlights the progress made from March 2004 to September 2004.

\section{Background}

Coal contains relatively low levels of mercury that range from 0.010 to 3.5 ppmw. However, the mercury emissions from coal combustion in power plants have received special attention because coal is burned in about 1700 power plants in the US. Mercury is classified as a hazardous air pollutant under the Clean Air Act Amendments (CAAA) of Title III. The EPA's 1998 Utility Air Toxics Report to the US Congress indicated that mercury posed the greatest concern of all the toxics emitted from power plants. It is reported that in 1999, 43 tons of mercury were emitted from US coal fired power plants.

Several control technologies are being studied. They mainly focus on pre-combustion and post combustion processes. Pre-combustion involves coal-cleaning technologies to reduce mercury burden at the source. Post combustion involves adsorption by carbon-based materials and conversion of mercury vapor to oxidized form for removal by wet system or particulate filters.

It is reported that $90 \%$ of mercury emitted from burning western coal is in the form of mercury vapor (elemental) however, combustion of eastern coal generates about 60\% elemental mercury and $40 \%$ divalent mercury. Removing elemental mercury from flue gas is a challenge.

\section{Objective and Approach}

The objective of this research is to evaluate the effectiveness of gold filter, which is pending patent, in removing mercury vapor from coal fired flue gas. Several filters were tested for its effectiveness in removing mercury from gas streams. The tests indicate about eighty-five to ninety percent mercury removals. The spent filters were then heated to less than $200{ }^{0} \mathrm{~F}$ and they released over 99 percent of the mercury. The above filter was prepared at the Montana Tech's mercury laboratory. After successfully completing these tests with home made filters, a professional plating company was asked to develop the filter according to the specifications given by the PI. These filters were then tested at the Montana Tech mercury laboratory for its mercury removal efficiency. After successful completion of the laboratory tests one of the filters were taken to a coal-fired power plant and tested under real conditions.

The filters were filled in a $2.5 \mathrm{~cm}$ diameter and $15 \mathrm{~cm}$ long plastic tube. A flow rate of $5 \mathrm{lpm}$ was maintained to provide a residence time of 0.3 seconds. The flow rate for this experiment was calculated based on 0.3 second residence time. The design of the test system is based on a proposed theory as follows. The filter efficiency could be assumed to follow a simple first order equation as follows:

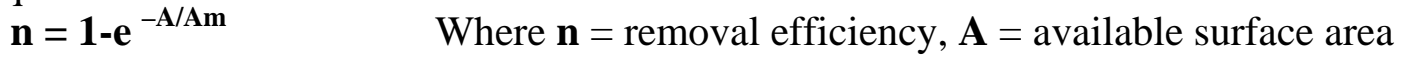

Am = surface area for one mass transfer unit

This simple equation proposed above will be used as the starting point to evaluate the engineering design of mercury filters. There is not enough information in the literature that explains the theoretical basis of amalgamation. Therefore, the data collected in this research project with different metal filters and sizes will be used to further evaluate, improve, or 
modify this proposed equation. It is also an added goal of the investigator to develop a theoretical basis for the mercury amalgamation with gold or silver surfaces.

\section{PROJECT TASKS}

\section{Experimental Procedures}

The laboratory experiments were conducted at Montana Tech of the University of Montana Mercury Laboratory. The experimental set up consists of a mercury vapor source, connected to a pump to draw about $5 \mathrm{l} / \mathrm{m}$ air containing mercury vapor. The entire experimental setup is under the fume hood. The mercury vapor generator consists of an elemental mercury vessel with an airflow controller to control the airflow and thus to produce the required inlet mercury concentrations for evaluating the filter. The mercury vapor is passed through the filter and the mercury vapor concentration levels at the inlet and outlet were measured to evaluate the filter efficiency. Concentration levels both at the inlet as well as at the outlet were measured by a Mercury Tracker. This mercury analyzer has sensitivity to measure concentration of $0.01 \mu \mathrm{g} / \mathrm{m}^{3}$ of mercury. The testing procedures continued till the mercury removal efficiency of the filter dropped to 50\%. Three tests were conducted with three different gold filters.

\section{Laboratory Test Results}

During the first test the average inlet mercury concentration level ranged from 60 to $180 \mathrm{ug} / \mathrm{m}^{3}$ and most of the test period the concentration was above $100 \mathrm{ug} / \mathrm{m}^{3}$ (Figure 1 ). The results showed 90\% removal efficiency for about 30 hours.

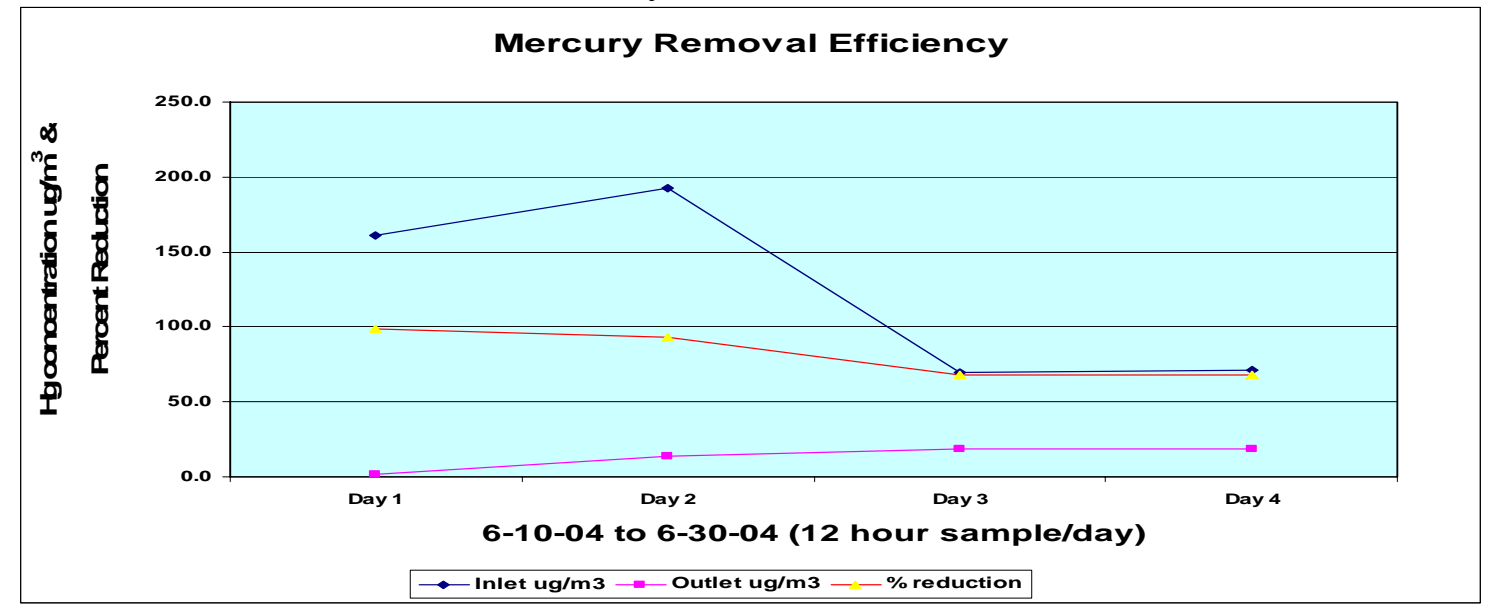

Figure 1

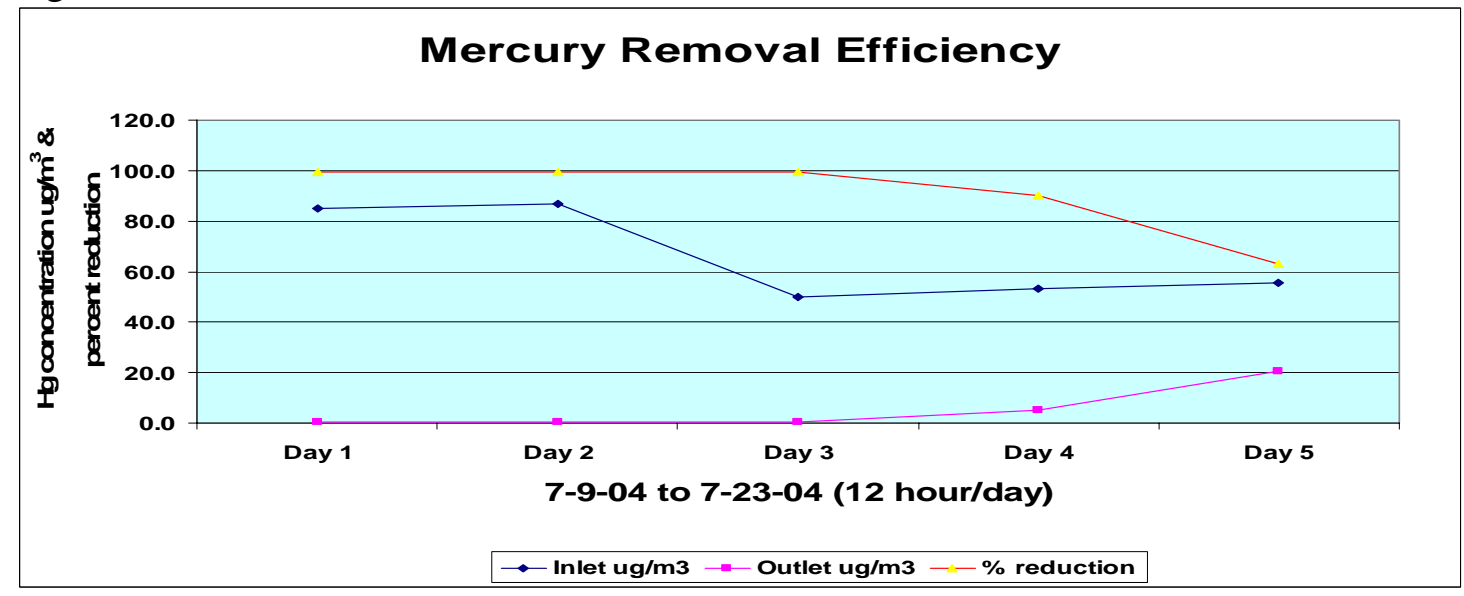


Figure 2

During the second test (Figure 2) the average inlet mercury concentration level ranged from 80 to $50 \mathrm{ug} / \mathrm{m}^{3}$. In the second test the $90 \%$ removal efficiency lasted for about 42 hours. With the third filter (Figure 3) the $90 \%$ efficiency lasted for about 84 hours where the concentration level ranged between 30 to $140 \mathrm{ug} / \mathrm{m}^{3}$ for most of the testing period.

The laboratory test results indicated that the removal efficiency with the filters lasted longer with lower inlet mercury concentrations. Further the filter was tested for its performance in the field at a flue gas stream of a coal fired power plant.

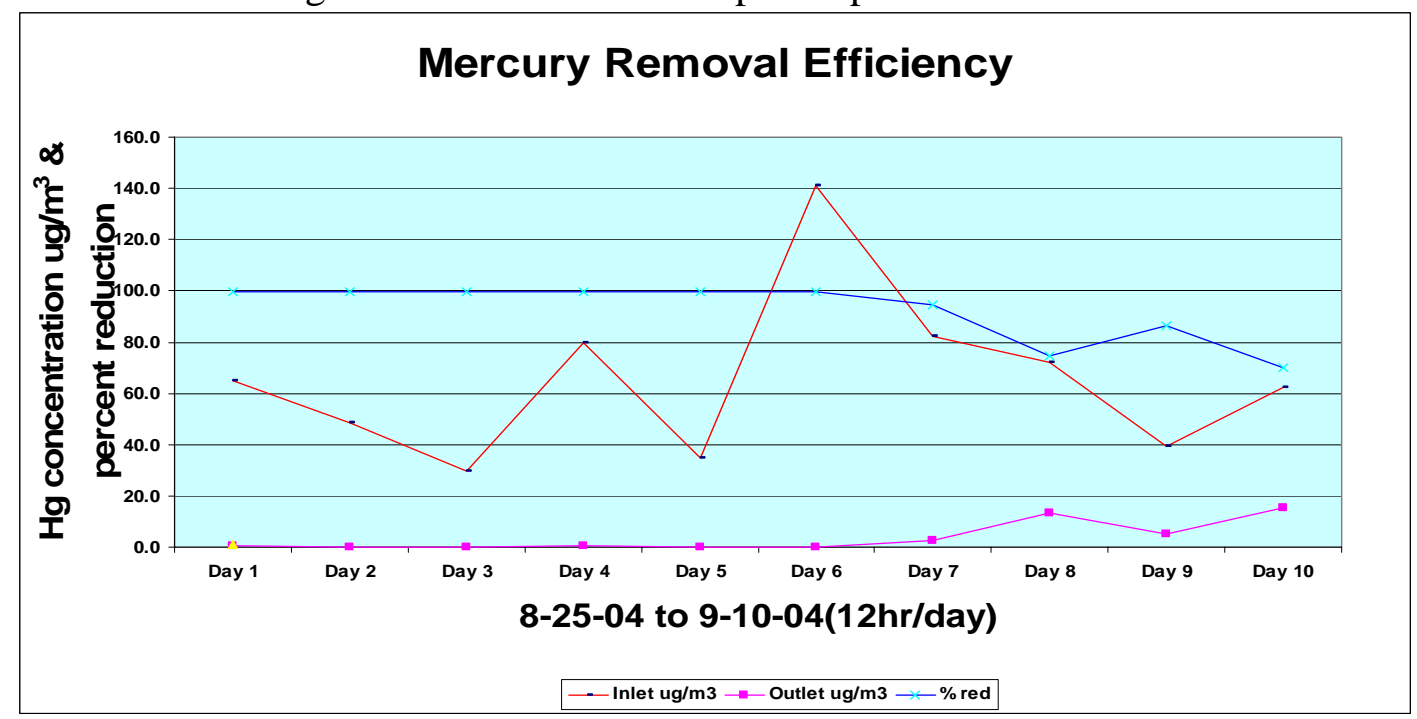

Figure 3

\section{Field Experiment and Results}

This fieldwork was conducted in a coal-fired power plants that uses western coal. One filter was tested in one of the flue gas streams. The objective of this initial field test is to check the performance of the filter in the real world conditions. Two different instruments, the Mercury Ultra Tracer UT-3000 which measures total gaseous mercury in air stream at ultra trace levels $\left(\mathrm{ng} / \mathrm{m}^{3}\right)$ and a portable mercury analyzer, Mercury Tracker 3000 that measures mercury levels in air streams as low as $0.01 \mu \mathrm{g} / \mathrm{m}^{3}$ were used.

The inlet mercury concentration levels seem to be fluctuating in the coal fired power plant flue gas. The Mercury Tracker results show more than 97\% mercury removal efficiency from the flue gas where as the Mercury Ultra Tracer results show 85 to 98\% efficiency. Over all the performance of this filter in real world conditions is equally as good as the laboratory results. This field study need be repeated further to confirm this. In the coal fired power plant flue gas stream the high relative humidity did not allow the testing to continue for longer period. Water condensation was occurring very fast and therefore the tests were terminated. It is considered that the sample line be treated to avoid water condensation.

\section{SUMMARY}

In summary, in this progress reporting period three gold filters were tested with mercury containing gas stream at the Montana Tech of the University of Montana's laboratory. Since the filters show high mercury removal efficiency at the laboratory preliminary tests were conducted in a coal fired flue gas stack. The results indicate success in using the filter for 
mercury removal efficiency. However, the testing with stack gas needs further sample conditioning and long term testing to confirm the efficiency of the filter. Thus the preliminary tests results indicate that gold filters can remove mercury vapor over ninety percent from coal fired flue gas streams.

\section{FUTURE WORK}

The performance test for gold will be continued for flue gas in a coal fired power plant. The filter efficiency and its removal capacity $(\mu \mathrm{g} / \mathrm{g})$, that is, the amount of mercury the filter can hold before its regeneration will be determined. The preliminary results also indicate that the spent filters may release mercury with minimum amount of heating. Similar tests are under way with silver filters also. The physico-chemical processes will be evaluated to better understand the amalgamation process. The literature review and analyzing the spent gold filters under SEM/EDX will give information to help understand the physico-chemical processes involved in amalgamation. The PI will write the final report at the end of the project. A project summary will be posted in the CAST web site as well as in Montana Tech's web site.

\section{REFERENCES*}

Hwang, J.Y., Huang, X., Tieder, R.E., Liu, X. “Control of Mercury Emissions from Coal Fired Power Plants Using Fly-Ash-Derived Carbon”, Michigan Technological University, EPA Grant Number R825370C028, www.es.epa.gov/ncer_abstracts/centers/cencitt/year3/material/hwang.html.

Ihle, J., “Mercury Emissions and Fuel Switching: What’s in Your Coal?”, October 2002. www.coalage.com/ar/coal_mercury_emissions_feul/.

Karatza, D.; Lancia, A.; Musmarra, D., "Fly Ash Capture of Mercuric Chloride Vapors From Exhaust Combustion Gas”, Environ.Sci.Technol.1998, 32, pg.3999-4004.

Mendioroz, S; Guijarro, M.I.; Bermejo, P.J.; Munoz, V., "Mercury Retrieval from Flue Gas by Monolithic Absorbents Based on Sulfurized Sepriolite”, Environ.Sci.Technol. 1999, 33, pg.1697-1702.

Mercury Study Report to Congress, EPA-452/R-96-001g, 1996.

Morency, J.R., Panagiotou, T., Senior, C.L. "Laboratory Duct Injection of a Elite-Based Mercury Sorbent”, Physical Sciences Inc.

Nordin, A.; Schager, P,; Hall, B., “ Mercury Speciation in Flue Gases: A Comparison of Results from Equilibrium Calculations with Results from Laboratory Experiments”, Swedish Fame Days, Turkoo, Finland, 1990.

Nriagu, J.O. Environment 1990, 32,7-33.

Tumati, P.R.; DeVito, M.S., "Partitioning Behavior of Mercury During Coal Combustion”, Joint ASME/IEEE Power Conference, Kansas City, KS, 1993.

*References from the original CAST proposal.

\section{PUBLICATIONS/PRESENTATIONS}

The data collected thus far was presented in an international mercury conference during June 2004. The preliminary results were also presented in the 2003 CAST annual conference in Charleston, West Virginia. At the end of spring, 2004 a paper will be presented in another technical conference also. 